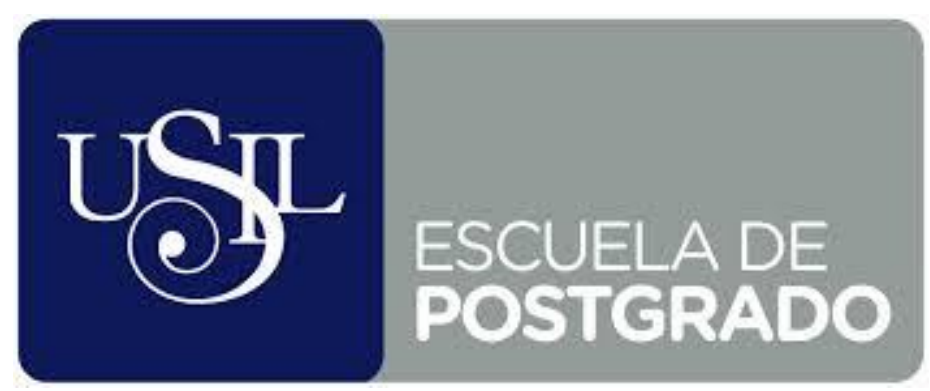

PROYECTO DE INVESTIGACIÓN

GERENCIAL APLICADO

PLAN DE NEGOCIOS DE UNA CONSULTORA DE COLOCACIÓN DE TRAINEES

"N \& M ASESORES"

MURIEL RAMIREZ DELGADO

NATALIA VELAYARCE ESPINOZA

ASESOR: Dr. EDMUNDO CASAVILCA MALDONADO

Maestría en Ciencias Empresariales

Lima - Perú

2017 
"N \& M ASESORES" 


\section{Resumen Ejecutivo}

El presente trabajo se desarrolló dentro del campo de estudio de los Recursos Humanos, dando origen a nuestro plan de negocios "N \& M ASESORES" cuya propuesta se basa en la búsqueda de talento en jóvenes estudiantes universitarios para su colocación en prácticas pre - profesionales.

La investigación inicia en los programas de intercambio cultural, dirigido a estudiantes universitarios y/o de instituto que desean vivir una experiencia de inmersión cultural durante sus vacaciones de verano (de diciembre a marzo). El programa ofrece a los estudiantes la posibilidad de realizar trabajos remunerados por un periodo y desarrollar las denominadas "soft skills" (independencia, responsabilidad, capacidad de decisión, seguridad en sí mismos, etc.). El perfil para aplicar a este tipo de programas es ser estudiante universitario, tener entre 18 y 27 años y dominar el idioma extranjero, esto último depende del país donde desea ir.

Se realizó el mismo patrón de búsqueda en el mercado local; sin embargo, la búsqueda no fue exitosa, lo más similar que pudimos encontrar fueron las prácticas pre -

profesionales en programas establecidos bajo una estructura de tutorial, complementando en el estudiante la teoría aprendida en clases.

Los practicantes universitarios de hoy en día se encuentran entre la Generación Y (Millennials) y Generación Z, se caracterizan por ser tecnológicos, autodidactas, creativos, buscan oportunidades laborales que estén relacionadas con sus pasiones y hobbies actuales. 
En el transcurso de nuestra búsqueda pudimos encontrar que algunas de las empresas con mayor nivel de ventas en el Perú, tienen programas estructurados para prácticas y trainees de universitarios, pero no necesariamente son los más atractivos, una de las causas es que no han sido actualizados para esta generación de jóvenes.

El mercado laboral actualmente se encuentra en un proceso de optimización de procesos constante, lo que ha llevado a las empresas a buscar socios estratégicos para sus procesos secundarios. Los procesos de reclutamiento, selección y tercerización de personal son los más usuales.

El proveedor externo, cada día se vuelve más cercano a la empresa ofreciendo una reducción de los costos de operación de la compañía, tiempos de selección de personal (cuentan con bolsa de trabajo donde ya tienen candidatos potenciales), permitiendo a la empresa dedicar más recursos a las actividades importantes para el giro del negocio.

Nuestra propuesta ofrece el proceso de selección para practicantes pre - profesionales a las empresas, actualizando sus programas de inducción a la generación actual y buscando tener una relación a largo plazo con otros servicios. La consultora también considera como cliente a los jóvenes estudiantes debido a que para hacer más atractiva nuestra propuesta es necesario contar con una base de datos y brindarles una constante asesoría con el fin de tener futuros profesionales competitivos.

El servicio ofrecido mediante el presente plan de negocio no tiene competencia en el mercado ya que las empresas consultoras que tienen el mayor porcentaje del mercado están concentradas en las colocaciones gerenciales y mandos medios de las empresas. 
Además, nosotros concretaremos nuestros objetivos contribuyendo con la gestión de las empresas, captando talento que cada vez es más escaso, y a la vez necesario para el crecimiento de las empresas.

Finalmente, se demuestra a lo largo de esta investigación que es una oportunidad de negocio, debido a que desde el punto de vista financiero valida su rentabilidad. 


\section{Índice}

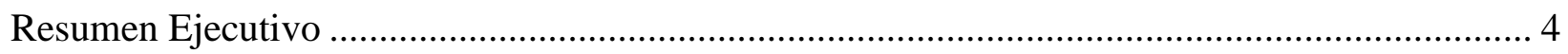

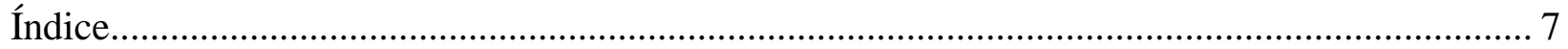

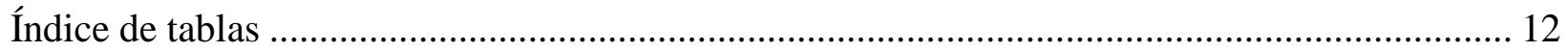

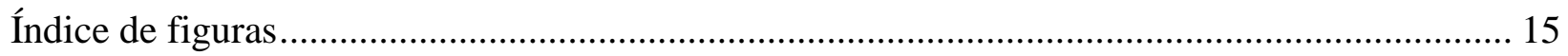

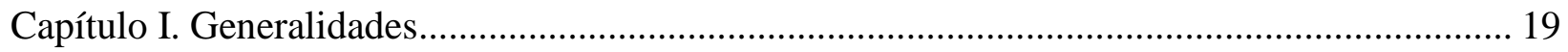

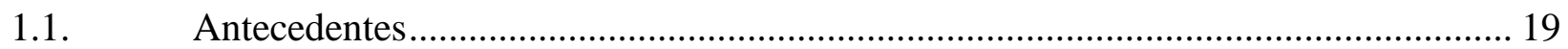

1.2. Determinación del problema u oportunidad ……………………………................. 23

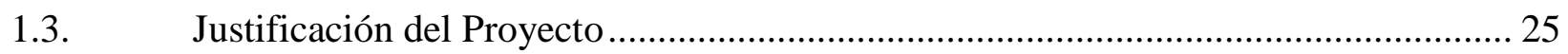

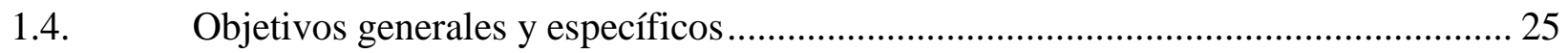

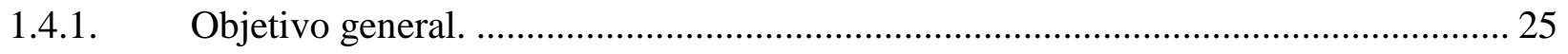

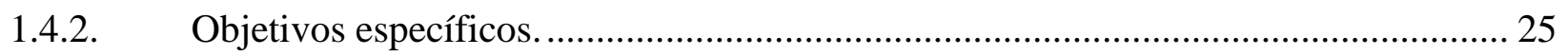

1.5. Alcances y limitaciones de la investigación .................................................................. 26



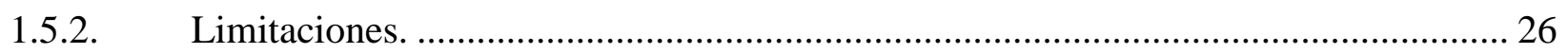

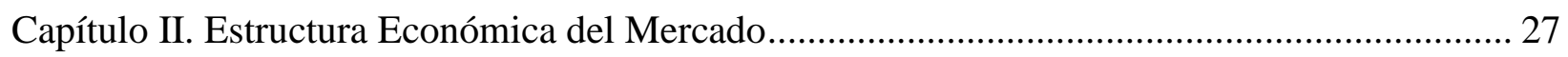

2.1 Descripción del estado actual del mercado.................................................................. 27

2.1.1 Segmentación de la industria y empresas que la conforman........................................ 31

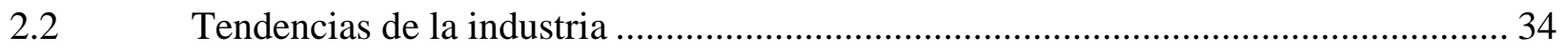

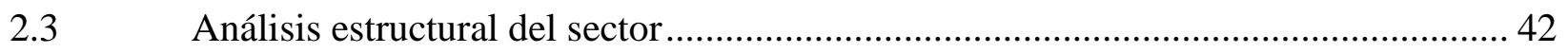

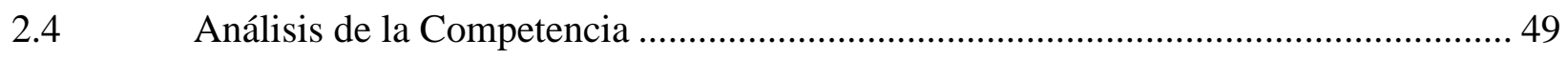

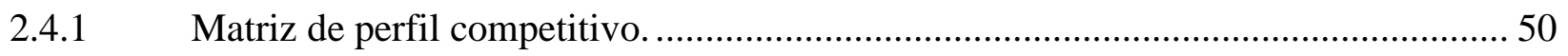

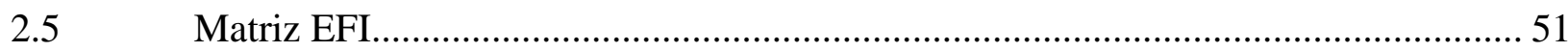

2.6 Análisis del contexto actual y esperado.................................................................... 52

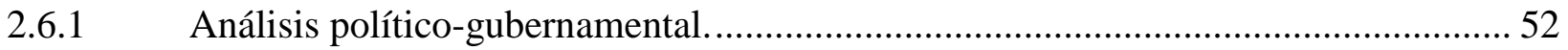




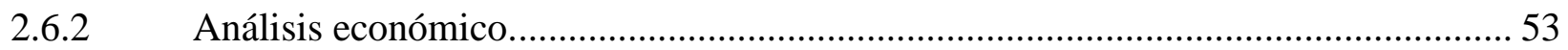

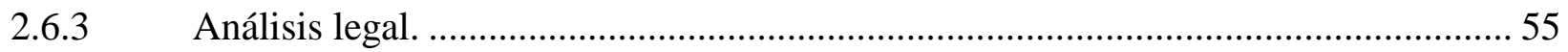

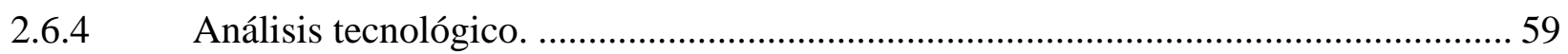

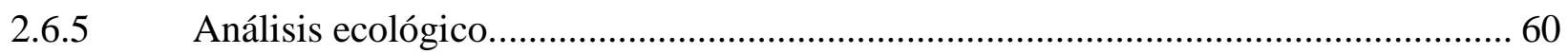

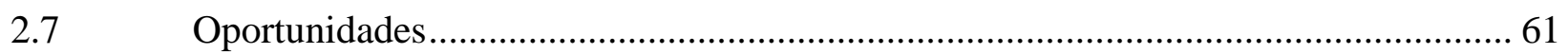

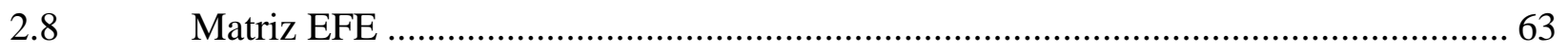

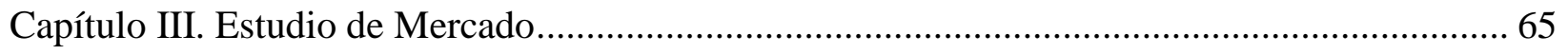

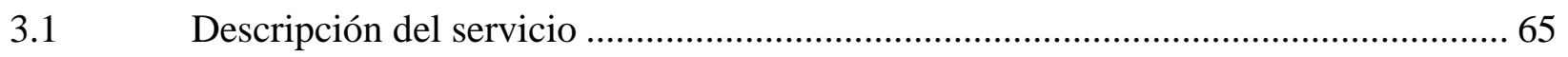



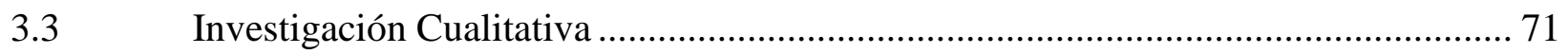

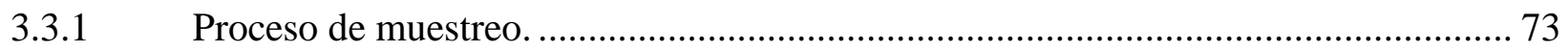

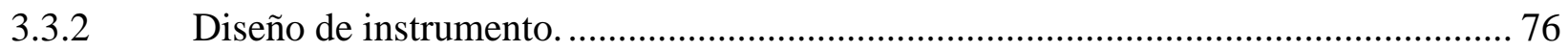

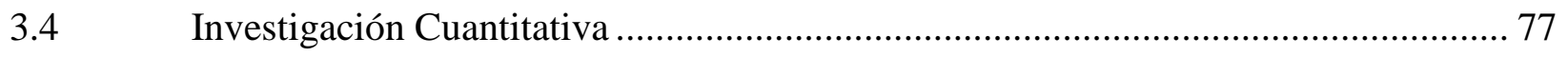

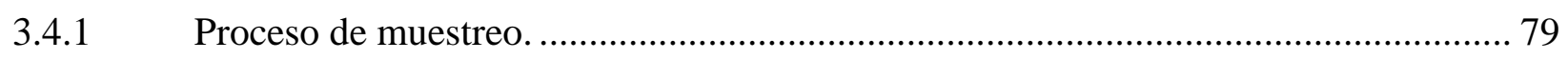

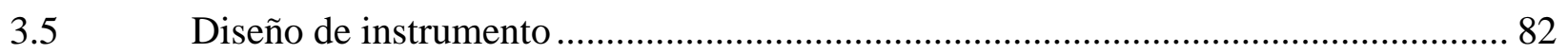

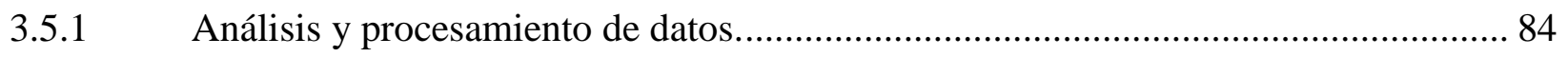

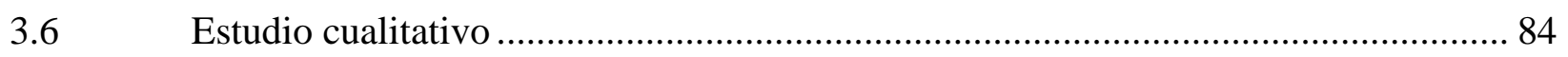

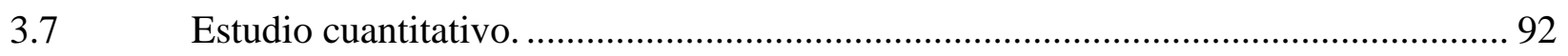

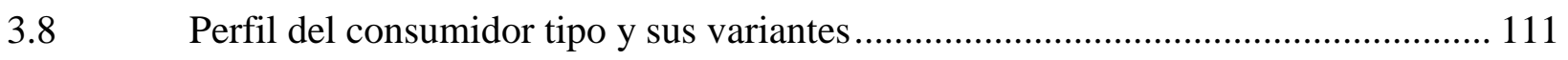

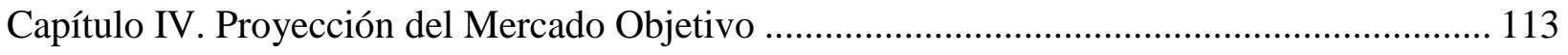

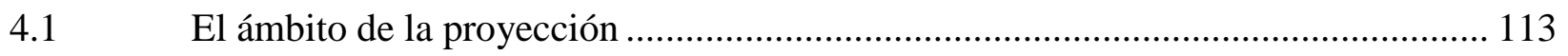

4.2 Selección del método de proyección. …………………………………………….... 113

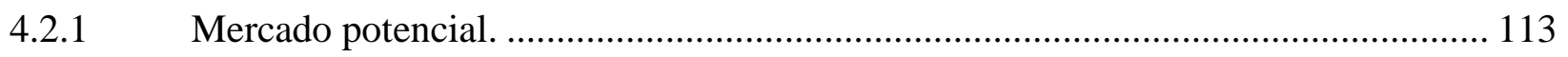

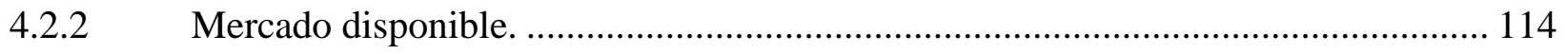

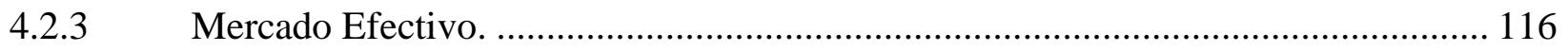




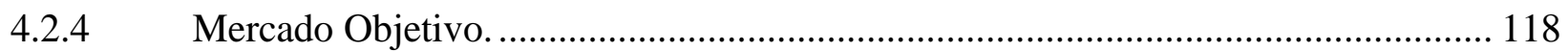

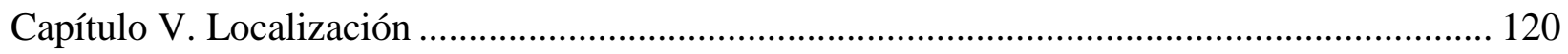

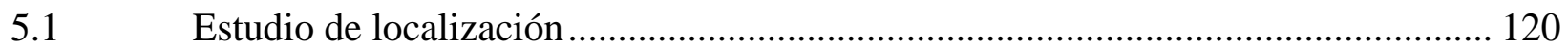

5.1.1 Definición de factores locales.......................................................................... 120

5.2 Determinación de la localización óptima. ………………………………............... 121

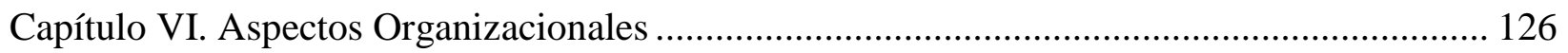

6.1 Caracterización de la cultura organizacional deseada .............................................. 126

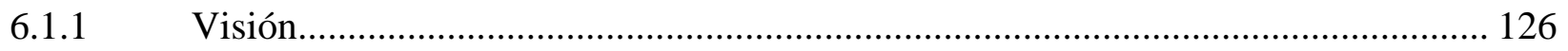

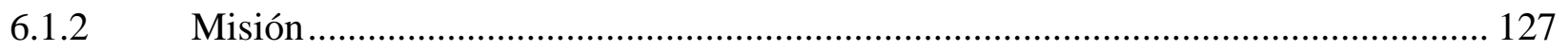

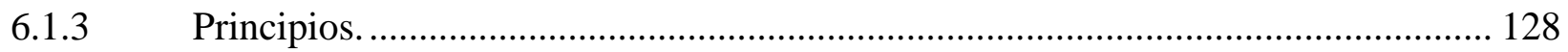

6.2 Formulación de estrategias del negocio.......................................................... 130

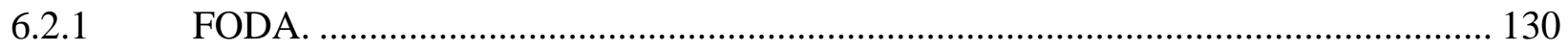

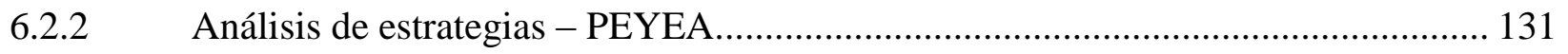

6.3 Determinación de las ventajas competitivas críticas ................................................. 133

6.4 Diseño de la estructura organizacional deseada ………............................................ 136

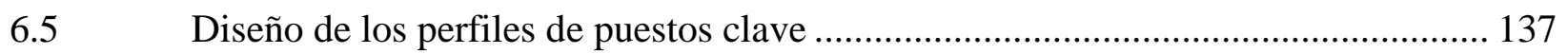

6.6 Remuneraciones, compensaciones e incentivos …………………………............ 138

Capítulo VII. Plan de Marketing............................................................................................ 142

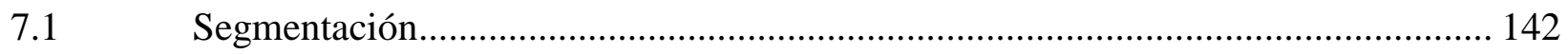

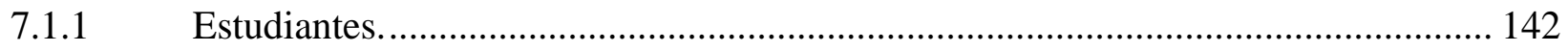

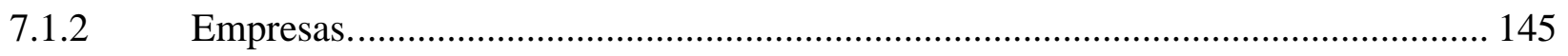

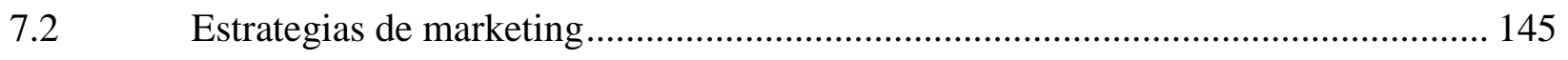

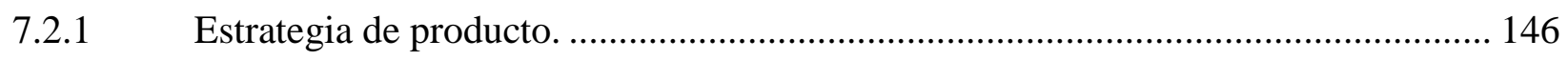

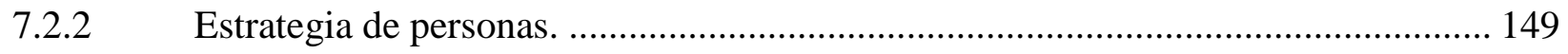

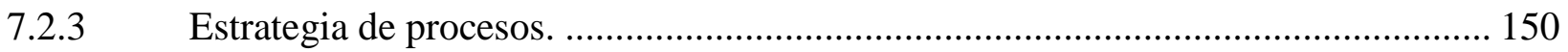




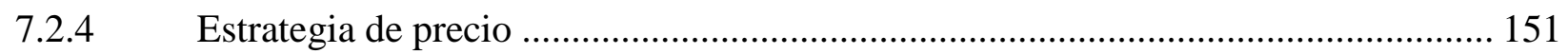



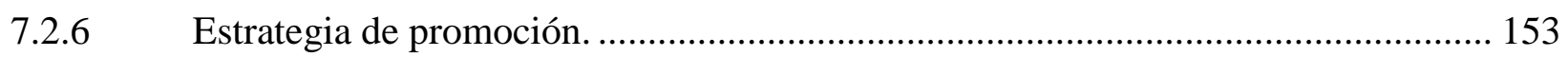

7.2.7 Estrategia de Evidencia Física .............................................................................. 154

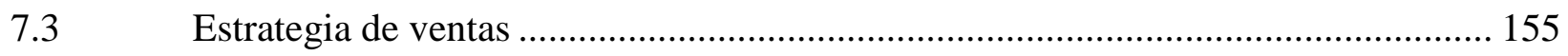



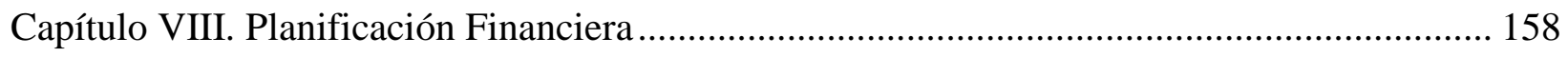

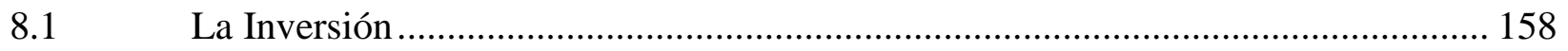

8.1.1 Inversión Pre - Operativa (Tangible e Intangible) ……………………………........ 158

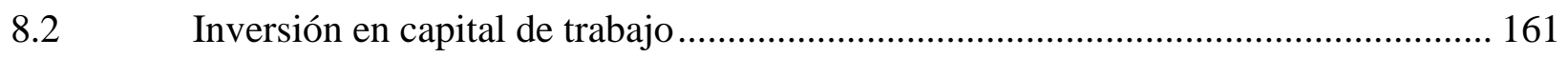

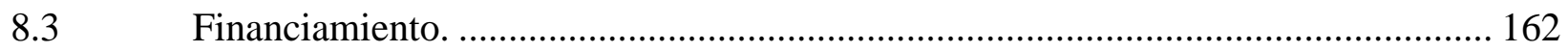

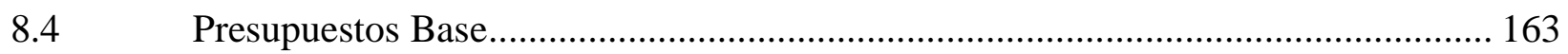

8.4.1 Presupuesto de Gastos Administrativos. ................................................................... 163

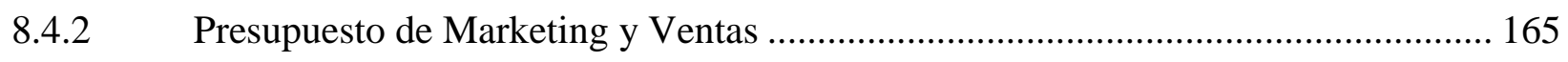

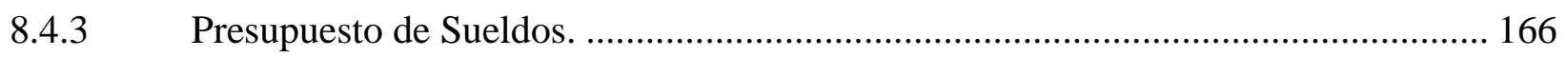

8.4.4 Presupuesto de Depreciación.................................................................................. 167

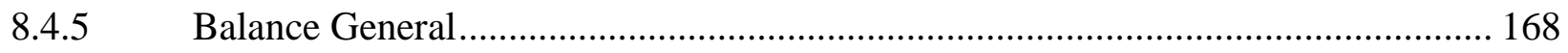

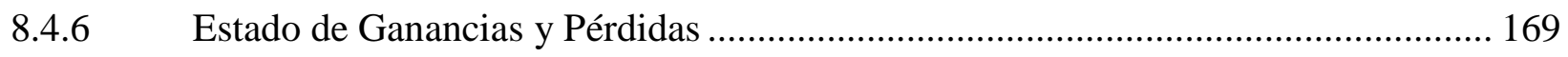

Capítulo IX. Evaluación Económica Financiera...................................................................... 170

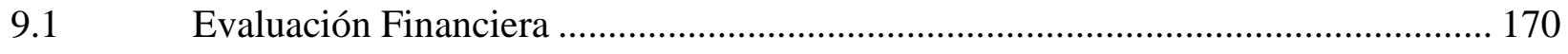

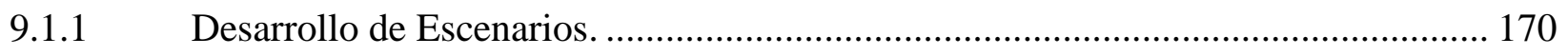

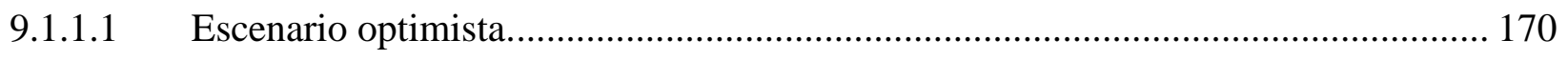

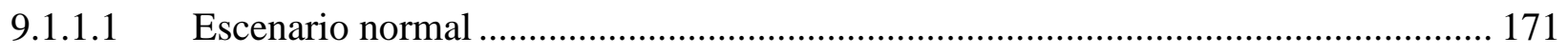

9.1.1.2 Escenario Pesimista ........................................................................................ 171

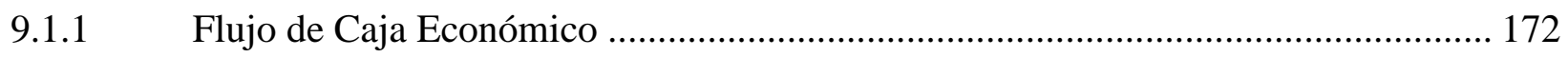




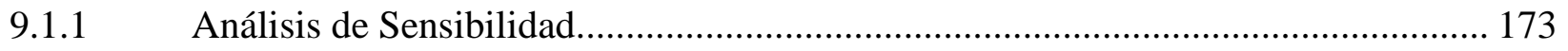

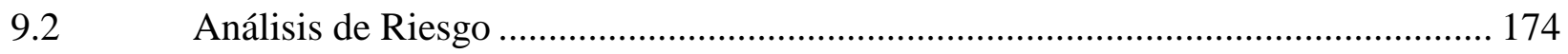

Capítulo X. Conclusiones y Recomendaciones ................................................................ 176

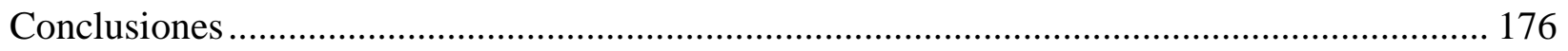

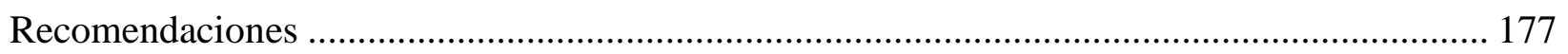

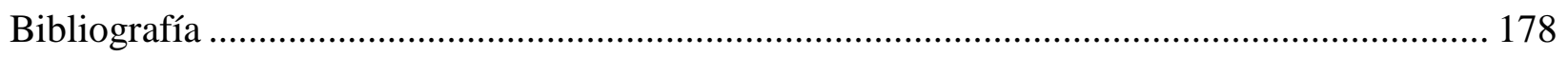

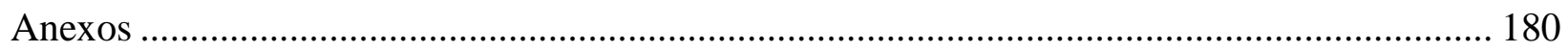

ANEXO 1: Ficha de Focus Group .................................................................................. 180

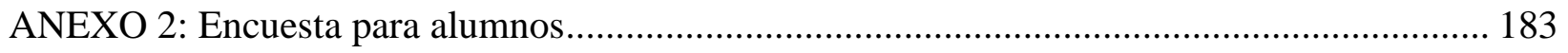

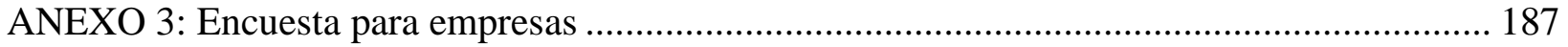

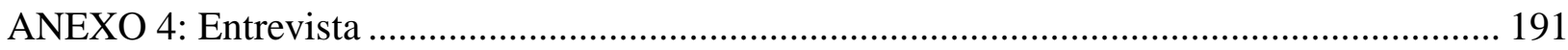

ANEXO 5: Tablas de formación para la matriz Peyea ........................................................... 192

ANEXO 6: Validación de experto para el área de localización.............................................. 196

ANEXO 7: Validación de costo de oficina....................................................................... 198

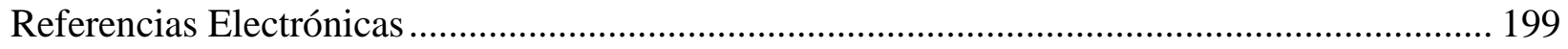




\section{Índice de tablas}

Tabla 1 Matriz de Atractividad de Poder de negociación de los Proveedores........................... 43

Tabla 2 Matriz de Atractividad Poder de Negociación de los Clientes. .................................... 44

Tabla 3 Matriz de Atractividad Amenaza de los Competidores. ............................................ 46

Tabla 4 Matriz de Atractividad Servicios Sustitutos. ........................................................... 47

Tabla 5 Matriz de Atractividad Amenaza de Nuevos Competidores. ..................................... 48

Tabla 6 Matriz de perfil competitivo ......................................................................... 50

Tabla 7 Evaluación de los Factores Externos. ................................................................. 51

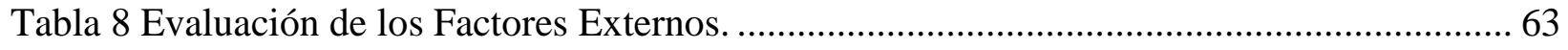

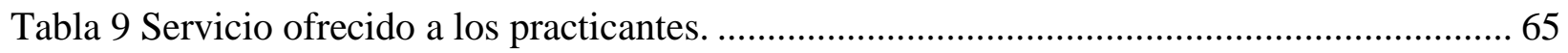

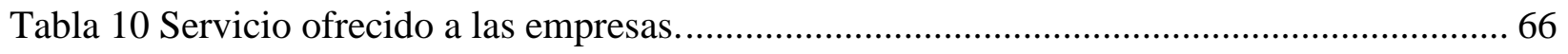

Tabla 11 Entrevistas a contactos en el área de RRHH...................................................... 75

Tabla 12 Alumnos matriculados, según tipo de universidad-. Lima, 2015 ............................. 79

Tabla 13 Cantidad de empresas en Lima, según segmento empresarial 2014 ......................... 81

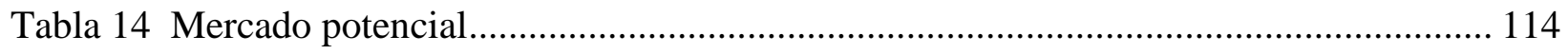

Tabla 15 Intención de compra (estudiantes) ................................................................. 115

Tabla 16 Disponibilidad de adquirir el servicio (empresas) ............................................ 116

Tabla 17 Disponibilidad de adquirir el servicio (estudiantes). ....................................... 117

Tabla 18 Disponibilidad de adquirir el servicio (empresas). .......................................... 118

Tabla 19 Proyección del mercado objetivo.................................................................... 119

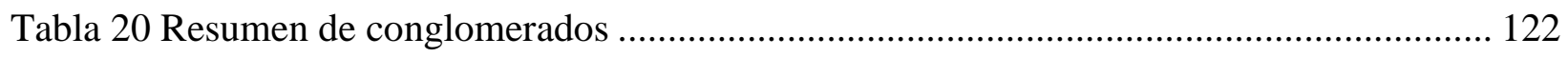

Tabla 21 Ranking de Factores - Macro Localización ....................................................... 123

Tabla 22 Preguntas claves para la construcción adecuada de la visión .................................. 126

Tabla 23 Preguntas claves para la construcción adecuada de la misión .................................. 128

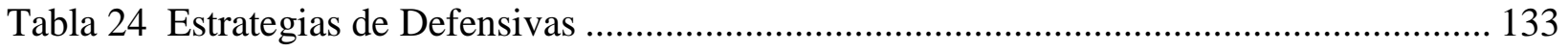




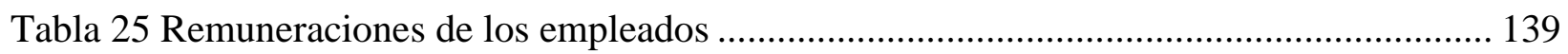

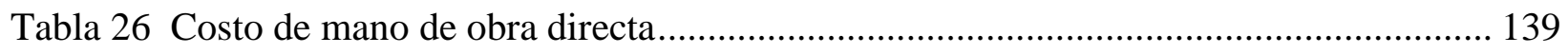

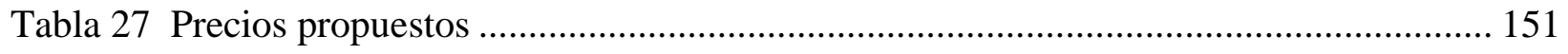

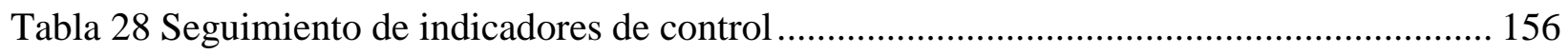

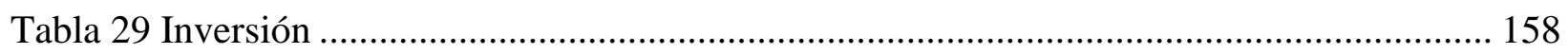

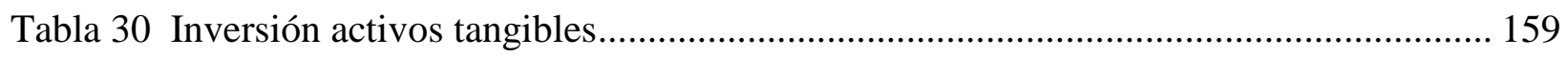

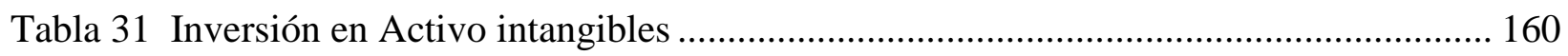

Tabla 32 Gastos de Constitución ................................................................................................ 161

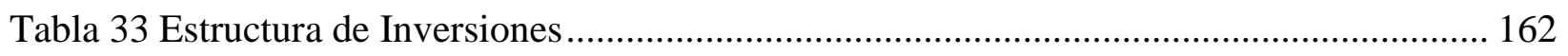

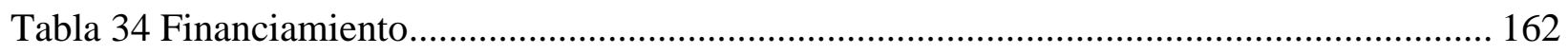

Tabla 35 Presupuestos de Gastos Administrativos ................................................................... 164

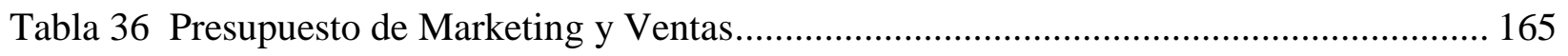

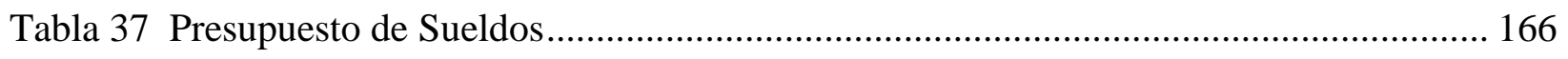

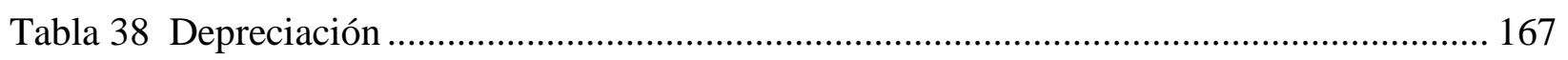

Tabla 39 Balance General (Inicio de Operaciones) …………………………….................... 168

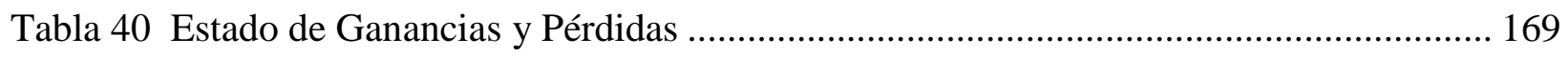

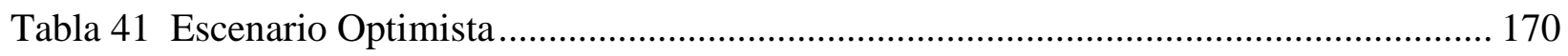

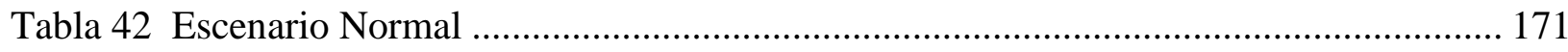

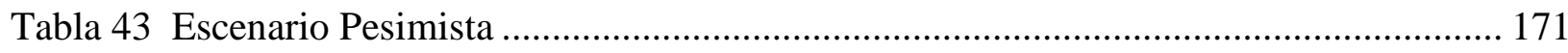

Tabla 44 Flujo de caja económico en soles acumulado ............................................................ 172



Tabla 46 Análisis de Costo de Oportunidad (COK) ...................................................................... 173

Tabla 47 Fuerza financiera y capacidades de Base (FF).......................................................... 192

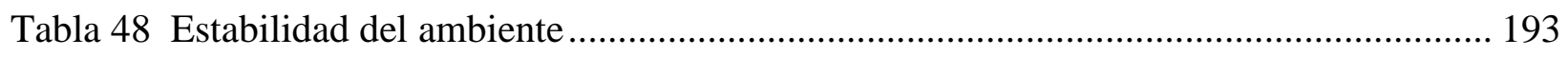

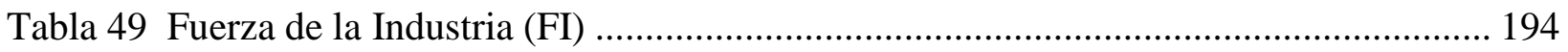




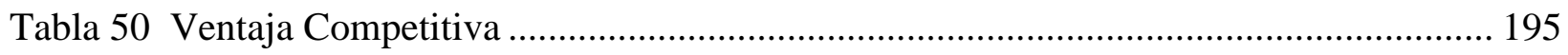




\section{Índice de figuras}

Figura 1. Cantidad de trabajadores dependientes por tamaño de la empresa, 2001-2010............ 28

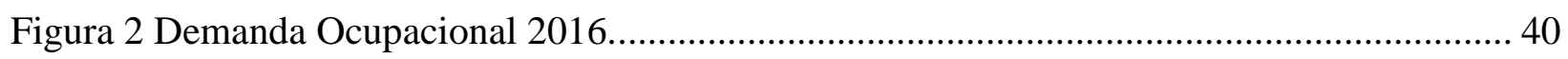

Figura 3 Requerimiento específicos de la Demanda Ocupacional 2016...................................... 41

Figura 4 Demanda Ocupacional - Actividades Empresariales, ................................................... 41

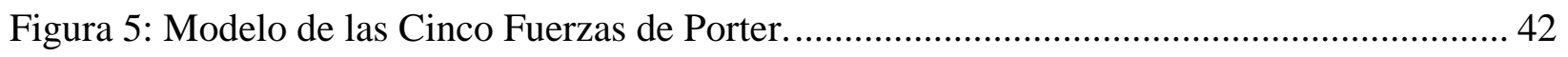

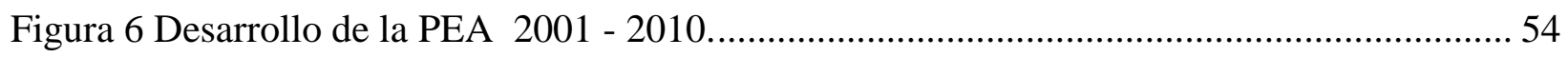

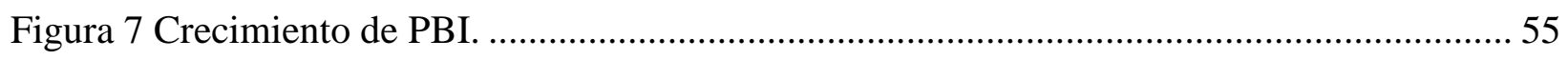

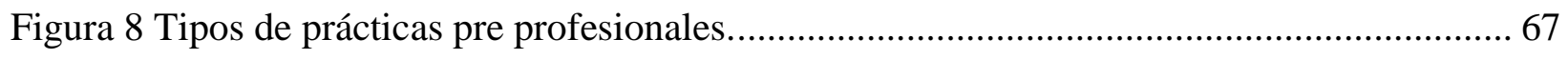

Figura 9 Segmentos de Mercado............................................................................................. 71

.Figura 10. Cantidad de alumnos por universidad de procedencia............................................... 93

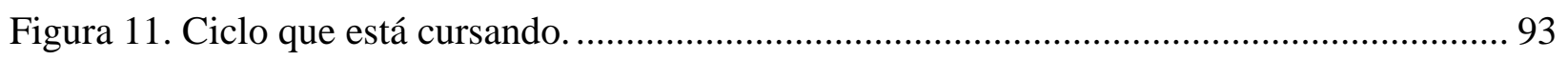

Figura 12. Importancia de realizar prácticas pre - profesionales. ................................................... 94

Figura 13. Motivaciones que llevan a realizar las prácticas. ………………………………......... 95

Figura 14. ¿Por cuál medio realiza la búsqueda de prácticas pre-profesionales? .......................... 96

Figura 15. ¿Con qué frecuencia busca las practicas pre - profesionales? ……………………..... 96

Figura 16¡Alguna vez ha utilizado una consultora para acceder a un proceso de selección? ....... 97

Figura 17. Si ha utilizado los servicios de una consultora ¿Cómo califica su experiencia?.......... 98

Figura 18.¿Cuál crees que son las ventajas de utilizar una consultora? ....................................... 99

Figura 19. ¿Cuál sería el nivel de probabilidad de adquirir los servicios de la consultora en

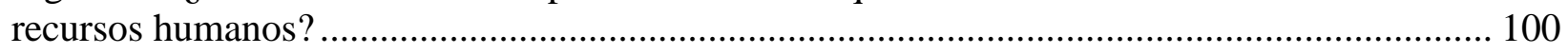

Figura 20. ¿Cuál es el precio que estaría dispuesto a pagar por la asesoría y los talleres ofrecidos por la consultora? ................................................................................................................... 101

Figura 21. ¿En qué distrito le gustaría que estén ubicadas las oficinas de la consultora? ........... 102

Figura 22. ¿Por qué medio le gustaría tener información de la consultora?................................. 102 
Figura 23.¿Qué tipo de presentación le gustaría tener de la empresa consultora? 103

Figura 24. ¿Qué tipo de servicio estaría dispuesto a comprar? ¿Qué tipo de servicio estaría dispuesto a comprar?

Figura $25_{¿}$ Cuántos practicantes contratan al año en su empresa? 104

Figura 26. ¿Con qué frecuencia al año contratan practicantes? 105

Figura 27. ¿Por cuál medio realiza la búsqueda de practicantes pre- profesionales? 106

Figura 28. ¿Alguna vez ha utilizado una consultora para acceder a un proceso de selección? .. 107 Figura 29. Si ha utilizado los servicios de una consultora ¿Cómo califica su experiencia?........ 107

Figura 30. ¿Cuál sería el nivel de probabilidad de adquirir los servicios de la consultora en recursos humanos?.

Figura 31. ¿Cuál es el precio que estaría dispuesto a pagar por los servicios ofrecidos por la consultora? 109

Figura 32. ¿En qué distrito le gustaría que este ubicado las oficinas de la consultora? 110

Figura 33. ¿Por qué medio le gustaría tener información de la consultora? 110

Figura 34. ¿Qué tipo de presentación le gustaría tener de la empresa consultora? 111

Figura 35 ¿Qué tipo de presentación le gustaría tener de la empresa consultora?

Figura 36. Ubicación de principales universidades públicas y privadas de Lima Metropolitana120

Figura 37. Análisis FODA. 131

Figura 38. Matriz de posición estratégica de la acción (PEYEA). 132

Figura 39 Cadena de valor del negocio. 136

Figura 40. Organigrama. 137

Figura 41. Logo del negocio. 149 


\section{Introducción}

El presente plan de negocios tiene como finalidad analizar la viabilidad de la consultora "N \& M ASESORES" en colocar alumnos universitarios para realizar prácticas pre profesionales. Por medio de la investigación realizada, encontramos en el sector de consultoras de Capital Humano un nicho de mercado para este modelo de negocio.

La expansión de las universidades ha creado una oferta educativa para diferentes niveles socioeconómicos; sin embargo, uno de los resultados de la educación superior se refiere a la inserción laboral que puedan obtener los estudiantes. Esta expansión ha creado una oferta de estudiantes que buscan ingresar a puestos laborales, en algunos casos sin mucho éxito debido a que no presentan la experiencia laboral pertinente ni las habilidades para desarrollar las funciones en la empresa.

La propuesta analiza dos puntos de vista; el estudiante al cual se le brinda la oportunidad de obtener las prácticas pre profesionales potenciando el desarrollo de sus habilidades, y las empresas que confían en el proceso de selección de los practicantes.

En el primer capítulo detallamos cómo vamos a desarrollar nuestro plan de negocios y definimos cuáles serán los objetivos, también hacemos hincapié en las limitaciones con las que nos encontramos en el proceso de investigación.

En el segundo capítulo hacemos una descripción del mercado actual, tendencia de la industria, análisis estructural del sector, análisis de la competencia, análisis del contexto actual y esperado. Todos los análisis detallados nos llevan a aterrizar la propuesta. 
En el tercer capítulo detallamos el estudio de mercado tanto desde el punto de vista cuantitativo y cualitativo, lo cual nos lleva a definir el perfil del consumidor tipo y sus variantes.

En el cuarto capítulo, hacemos la proyección del mercado, para ello identificamos nuestro mercado potencial, disponible, efectivo y objetivo.

En el quinto capítulo, determinamos nuestra ubicación física de las oficinas, para ello realizamos un estudio de localización (análisis de micro y macro localización).

En el sexto capítulo se desarrollan los aspectos organizacionales, abarcará la visión, misión, principios, la formulación de la estrategia del negocio y el diseño de la estructura organizacional deseada.

En el séptimo capítulo, nos enfocamos en desarrollar el plan de marketing desde la segmentación, estrategia de ventas y evaluación.

En el octavo capítulo, se explicará la inversión, cómo se realizará el financiamiento y los presupuestos base.

Por último, en el noveno capítulo, se evaluará el proyecto tomando en cuenta el valor actual, la tasa interna de retorno, el periodo de recuperación del capital y la evaluación financiera.

En la parte final del plan de negocios se detallan las conclusiones y recomendaciones del análisis previo del mercado y evaluación económica. 


\section{Capítulo I. Generalidades}

En el presente capítulo se determinarán los antecedentes sobre los temas de capacitación juvenil, la situación los jóvenes en América Latina, la situación actual de las prácticas pre profesionales en el país, y cómo estas son importantes en la formación profesional de los jóvenes universitarios. Además, en este capítulo se determina el problema, los objetivos -generales y específicos-, así como los alcances y limitaciones del presente plan de negocio.

\subsection{Antecedentes}

La Organización Internacional del Trabajo (OIT) considera que los jóvenes son partícipes principales del cambio positivo en las sociedades, ya que de ellos depende el futuro de la nación. Este proceso será positivo siempre y cuando respondan adecuadamente a desafíos en temas laborales, económicos, educativos, sociales, políticos y tecnológicos.

A su vez, el Banco Mundial visibiliza la necesidad de invertir en los jóvenes para que sea posible un desarrollo favorable. Identifica cinco etapas básicas para la inversión: el estudio, el inicio de la etapa laboral, la adopción de un estilo de vida saludable, la formación de una familia y el ejercicio de sus derechos cívicos. ${ }^{1}$

En el 2014,73.3 millones de jóvenes estaban desempleados, esta cifra era menor que en el 2009 que era cerca a los 76.6 millones. Siendo la tasa de desempleo juvenil mundial de 13\%. Este grupo social tiene más dificultades de ingresar al mercado laboral, ya que su tasa de desempleo es casi tres veces más que la tasa de desempleo adulto. Esta situación hace que

\footnotetext{
${ }^{1}$ Banco Mundial, El desarrollo y la próxima generación. Informe sobre el desarrollo mundial, 2007
} 
los jóvenes tengan una situación difícil de enfrentar que influye en su futuro y las decisiones que tomen tendrán efecto en su calidad de vida. Según el Banco Mundial, si un joven inicia su vida laboral en un empleo informal es muy probable que continúe en la informalidad, sin tener muchas opciones de un trabajo estable y formal.

Las prácticas pre profesionales, tienen como objeto orientar y capacitar de manera técnica y profesional a los estudiantes o recién egresados de alguna carrera técnica o universitaria.

En el Perú, estas prácticas son realizadas mediante un convenio celebrado entre el centro de estudios y la empresa privada o entidad pública. En este convenio la empresa o entidad pública se compromete a orientar al estudiante y capacitarlo en todo lo necesario, al finalizar esta, se deberá entregar un certificado donde legaliza el desarrollo de la misma. Estas prácticas no generan un vínculo laboral entre el estudiante y la empresa; sin embargo, se determina que los practicantes tienen prioridad y una opción preferencial para postular en plazas laborales similares a sus prácticas, dentro del mismo centro laboral ${ }^{2}$.

En el "Diagnóstico de la Formación Profesional en el Perú", realizado por el Ministerio de Trabajo y Promoción Social, se ha determinado que actualmente, la formación profesional ha sufrido cambios, ya que, antes estaba centrada solo en la creación de conocimientos, destrezas y habilidades para que sirvan en un determinado empleo. Ahora ya no solo esto es necesario, ya que la formación profesional, además de lo descrito anteriormente, busca la formación continua, no basta con adquirir conocimientos al inicio de

\footnotetext{
${ }^{2}$ Diagnóstico de la Formación Profesional en el Perú -Consejo Nacional de Trabajo y Promoción Social/ Comisión de Formación Profesional y Capacitación para el Trabajo- Ministerio de Trabajo y Promoción Social 1999
} 
la vida académica, sino ir implementando competencias tecnológicas y habilidades blandas que sirvan para la adaptación en cualquier escenario laboral.

La formación profesional ya no busca preparar a los jóvenes en el plano académico, con conocimientos, destrezas y habilidades. Si no, la generación de competencias en los futuros profesionales para que desarrollen un abanico de capacidades que le brindarán la oportunidad de transferirse de un empleo a otro. Esto hace que se disminuya el riesgo de obsolescencia, ya que son capaces de adaptarse a varios perfiles labores lo cual mejora su empleabilidad. $^{3}$

Si bien, la realización de prácticas profesionales es pensada como el espacio donde el alumno universitario adquiere nuevos aprendizajes y aptitudes para su preparación en el mundo laboral en un corto a mediano plazo, debemos preguntarnos qué aportan estas prácticas a la misma casa de estudios, plana docente, y centro de labores. Ya que es ahí donde se podrán medir los conocimientos impartidos y se podrá realizar un balance entre lo enseñado y lo que el mercado realmente necesita.

La facultad de Psicología de la Universidad Nacional de Mar de Plata (Argentina) ${ }^{4}$, realizó una evaluación del aporte de las prácticas pre profesionales en la formación de los alumnos universitarios, en dicho texto ubican a las prácticas como un espacio necesario y

\footnotetext{
${ }^{3}$ Diagnóstico de la Formación Profesional en el Perú -Consejo Nacional de Trabajo y Promoción Social/ Comisión de Formación Profesional y Capacitación para el Trabajo- Ministerio de Trabajo y Promoción Social 1999

${ }^{4}$ Aporte de las Prácticas Pre-Profesionales a la Formación de Alumnos Universitarios en Practicas ExtensionistasLic. Graciela Llarull - Lic. Silvia Rovira - Lic. Florencia Gómez - Lic. Berger Valeria /Grupo De Extensión G.I.E.S Facultad De Psicología De La Universidad Nacional De Mar Del Plata Argentina
} 
primordial para que el alumno pueda tener un contacto con la realidad y cómo se va desenvolviendo en un ambiente laboral.

Es así como se pudo determinar que el alumno se enfrenta a sus miedos, limitaciones, valoraciones personales y prejuicios propios ante esta nueva experiencia, lo cual si no es correctamente manejado puede tener efectos contraproducentes en el mismo alumno, ya que no podrá cumplir con objetivos planteados, tantos personales, del puesto y de la carrera. Es importante tener la capacidad de poder lidiar con alguna posibilidad de frustración al trabajar en condiciones no ideales y manejando problemas complejos. Cuando la idealización del trabajo soñado no va acorde con la primera práctica.

Dentro de este ensayo se enlistan una serie de beneficios que conllevan realizar prácticas pre profesionales, las cuales a continuación señalamos algunos que consideramos se aplican para todas las carreras en general:

- Se realiza una verificación y confrontación de discursos académicos, teorías y conocimientos aprendidos versus la realidad cotidiana.

- Desarrolla la capacidad de poder interactuar con la persona, ya sea superior, par, usuario, etc.

- Interacción con otros profesionales con la intención de realizar un trabajo interdisciplinario.

- Ser consciente de las ventajas y limitaciones propias para poder realizar un trabajo. 
- Generación de interrogantes sobre determinadas tareas y poder solucionarlas no sólo con conocimiento académico.

- Entrar en contacto con una realidad que será la cotidiana cuando sean profesionales.

En entrevistas realizadas a diferentes estudiantes universitarios, se les preguntó acerca de las principales razones por las cuales estos laboran, luego de analizarlas se determinaron tres factores: por necesidades económicas, búsqueda de aprendizaje y experiencia profesional. Estos factores fueron discutidos a continuación por Planas.

Para Planas J. ${ }^{5}$ (2011), en su discusión sobre si ¿tienen valor profesional el trabajo durante los estudios?, menciona que desde la óptica de la adquisición de competencias laborales y de la profesionalización tiene efectos positivos en la calidad de la inserción laboral (altos niveles de probabilidad de inserción laboral). Él llega a la conclusión que trabajar durante los años de estudio constituye aprendizajes y mejora las habilidades que se van descubriendo en los estudiantes.

\subsection{Determinación del problema u oportunidad}

La empleabilidad en el Perú es un problema el cual se enfrenta día a día, de acuerdo con los recientes estudios de la Organización Internacional del Trabajo (OIT), un indicador que demuestra la gravedad del tema es el alto porcentaje de puestos informales, frente a

\footnotetext{
${ }^{5}$ Planas J. (2011). Análisis acerca de los estudiantes que trabajan ¿tienen valor profesional el trabajo durante los estudios? México. Pág. 1
} 
aquellos que, si cuentan con un trabajo formal y estable, es decir seis de cada diez jóvenes tienen trabajos informales ${ }^{6}$.

En nuestro país, según la consultora CL Selections ${ }^{7}$ la empleabilidad de los jóvenes universitarios (entre 17 a 22 años) es baja, ya que menos del 30\% tiene un empleo, pero casi siempre este no tiene relación con su carrera. Es por eso por lo que se recomienda que para elevar su empleabilidad y ser más atractivos en el mercado, los estudiantes opten por realizar sus prácticas a partir del quinto ciclo y en el sector de la carrera que estudian.

El especialista señala que el hecho de practicar desde la mitad de la carrera les permitirá afianzar conocimientos, y podrá conocer diversos sectores de la industria. Es importante que trabajen en lo que le apasione.

Conseguir las primeras prácticas no es algo fácil ya que la falta de experiencia es un factor limitante, es por eso que se recomienda que el alumno refuerce su empleabilidad, de esa manera es más atractivo al mercado. Para ser empleable se recomienda desarrollar competencias, conseguir logros, participar en proyectos y manejar las habilidades blandas (comunicación efectiva, orientación a resultados, proactividad y capacidad analítica), además del idioma y el manejo de software.

\footnotetext{
${ }^{6}$ Organización Internacional del Trabajo. (2015, April 22). 27 millones de jóvenes en la informalidad en América Latina y el Caribe. Revisado el 17 de junio, 2017, recolectado desde http://www.ilo.org/americas/sala-deprensa/WCMS_362579/lang--es/index.htm

${ }^{7}$ Gestión. (2017). Universitarios deben comenzar prácticas pre profesionales desde quinto ciclo de sus carreras. Recolectado el 14 de junio de 2017, desde: http://gestion.pe/empleo-management/universitarios-deben-comenzarpracticas-pre-profesionales-desde-quinto-ciclo-sus-carreras
} 


\subsection{Justificación del Proyecto}

El plan de negocio se justifica en el hallazgo de un nicho de mercado en la rama de servicios profesionales junto con la necesidad de los estudiantes de obtener una inserción laboral adecuada, en función a sus expectativas académicas y laborales.

Se genera valor en el servicio realizando la gestión de selección y acompañamiento en la curva de aprendizaje a los trainees, liberando de estas funciones a las empresas y nosotros tomando un rol de socios estratégicos.

A largo plazo al mantener una cartera de clientes, nos brinda mayores posibilidades de ampliar diferentes tipos de servicios.

\subsection{Objetivos generales y específicos}

\subsubsection{Objetivo general.}

Realizar un plan de negocios de una empresa especializada en ofrecer servicios para prácticas pre profesionales, teniendo en cuenta las el entorno, estrategias y buscando la viabilidad de esta.

\subsubsection{Objetivos específicos.}

1. Diseñar el plan de negocio para el desarrollo de la inserción laboral en jóvenes estudiantes a través de la consultora M \& N en Lima Metropolitana.

2. Realizar el plan de marketing para el desarrollo de la inserción laboral en jóvenes estudiantes a través de la consultora M \& $\mathrm{N}$ en Lima Metropolitana. 
3. Elaborar el plan económico - financiero para el desarrollo de la inserción laboral en jóvenes estudiantes a través de la consultora $\mathrm{M} \& \mathrm{~N}$ en Lima Metropolitana.

\subsection{Alcances y limitaciones de la investigación}

\subsubsection{Alcance.}

Estudiantes de los últimos ciclos de las universidades de Lima Metropolitana que tengan más de 1500 matriculados.

\subsubsection{Limitaciones.}

Acceso a estadísticas en la colocación de practicantes, áreas de prácticas profesionales de las universidades, ya que no llevan un registro del material de sus egresados.

Debido a que las empresas clientes son empresas corporativas, se dificultó el alcance de la información (baja red de contactos). 


\section{Capítulo II. Estructura Económica del Mercado}

En este capítulo se tratará sobre el estado actual del mercado laboral, específicamente el de prácticas pre profesionales en los jóvenes universitarios, además, se realizará un análisis de la competencia, junto con la tendencia del mercado para los próximos años, se realizará el análisis estructural del sector, y el análisis PESTEL.

\subsection{Descripción del estado actual del mercado}

El crecimiento económico de las empresas en los diversos sectores se viene dando desde el año 2000 y esto ha llevado a que dentro de sus socios estratégicos se encuentren las consultoras de recursos humanos. Es por ello, que estos servicios son demandados por las empresas más importantes -no sólo por la necesidad de tener una planilla más grande y de poseer una mayor capacidad financiera para asumir los costos— sino por tener más apertura hacia las consultorías de recursos humanos ya que estas cuentan con un mayor conocimiento del mercado. A diferencia de las pequeñas y micro empresas que suelen considerar a la consultoría como un servicio muy costoso, complejo y poco confiable.

Como se muestra en la Figura 1, hasta el 2011, el 70\% de los trabajadores, pertenecían en pequeñas empresas (de 10 empleados como máximo) y un 20\% lo hacía en empresas como más de 100 empleados. Las empresas medias (de 11 a 99 empleados) son un pequeño porcentaje dentro del mapa de empresas que trabajan en el país. Es así que se puede determinar que la fuerza laboral del país radica en empleados (50\%) e independientes (34\%), y la mayoría de trabajadores lo hacen en pequeñas empresas (70\%) 


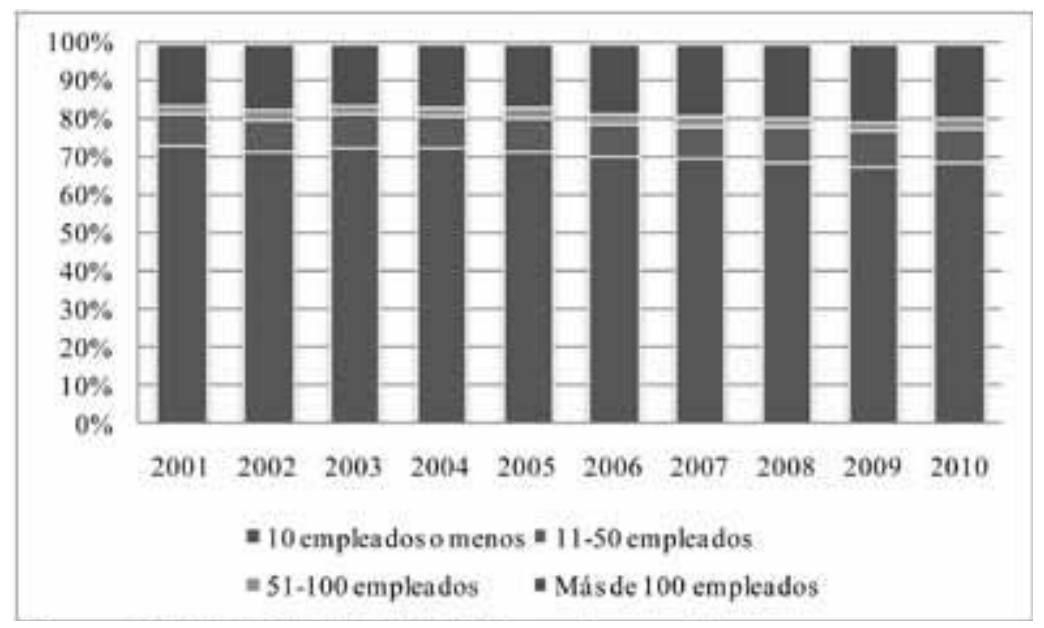

Figura 1. Cantidad de trabajadores dependientes por tamaño de la empresa, 2001-2010. Tomado de "Perú: Perfil de pobreza por departamentos 2001-2010", por el Instituto Nacional de Estadística e Informática (INEI) 2011.Recuperado de https://www.inei.gob.pe/media/MenuRecursivo/publicaciones_digitales/Est/Lib0981/Libr o.pdf

Según el diario Gestión ${ }^{8}$ (2015), ante la pregunta, ¿Qué busca el mercado laboral en los trabajadores de hoy?, el Director Comercial de Manpower, Juan Lizárraga, señala que existe un desequilibrio entre la abundante demanda de trabajo y la escasez de talento, la principal brecha a vencer ante el desempleo. Los mercados, las empresas y consumidores se han sofisticado, de tal manera que la demanda interna de talento se ha optimizado más no la capacidad de la oferta. Si bien la educación no es óptima, las características más valoradas por las empresas a la hora de reclutar son:

a. Especialización. El mercado requiere de personal especializado en áreas específicas. 
b. Idiomas. El idioma inglés es el más requerido debido a que muchos inversionistas desean comunicarse con otros clientes y estos deben utilizar un lenguaje común para los negocios.

c. Soft skills. Entre las habilidades blandas más requeridas está la capacidad de liderazgo, inteligencia emocional, y la resiliencia.

d. Capacidad de gestión. Esta habilidad se encuentra dirigida a los perfiles de ejecutivos, jefaturas, gerencias medias y altas gerencias.

Actualmente, existen diferentes herramientas para el reclutamiento, como el uso de plataformas de selección. En el caso de Manpower, han desarrollado aplicativos de 3 pasos, el ATS o Aplicant Tracking System, que recoge toda la información de los candidatos en cada una de las etapas del proceso y permite controlar indicadores claves.

El tema salarial también es muy importante dentro de este tema, muchas empresas no saben calcular la remuneración idónea para su personal, lo que conlleva que tengan una alta tasa de rotación o lo que es peor, que tengan puestos disponibles casi siempre. Esto se debe a tres factores:

- Tecnología, algunos puestos requieren de personal con conocimientos específicos como el manejo de algún programa tecnológico, por lo que requerir a un personal especializado es primordial y el abanico de candidatos sea reducido.

- Globalización, actualmente existen grupos de trabajos internacionales, que laboran en una misma empresa, en una misma área, bajo un mismo proyecto, 
pero en lugares distintos, por lo que muchas veces es necesario que tengan que mudarse a otros países.

- Profesionales más empoderados, gracias a las redes sociales, cada profesional valora más sus logros, habilidades y reconoce fácilmente lo que el mercado requiere.

Según la Dirección Nacional de Inspección de Trabajo del Ministerio de Trabajo y Promoción Social ${ }^{9}$, señala que en 2015 existieron alrededor de 40,000 a 60,000 practicantes entre pre profesionales y profesionales que realizaron algún tipo de prácticas. Se determina que la subvención económica no debe ser menos que la remuneración mínima vital, es decir de S/. 850.00 soles, pero es cada empresa la que puede colocar el monto por práctica, esto depende mucho según la escala de remuneraciones que posee.

Según la "Demanda de ocupaciones al 2016" realizada por el Ministerio de Educación, señala que uno de los problemas del mercado laboral en el país es la desigualdad que existe entre la oferta educativa y la demanda de trabajo, es así que podemos apreciar que actualmente alrededor del $52 \%$ de los trabajadores que tienen educación superior están en trabajos que no tienen relación con su educación recibida. De ese total el $43.8 \%$ de los egresados de una universidad no se encuentran en puesto de trabajo acorde a sus estudios.

\footnotetext{
${ }^{9}$ Pymex. (2016). ¿Cuánto es el sueldo de un practicante en el Perú? Revisado el 17 de junio, 2017, recolectado desde: https://pymex.pe/liderazgo/cuanto-es-el-sueldo-de-un-practicante-en-el-peru
} 


\subsubsection{Segmentación de la industria y empresas que la conforman.}

Hemos dividido a la industria según su registro de actividad económica y su número de trabajadores, es así que hemos realizado una segmentación en tres niveles:

- Empresas registradas con la misma actividad económica, con matriz internacional (Número de trabajadores mayor a 1,000).

- Empresas registradas con la misma actividad económica (Número de trabajadores menor a 1,000).

- Empresas registradas con actividades económicas similares.

Empresas registradas con la misma actividad económica. (Número de trabajadores mayor a 1,000). En este rubro encontramos a Manpower y Adecco las dos consultoras de recursos humanos más grandes del sector, el público al que van dirigido es amplio ya que trabajan en todos los rangos laborales (técnicos, prácticas, ejecutivos, jefaturas, mando medio). Sin embargo, al tener una amplia propuesta no se especializan en el grupo universitario ni en las prácticas pre profesionales.

\section{- Manpower Group}

Líder mundial en consultoras de recursos humanos, presta servicios que contribuyen a que las empresas logren sus objetivos de negocio y de capital humano. A nivel mundial tiene un volumen de ventas de 19 mil millones de dólares, donde tiene sedes en 72 países. La empresa inicia sus actividades en el Perú en 1996 y cuenta con una planilla de 3,160 trabajadores. 
- ADECCO

Consultora internacional con sede en Perú, dentro de los diversos servicios ofrece la selección de personal, donde se encuentra dividida en categorías profesionales: Proyectos masivos (requerimientos por volumen), Adecco selección (profesional administrativo, técnico, profesionales y jefaturas) y Adecco Professional (personal especializado, mandos medios, ejecutivos). La empresa inicia actividades en 1998 y cuenta con una planilla de 5,321 de trabajadores

Empresas registradas con la misma actividad económica. (Número de

trabajadores menor a 1,000). En este nivel podremos encontrar a las consultoras que no se especializan en jóvenes estudiantes, sino que trabajan a solicitud de la empresa, y generalmente trabajan con egresados de universidades e institutos. Si bien no ofrecen un servicio similar están en todas las condiciones de poder ofrecerlo sin problema alguno.

- Innovación Empresarial

Realiza la selección de personal y divide en tres grupos: Alta gerencia, Jefaturas y talento masivo. No dan más información sobre la colocación de practicantes, pero al poder trabajar con selecciones numerosas podrían implementar la colocación de practicantes. La empresa inicia sus actividades en el Perú en 1995 y cuenta con una planilla de 14 trabajadores.

- Solimano Asociados

Es una Consultora de Recursos Humanos que nace en 1985 con el objetivo de prestar a las empresas asesoría en servicios de Evaluación y Selección de 
Personal. A la fecha cuenta con nueve trabajadores.

Empresas registradas con actividades económicas similares. Estas empresas definitivamente no ofrecen un servicio especializado, se encuentran ubicadas dentro del sector de asesoramiento empresarial o actividades de consultoría de gestión.

\section{- ABCG PERÚ}

Consultora peruana de recursos humanos, dentro de los servicios que ofrecen se encuentra la evaluación y selección de personal técnico, es decir se enfocan en estudiantes y egresados de carreras técnicas. El perfil de empresas con las que trabajan son generalmente mineras o manufacturas. La empresa inicia sus actividades en el Perú en 2000 y cuenta con una planilla de tres trabajadores.

- LARC Consultores

Dentro de los servicios brinda la selección de personal, enfocado en profesionales. La empresa inicia sus actividades en el Perú en 2008 y cuenta con una planilla de 10 trabajadores.

- Pigmalión Consultores

Consultora peruana, dentro de los servicios ofrece la selección de personal, no trabajan directamente con practicantes pre profesionales, pero si con entrenadores, egresados no más de 1 año. La empresa inicia sus actividades en el Perú en 1997 y cuenta con una planilla de 18 trabajadores. 


\subsection{Tendencias de la industria}

El mercado laboral se encuentra en un constante cambio, las empresas deben estar en una constante actualización sobre las tendencias del mercado y las necesidades de sus trabajadores. Es común que en una empresa convivan trabajadores de distintas generaciones y posean características específicas, como es el caso del uso de la tecnología y la inmediatez de la información.

Es así que el Workforce Institute en Kronos Incorporated y Dan Schawbel, miembro del organismo ${ }^{10}$, han logrado identificar algunas de las principales tendencias que se encuentran en el mercado laboral.

- El año del talento: Las áreas de recursos humanos y de reclutamiento de talentos tienen como principal premisa tener en la organización empleados comprometidos, ya que la relación con lograr los objetivos económicos de la empresa es proporcional a tener empleados que se identifiquen con esta. Es así como la relación empleadoempleador se vuelve más dinámica.

- Beneficios únicos como ventaja competitiva: Existe una competencia entre las empresas para captar a los mejores talentos, es así que dentro de la oferta que ofrece el empleador para que los empleados decidan trabajar con él, son los beneficios adicionales que pueden brindarle, como préstamos estudiantiles, seguros médicos gratuitos, guardería, etc.

\footnotetext{
${ }^{10}$ Workforce Institute en Kronos Incorporated y Dan Schawbel. (2016). 10 tendencias de capital humano en 2016. Revisado el 17 de junio, 2017, recolectado desde: Forbes Sitio web: https://www.forbes.com.mx/10-tendencias-decapital-humano-en-2016/
} 
- La aceptación de empleados 'boomerang' (los que se van y regresan): Una práctica que se está volviendo cotidiana entre los trabajadores, es dejar de laborar en una empresa y luego de un tiempo regresar a esta. Esto sucede por el fácil acceso a nuevas ofertas laborales. $\mathrm{Al}$ aceptar trabajadores "boomerang", la empresa no necesitará brindar mucha capacitación, ya que están familiarizados con la cultura y llegan a la empresa con perspectivas e ideas nuevas.

- El déficit de liderazgo comenzará a llenarse conforme los boomers se retiren. Durante los siguientes años los baby boomers comenzarán a jubilarse y los millenials empezarán a ocupar puestos más altos, esto hace que las empresas deban ir realizando planes de capacitación para los nuevos gerentes.

- La flexibilidad en el lugar de trabajo se convierte en el tema de conversación más popular.: La nueva generación, los millenials, tienen una manera distinta de ver la vida y, por ende, la vida laboral. Esto hace que la flexibilidad en el centro de trabajo sea un punto importante para poder decidir laborar en ella. Sobretodo, cuando se espera que en los próximos años los Millennials tengan hijos.

- Las compañías toman en serio el diseño de la oficina y lo usan como una manera de incrementar la colaboración y atraer al mejor talento. El co-working o trabajo colaborativo es una de las tendencias en la industria, el diseño de la oficina y de la empresa en sí es fundamental para que el trabajador se sienta a gusto. Ya no hay más espacios individuales, sino una gran sala donde todos interactúan, proponen y discuten los temas diarios.

- La licencia por maternidad: un beneficio que cobra cada vez más relevancia 
entre los empleados. Con el fin de mejorar los beneficios a sus empleados y además de ser atractivos para los futuros talentos, las empresas ofrecen beneficios de maternidad, más allá de los otorgados por ley.

Estas tendencias, hacen que veamos un panorama favorable para nuestro plan de negocios, todas demuestran que estamos frente a un mercado flexible capaz de migrar al cambio.

Debido al desarrollo económico del país, muchas empresas, antes consideradas como pequeñas y medianas, han crecido y se han convertido en competidoras de las empresas más grandes del sector. Este desarrollo implica un crecimiento y adopción de nuevos retos en diferentes áreas, como en recursos humanos (capital intelectual).

Ante esta demanda, la necesidad de apoyo en la selección (reclutamiento), capacitación y seguimiento de procesos de capital humano aparecen como una alternativa a las consultoras que se enfocan en garantizar un clima organizacional adecuado a sus clientes. Sin embargo, muchas empresas aún no deciden tomar los servicios de una consultora, debido que consideran que los precios son muy elevados y no existe una buena relación entre el costo-beneficio obtenido.

Según el artículo de Semana Económica (2015), “Las consultoras en recursos humanos que aún no hacen clic"11 indica que uno de los principales problemas es que estas deben tener un gran conocimiento del mercado y del sector donde trabajan. Por ello,

\footnotetext{
${ }^{11}$ Semana económica (2013), Las consultoras en recursos humanos que aún no hacen clic. Revisado el 17 de junio, 2017, recolectado desde: http://goo.gl/kd8Qob
} 
la consultora no llega a ahondar sobre el tipo de mercado y por ende no brindan resultados satisfactorios. Otro inconveniente, es que la consultora, al ser un socio estratégico, debe obtener la filosofía y cultura organizacional de sus clientes.

En el 2011, el ingreso de las consultoras en general fue de 1,687 millones ${ }^{12}$, este monto incluyó todas las áreas del negocio, que, en algunos casos, pueden ser distintos a la consultoría de recursos humanos. Con esta información de facturación, se puede determinar la especialización de las principales empresas de servicios en consultoría. Según el Instituto de Comercio Exterior (ICEX) en el estudio realizado al mercado de la consultoría en Perú, el 32\% de las consultoras están dedicadas a temas de ingeniería, mientras un $31 \%$ son consultoras integrales (recursos humanos).

En los últimos años, a medida que existen más corrientes y estudios sobre los recursos humanos, las consultoras van ampliando los servicios que ofrecen, buscando la manera de personalizar el servicio.

Un importante problema es el crecimiento de la informalidad en la región, debido que es una amenaza para las consultoras en recursos humanos, ya que estas empresas no contratan a una empresa especializada en recursos humanos porque sus contratos son informales (no lo hacen de acuerdo con la ley) y pueden requerir trabajadores sin beneficios, adicionalmente a ello les resultaría muy caro porque trabajan a destajo ya que sus actividades son principalmente artesanales y mecánicas. Sin embargo, la cantidad de personas que estudian y trabajan es significativa, debido a las condiciones del mercado,

\footnotetext{
${ }^{12}$ ICEX (2011). Perú: The Top 10.000 compañías. Recolectado de la página web: http://goo.gl/1dc8fA
} 
por ello, se genera una oportunidad para el diseño de negocio.

Un punto importante es la comunicación entre los gobiernos, autoridad civil, e instituciones educativas para cumplir con el ritmo de crecimiento de la región.

En un mundo globalizado, el reclutamiento de recursos humanos no está fuera de esta tendencia, ya que desarrollan estrategias para atraer talento mundial, además el objetivo es de retenerlos debido que estos se pueden ir a otros países.

En estos años ha estado ganando espacio un tipo de práctica distinta a lo ya conocido, las prácticas profesionales online. Esto ya se viene practicando en España, país donde se requiere alrededor de 150,000 practicantes anuales, generalmente los sectores dónde más realizan estas prácticas son el tecnológico, negocios, comunicaciones. ${ }^{13}$

El portal Universia realizó en el 2015 un estudio del mercado laboral en España y la Unión Europea para conocer las nuevas tendencias. Las conclusiones a las que llegaron fueron las siguientes ${ }^{14}$ :

- Actualmente dentro del mercado laboral conviven 3 generaciones de trabajadores, cada cual con sus propias características, metas, ventajas y deficiencias: Baby boomers, Generación X, Generación Y

\footnotetext{
${ }^{13}$ Universia España. (2014). Prácticas profesionales online: la nueva tendencia laboral. Revisado el 17 de junio, 2017, recolectado desde: http://noticias.universia.es/en-portada/noticia/2014/07/30/1108783/practicas-profesionalesonline-nueva-tendencia-laboral.html

${ }^{14}$ Universia España. (2015). El mercado laboral hoy y las tendencias a futuro. Revisado el 17 de junio, 2017, recolectado desde: http://noticias.universia.es/portada/noticia/2015/10/02/1131866/mercado-laboral-hoy-tendenciasfuturo.html\#
} 
- Baby Boomers, personas nacidas entre los años 40 y 60, cuando llegaron al mercado laboral, cambiaron la idea tradicional de empleo. Los trabajadores de esta generación se caracterizan por ser competitivos, aceptar retos, positivos, son ambiciosos. El poder en el trabajo se consigue por tener experiencia, y eran los hombres los que siempre ocupaban posiciones altas, las mujeres no.

- Generación X, aquellos que nacieron a inicios de la década del 60 y hasta inicios del 80, ellos se caracterizan por ser informales, escépticos, dan más importancia a la familia, por ende, trabajan menos horas, consideran que para obtener una posición de poder debe ser por medio de su mérito propio.

- Generación Y, actualmente es la generación más joven dentro del mercado laboral, son los nacidos entre 1980 y 1993, conocidos como Millennials, esta generación es experta en tecnología, pragmáticos, necesitan feedback, buscan tener un equilibrio entre su vida personal y profesional. Para ellos, tener poder simboliza manejar habilidades y conocimientos.

Sin embargo, la futura generación de trabajadores es llamada Generación Z, conformada por aquellos que nacieron entre 1994 y 2010, a ellos se les conoce como nativos digitales, con preferencia en empleos virtuales, no le dan mucho valor a la interacción con el personal. Ven al trabajo solo como un medio para conseguir otras cosas.

Esto ubica a nuestro público objetivo dentro de la Generación Z.

En la Encuesta de Demanda Ocupacional 2016 (ver Figura 2), se señala que 
existen 4,936 empresas que tienen más de 20 trabajadores, de estas, cerca del 33.1\% contratarían personal en este año, es decir cerca de los 40,605 trabajadores en todo el país. Y de este número se prevé que el $13.8 \%$ sean profesionales universitarios.

Además, se ve que el tema de la edad no es preferente para ocupar plazas, ya que solo un $46.7 \%$ de empresas solicitan un rango de edad para sus puestos. (ver Figura 3)

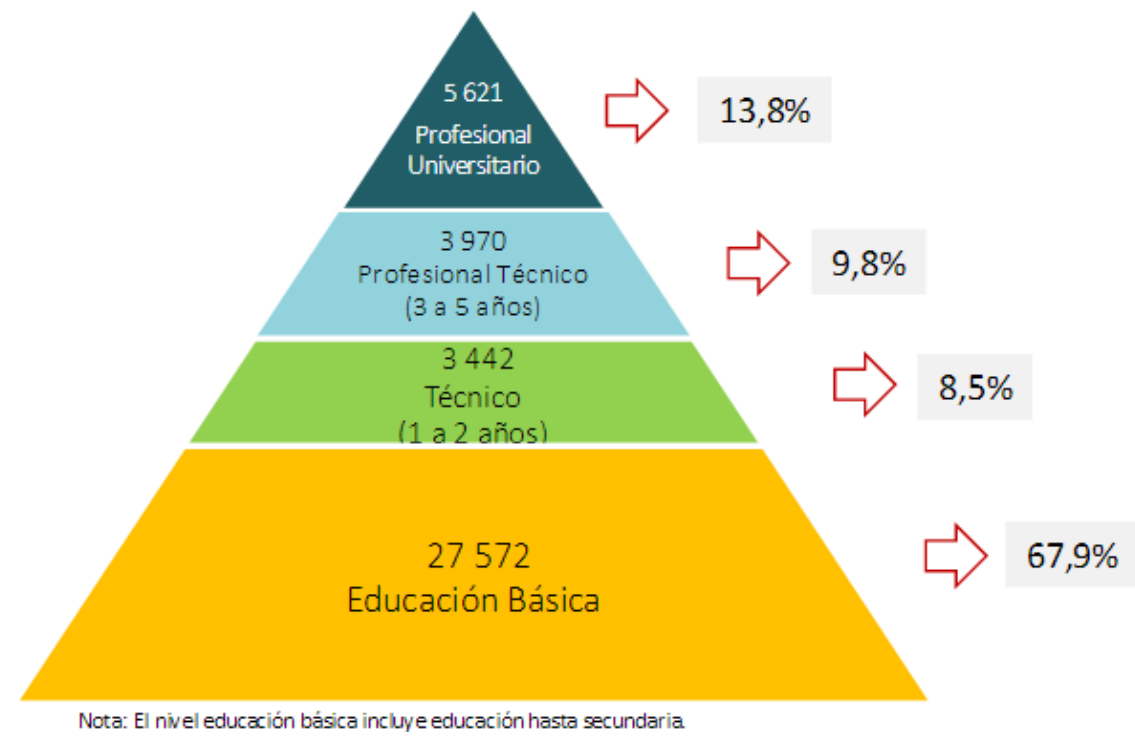

Figura 2 Demanda Ocupacional 2016.

Tomado de "Demanda de Ocupaciones al 2016 - Encuesta de Demanda Ocupacional 2016" por la Dirección General de Promoción del Empleo (DGPE), 2016. Recuperado de: http://www.mintra.gob.pe/archivos/file/estadisticas/peel/publicacion/2016/edoDO_2016.pdf 


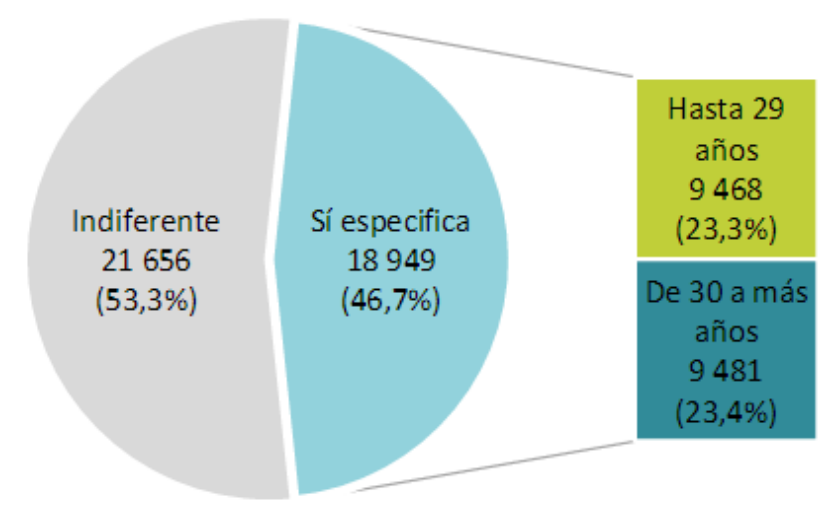

Nota La suma de las partes puede nocoincidir con el total debido al redondeo de las cfras Fuente: MTPE - DGPE - Encuesta de Demanda Ocupacional, 2016.

Elaboración: MTPE - DGPE - Dirección de Investigación Socio Económico Laboral (DISEL).

Figura 3 Requerimiento específicos de la Demanda Ocupacional 2016.

Tomado de "Demanda de Ocupaciones al 2016 - Encuesta de Demanda Ocupacional 2016" por la Dirección General de Promoción del Empleo (DGPE), 2016. Recuperado de: http://www.mintra.gob.pe/archivos/file/estadisticas/peel/publicacion/2016/edoDO_2016.p df

Además, los sectores que más demandan personal, son las actividades empresariales, tal y como se ve en la Figura 4.

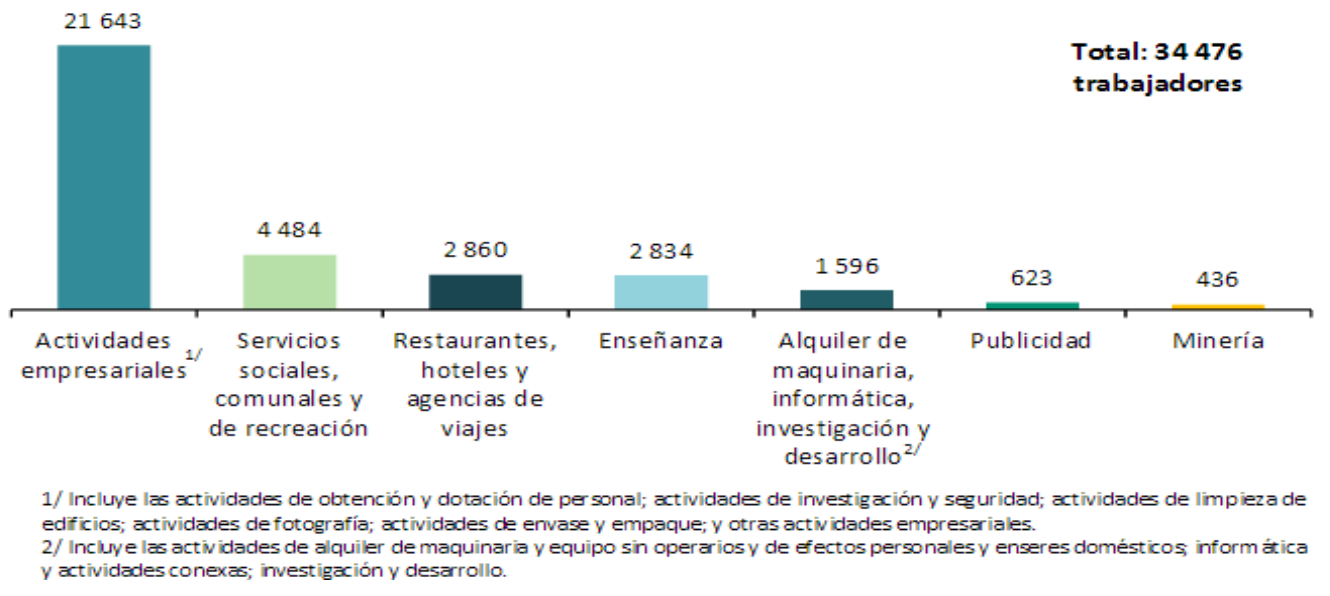

Figura 4 Demanda Ocupacional - Actividades Empresariales,

Tomado de "Demanda de Ocupaciones al 2016 - Encuesta de Demanda Ocupacional 2016" por la Dirección General de Promoción del Empleo (DGPE), 2016. Recuperado de: http://www.mintra.gob.pe/archivos/file/estadisticas/peel/publicacion/2016/edoDO_2016.p df 


\subsection{Análisis estructural del sector}

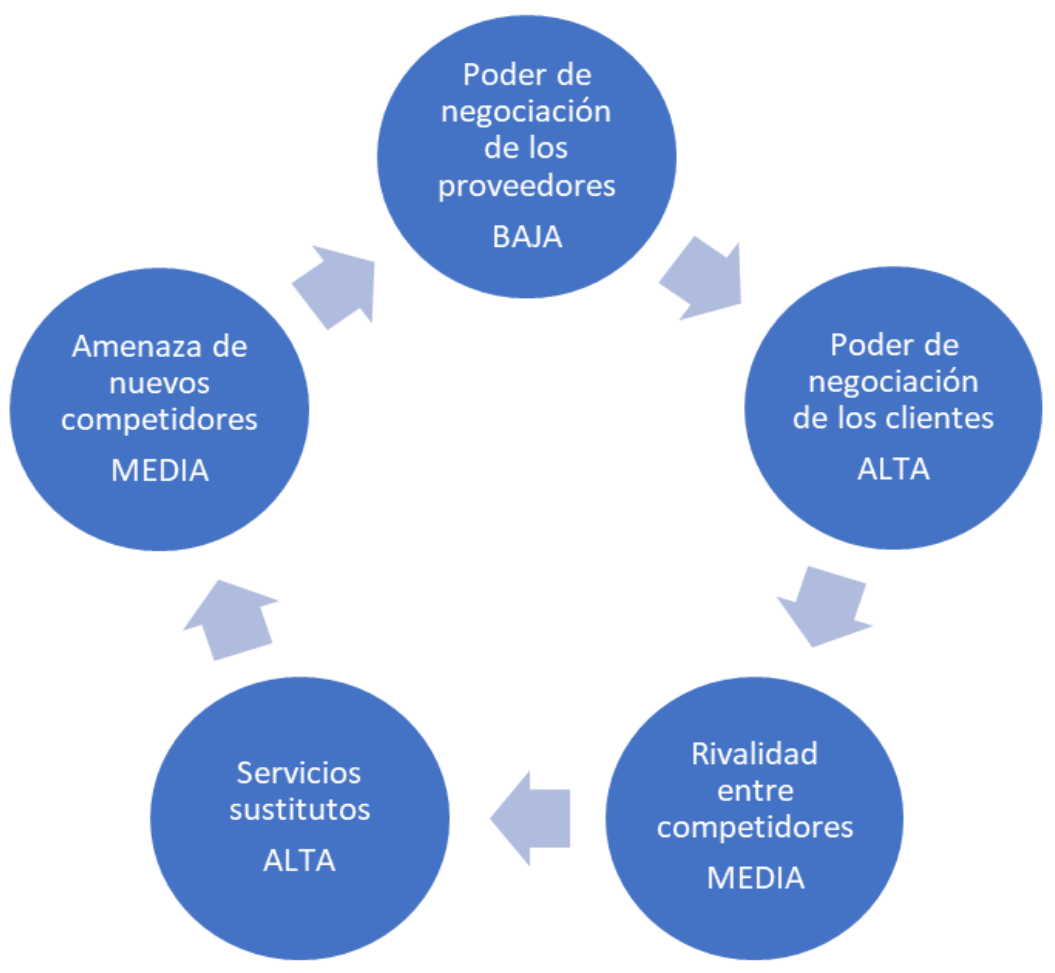

Figura 5: Modelo de las Cinco Fuerzas de Porter. Elaboración Propia.

Las cinco fuerzas de Porter es una herramienta que tiene como objetivo maximizar los recursos de la empresa y de esa forma poder sobresalir entre la competencia. Por medio de ésta se realiza un completo análisis de la empresa utilizando un estudio de la industria actual, esto con el objetivo de conocer dónde se encuentra ubicada nuestra empresa en relación a las demás empresas del sector. Tal y como se ve en la Figura 5 y en las siguientes matrices, se han analizado cada una de las fuerzas, las cuales están divididas en cinco rangos, siendo el $\mathrm{N}^{\circ} 1$ la calificación más baja y el ํ5 la calificación más alta.

a) Poder de negociación de los proveedores (ver Tabla 1)

Los proveedores que van a contribuir con el funcionamiento del negocio son 
profesionales específicos en temas legales, sistemas, contabilidad, etc.

Cantidad de proveedores, en el mercado encontramos una gran oferta de proveedores pudiendo conseguir buenos precios y beneficios adicionales. Calificación: Baja.

Poder de decisión en el precio por parte del proveedor, de acuerdo con lo analizado en el punto previo la gran oferta de proveedores no le permite tener poder de decisión en el precio. Calificación: Baja.

Nivel de organización de los proveedores, los precios por sus servicios se encuentran dentro de una banda, por ello podemos definir que se encuentran organizados los proveedores. Calificación: Media.

Impacto de Insumos, los servicios ofrecidos por nuestros proveedores tienen relación con la parte administrativa de la consultora. Calificación: Baja.

Tabla 1

Matriz de Atractividad de Poder de negociación de los Proveedores.

$\begin{array}{lllllll}\text { Poder de negociación de los proveedores } & 1 & 2 & 3 & 4 & 5 & \text { Ponderado }\end{array}$

$\begin{array}{lll}\text { Cantidad de proveedores en la industria. } & X & 1.75\end{array}$

Poder de decisión en el precio por parte del proveedor. $\quad \mathrm{X}$

$\begin{array}{ll}\text { Nivel de organización de los proveedores } & \text { X }\end{array}$

Impacto de Insumos. $\quad \mathrm{X}$

Nota. Elaboración propia

En esta matriz podemos apreciar que la fuerza de poder de negociación de los proveedores es baja y no tiene un gran efecto en el negocio. 
b) Poder de negociación de los clientes (ver Tabla 2).

Productos sustitutos, el mercado no registra el mismo modelo de negocio, pero no es difícil de replicar. Calificación: Alta

Diferenciación, servicio personalizado, pero carece de identificación con la marca. Calificación: Media

Volumen de Compra, teniendo en cuenta que nuestro perfil es colocación de practicantes el requerimiento es a solicitud del cliente que debe darse bajo condiciones contractuales. Calificación: Alta

Concentración de Clientes, el número de cliente no se encuentra definido ya que el mercado se encuentra en crecimiento, la figura actual son clientes corporativos. Calificación:

Alta

Tabla 2

Matriz de Atractividad Poder de Negociación de los Clientes.

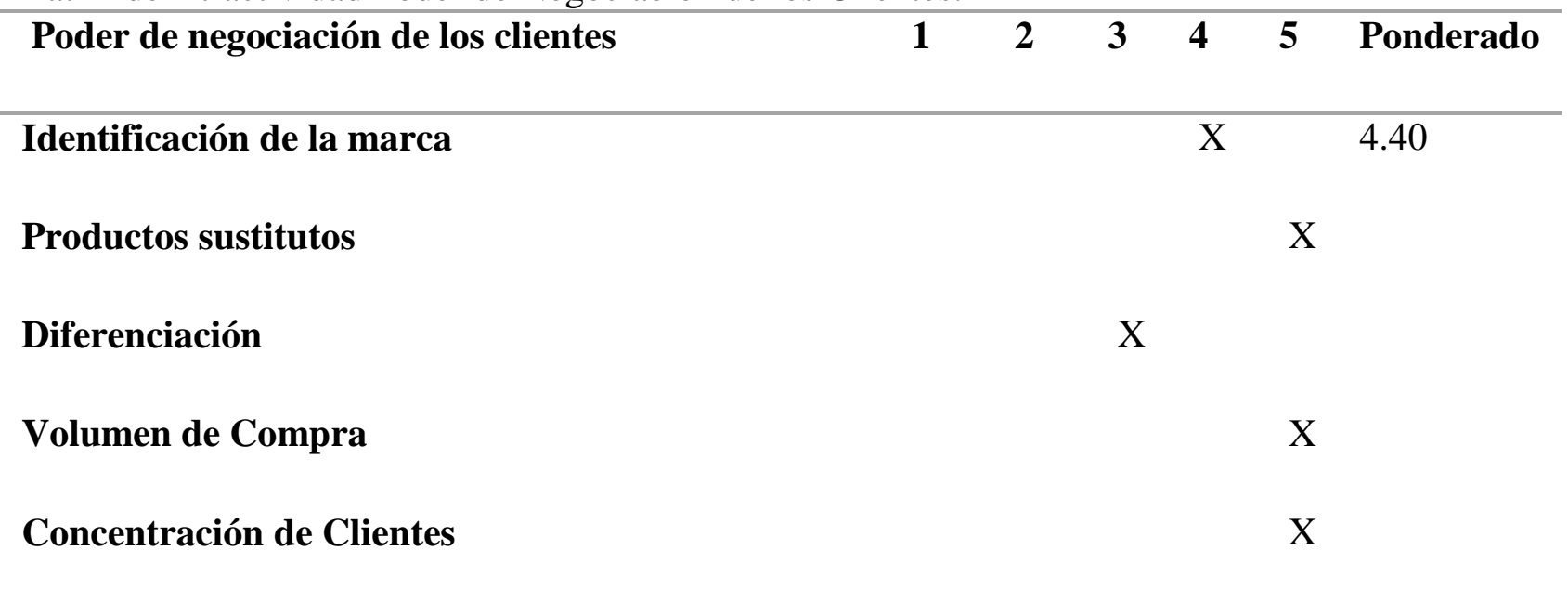

Nota. Elaboración propia

En la matriz de atractividad del poder de negociación de los clientes, tiene una 
calificación alta, ya que, si bien este negocio es nuevo en el rubro, este es fácil de replicar, al ser una marca nueva aún carece una identificación de estas.

c) Amenaza de los nuevos competidores (ver Tabla 3)

Diversidad de los competidores, Existe una gran variedad consultoras de recursos humanos que ofrecen servicios muy similares a lo planteado. Calificación: Alta.

Costos fijos elevados, el modelo de negocio no necesita una gran inversión en activos fijos. Calificación: Baja.

Grupos Empresariales, el sector no se encuentra representado por grupos. Calificación: Baja.

Equilibrio entre capacidad y producción, puede generar rivalidad en el sector, debido a que la eficacia con la que se atienda al cliente dependerá de la base de datos que maneje la consultora. Calificación: Media.

Crecimiento de demanda, el mayor uso de las consultoras por parte de las empresas para sus procesos de selección evidencia el crecimiento. Calificación: Alta. 
Tabla 3

Matriz de Atractividad Amenaza de los Competidores.

Amenaza de los competidores

$\begin{array}{llllll}1 & 2 & 3 & 4 & 5 & \text { Ponderado }\end{array}$

Diversidad de los competidores $\mathrm{X}$

Costos fijos elevados

$\mathrm{X}$

Grupos Empresariales

$\mathrm{X}$

$\mathrm{X}$

3.00

\section{Equilibrio entre capacidad y producción}

Crecimiento de demanda

$\mathrm{X}$

Nota. Elaboración propia

En la matriz de atractividad de amenaza de los competidores, se ve que esta fuerza tiene una calificación media-alta ya que tiene factores altos como la diversidad de competidores (existen muchas empresas de recursos humanos) y el crecimiento de la demanda, las empresas solicitan más consultoras de recursos humanos. Por otro lado, tanto los costos fijos que no son elevados y la nula representación de grupos empresariales tienen una calificación baja.

d) Servicios sustitutos (ver Tabla 4)

Disponibilidad de sustitutos cercanos, las empresas vigentes en el mercado se encuentran en la capacidad de ofrecer el mismo servicio. Calificación: Alta.

Nivel percibido de diferenciación de producto o servicio, no registra el mercado un modelo de negocio similar, pero es de fácil imitación. Calificación: Media.

Coste o facilidad del comprador, al tener un servicio personalizado, el cliente no le genera complejidad cambiar de proveedor. Calificación: Alta. 
Propensión del comprador a sustituir, los clientes no muestran perfil de fidelidad hacia quien brinde el servicio. Calificación: Alta.

Tabla 4 Matriz de Atractividad Servicios Sustitutos.

$\begin{array}{lllllll}\text { Servicios sustitutos } & 1 & 2 & 3 & 4 & 5 & \text { Ponderado }\end{array}$

Disponibilidad de sustitutos cercanos $\mathrm{X}$

Nivel percibido de diferenciación de producto o

servicio

X 4.50

Coste o facilidad del comprador $\mathrm{X}$

Propensión del comprador a sustituir X

Nota. Elaboración propia

Esta matriz sobre los servicios sustitutos tiene una calificación alta, esto debido a que, si bien no existen empresas que den el mismo el mismo servicio que el nuestro, las consultoras de recursos humanos tienen la capacidad de poder implementar dicho servicio.

e) Amenaza de nuevos competidores. (ver Tabla 5)

Barreras a la entrada, No existen barreras de entrada al mercado de consultoría. Calificación: Baja.

Política gubernamental, se puede presentar una reforma en la creación de pequeñas empresas a solicitud del gobierno de turno. Calificación: Media.

Desventaja en costes independientemente de la escala, las empresas que lideran el mercado de consultoras de Recursos Humanos presentan mayor inversión en tecnología. 
Calificación: Alta.

Inversiones de capital, el rubro no maneja altos importes en los que se refiere a capital inicial, lo que da ventaja a nuevos competidores. Calificación: Alta.

Economías de escala, la base de datos es considerada para las consultoras el recurso principal debido a que no tenemos presente en un modelo de negocio idéntico, las consultoras competitivas manejan base de datos amplios. Calificación: Alta.

Tabla 5

Matriz de Atractividad Amenaza de Nuevos Competidores.

$\begin{array}{llllllll}\text { Amenaza de nuevos competidores } & 1 & 2 & 3 & 4 & 5 & \text { Ponderado }\end{array}$

Barreras a la entrada $\quad$ X

Política gubernamental

$\mathrm{X}$

Desventaja en costes independientemente de la

escala

X $\quad 3.60$

Inversiones de capital

$\mathrm{X}$

Economías de escala $\quad \mathrm{X}$

Nota. Elaboración propia

En conclusión, el diseño de negocio no contiene barreras de ingreso, ya que es fácil obtener los mecanismos, procesos e implementación de las consultoras, pero el inconveniente es lograr mantenerse en el mercado, debido a que deben poseer herramientas tecnológicas en las que deben apoyarse (barreras de salida). 


\subsection{Análisis de la Competencia}

Dentro de la competencia directa existen dos empresas que han desarrollado valores y misiones similares al diseño de negocio que se desea implementar, estas son Manpower Group y ADECCO. Según el reporte del diario Gestión ${ }^{15}$ (2014), ambos gerentes CEO para América Latina pronuncian sus perspectivas acerca de la región y comentan la oportunidad del bono demográfico. Según Mónica Flores M. (2014), el reto para el sostenimiento del diseño del negocio se debe al bono demográfico en la edad de trabajo. La población económicamente activa es mayor que la dependiente conformada por niños y adultos mayores, en ese sentido el potencial productivo de la economía es superior. Los diferentes ritmos de crecimiento en cada país crean las oportunidades y los escenarios para presentar los talentos con las competencias adecuadas y atractivas para el lugar de inversión.

\footnotetext{
${ }^{15}$ Gestión (2014). Manpower y Adecco se pronuncian: La oportunidad de del bono demográfico. Recuperado de la página web: http://goo.gl/tEhF8B
} 


\subsubsection{Matriz de perfil competitivo.}

Tabla 6

Matriz de perfil competitivo

Según la información anterior se puede construir el siguiente cuadro de matriz de competencia:

\begin{tabular}{|l|c|c|c|c|c|c|c|}
\hline \multirow{2}{*}{$\begin{array}{c}\text { Factores críticos } \\
\text { para el éxito }\end{array}$} & \multirow{2}{*}{ Peso } & \multicolumn{2}{|c|}{ N \&M ASESORES } & \multicolumn{2}{c|}{ Manpower } & \multicolumn{2}{c|}{ Adecco } \\
\cline { 3 - 8 } & Calificación & $\begin{array}{c}\text { Peso } \\
\text { ponderado }\end{array}$ & Calificación & $\begin{array}{c}\text { Peso } \\
\text { ponderado }\end{array}$ & Calificación & $\begin{array}{c}\text { Peso } \\
\text { ponderado }\end{array}$ \\
\hline $\begin{array}{l}\text { Participación del } \\
\text { mercado }\end{array}$ & 0.30 & 1 & 0.30 & 4 & 1.20 & 3 & 0.90 \\
\hline $\begin{array}{l}\text { Ubicación de } \\
\text { Instalaciones }\end{array}$ & 0.20 & 3 & 0.60 & 2 & 0.40 & 3 & 0.60 \\
\hline $\begin{array}{l}\text { Posición } \\
\text { financiera }\end{array}$ & 0.20 & 1 & 0.20 & 3 & 0.60 & 2 & 0.40 \\
\hline $\begin{array}{l}\text { Calidad del } \\
\text { servicio }\end{array}$ & 0.20 & 3 & 0.60 & 3 & 0.60 & 3 & 0.60 \\
\hline Productos nuevos & 0.10 & 3 & 0.30 & 2 & 0.20 & 2 & 0.20 \\
\hline Total & 1.00 & & 2.00 & & 3.00 & & 2.70 \\
\hline
\end{tabular}

Nota: Elaboración propia. Los valores de las calificaciones son los siguientes: 1- menor debilidad a 4 - mayor fuerza.

Se tomaron los factores tradicionales (Apolinar García) ${ }^{16}$, se tiene en cuenta, como prioridad la participación de mercado como el factor principal. Esta matriz reafirma que el liderazgo muy marcado lo tienen Manpower seguido de

Adecco, tener en consideración que se está haciendo la comparación con competencia que se encuentra en el mismo sector de consultoras de Recursos humanos pero nuestro servicio difiere a la propuesta que tienen encaminadas ambas empresas.

\footnotetext{
${ }^{16}$ Apolinar E.García. (2013). Estrategias Empresariales. Una visión holística. Bogotá, Colombia: Bilineata Publishing.
} 


\subsection{Matriz EFI}

Tabla 7

Evaluación de los Factores Externos.

Factores determinantes de éxito Peso Calificación $\begin{gathered}\text { Peso } \\ \text { Ponderado }\end{gathered}$

\section{Fuerzas}

1 Base de datos de estudiantes con perfiles definidos

$0.12 \quad 3 \quad 0.36$

2 Diseño de negocio con valor agregado debido que se puede extrapolar con las instituciones educativas

$\begin{array}{lll}0.1 & 2 & 0.2\end{array}$

3 Nicho de mercado para segmento de estudiantes con necesidad de inserción laboral

$\begin{array}{lll}0.11 & 4 & 0.44\end{array}$
4 Flexibilidad del servicio, de acuerdo con las necesidades del mercado

$\begin{array}{lll}0.11 & 3 & 0.33\end{array}$

5 Bajos costos operativos

0.

$3 \quad 0.3$

\section{Debilidades}

1 Falta de mayor especialización de clientes según segmento geopolítico

$\begin{array}{lll}0.07 & 2 & 0.14\end{array}$

$2 \begin{aligned} & \text { Falta de personal con especialización en coaching con } \\ & \text { experiencia en estudiantes de prácticas pre profesionales }\end{aligned}$

$\begin{array}{lll}0.11 & 3 & 0.33\end{array}$
$3 \begin{aligned} & \text { Resistencia al cambio por parte de las instituciones } \\ & \text { educativas y empresariales }\end{aligned}$

$\begin{array}{lll}0.11 & 3 & 0.33\end{array}$

4 No se encuentra con el posicionamiento de la marca

$\begin{array}{lll}0.1 & 3 & 0.3\end{array}$

Debido a que el equipo de trabajo es pequeño, la renuncia

5 de uno de sus miembros puede desestabilizar la eficacia del servicio

$\begin{array}{lll}0.07 & 2 & 0.14\end{array}$

Nota: Elaboración propia.

El análisis se ha realizado en base a la información del sector, debido a que la presente investigación es un plan de negocio de una empresa nueva. 
El valor del promedio ponderado es 2.87 por encima del promedio. Esto nos indica que hay factores dentro de las fortalezas internas que pueden ser aprovechadas.

El factor más importante que afecta a esta industria es el nicho de mercado para el segmento de estudiantes con necesidad de inserción laboral, cuyo peso es de 0.44.

En la Matriz de Evaluación de los Factores Internos, su peso ponderado total de las oportunidades es de 1.63 y de las amenazas es 1.20 , lo cual puede ser interpretado como escenario favorable para el sector.

Se asignó un peso relativo a cada factor, de 0.0 (no es importante) a 1.0 (muy importante). La suma de todos los pesos asignados a los factores debe sumar 1.0

La calificación de 1 a 4 a cada uno de los factores determinantes para la implementación de las estrategias presentes en el plan de negocios están respondiendo con eficacia al factor, donde 4 = una respuesta superior, $3=$ una respuesta superior a la media, $2=$ una respuesta media y 1 = una respuesta mala.

\subsection{Análisis del contexto actual y esperado}

\subsubsection{Análisis político-gubernamental.}

- Informalidad en el país

El Perú como país tiene un reto pendiente llamado INFORMALIDAD, el cual afecta directamente nuestra propuesta debido a que los hoy estudiantes universitarios futuros profesionales se van a desenvolverse en un mercado laboral con este gran problema.

El Ministerio de Trabajo ha tomado cartas en el asunto y ha propuesto 
inspecciones mediante un organismo SUNAFIL.

- Poca estabilidad en los poderes del Estado

Actualmente existe una fractura en los poderes del Estado, especialmente del ejecutivo y legislativo, esto debido a que dos partidos políticos diferentes lideran cada uno, debido a esto se ha producido un estancamiento en las políticas generales, como en la economía. Ya que, las propuestas que realiza el ejecutivo muchas veces no son aprobadas por el legislativo generando estancamiento en el país.

Estos factores son contraproducentes con el negocio propuesto, ya que existe mucha informalidad en las empresas, las cuales no siempre invierten en consultoras de recursos humanos, además de no poder brindar a los empleados las condiciones mínimas para poder realizar un buen trabajo. Además, la poca estabilidad política que sucede en el país hace que crezca una desconfianza para poder invertir en un servicio tercero.

\subsubsection{Análisis económico.}

- Mejorar la productividad y competitividad de nuestra economía.

La cifra oficial -según INEI- es que el PBI cerró en el 2015 en un 3.3\%, la cual causó asombro debido a que durante todo el año se especuló que no superaría la del año 2014 (2.4\%). Pero si analizamos el sector más allá de la cifra, la preocupación común es conocer cómo los peruanos van a sentir este incremento, ya que de lo contrario solo será un número más.

- Aumento de la Población Económicamente Activa (PEA) 
En los últimos años la población en edad de trabajar ha ido creciendo, es por eso por lo que la PEA está teniendo una tendencia ascendente (ver figura 6).

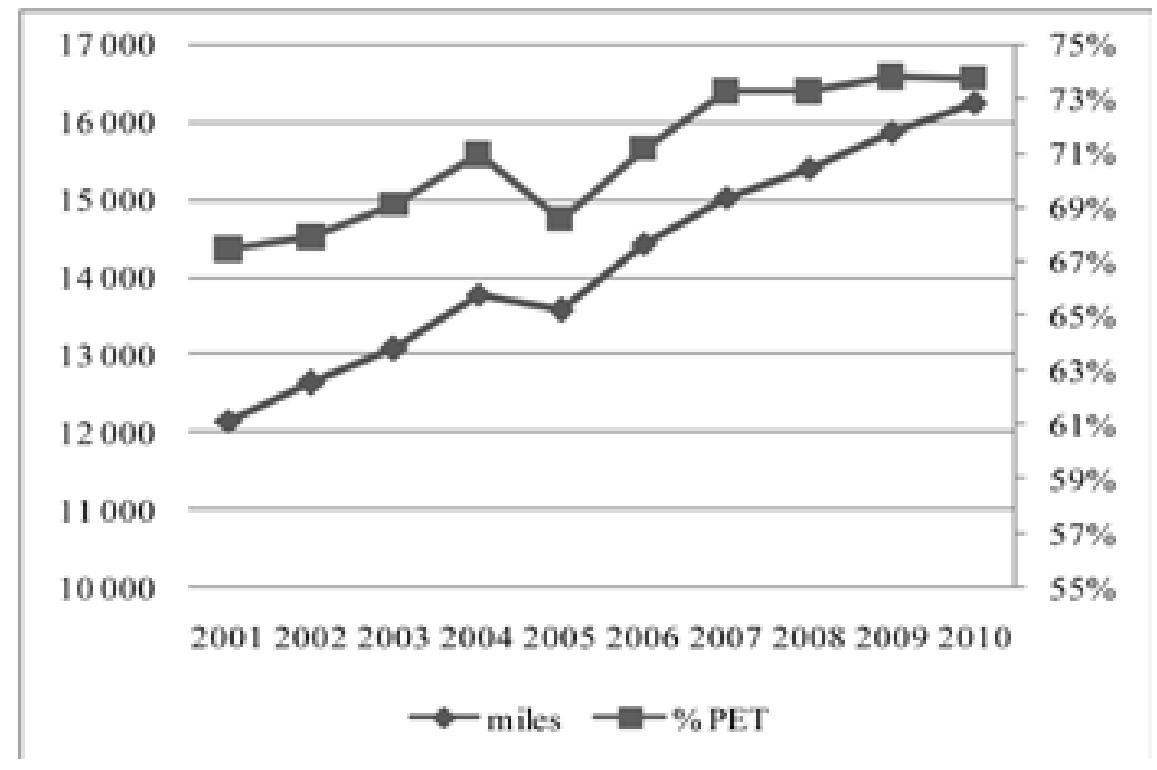

Figura 6 Desarrollo de la PEA 2001 - 2010.

Tomado de "Perú: Perfil de pobreza por departamentos 2001-2010", por el Instituto Nacional de Estadística e Informática (INEI) 2011.Recuperado de https://www.inei.gob.pe/media/MenuRecursivo/publicaciones_digitales/Est/Lib0981/Libro.pdf

- Crecimiento del PBI

Tal y como se muestra en la Figura 7, el crecimiento del PBI tiene como uno de sus resultados al crecimiento del empleo, a pesar de que el 2009 el PBI sufrió una caída debido a la crisis económica internacional, esto no repercutió en la tasa del crecimiento del empleo. 


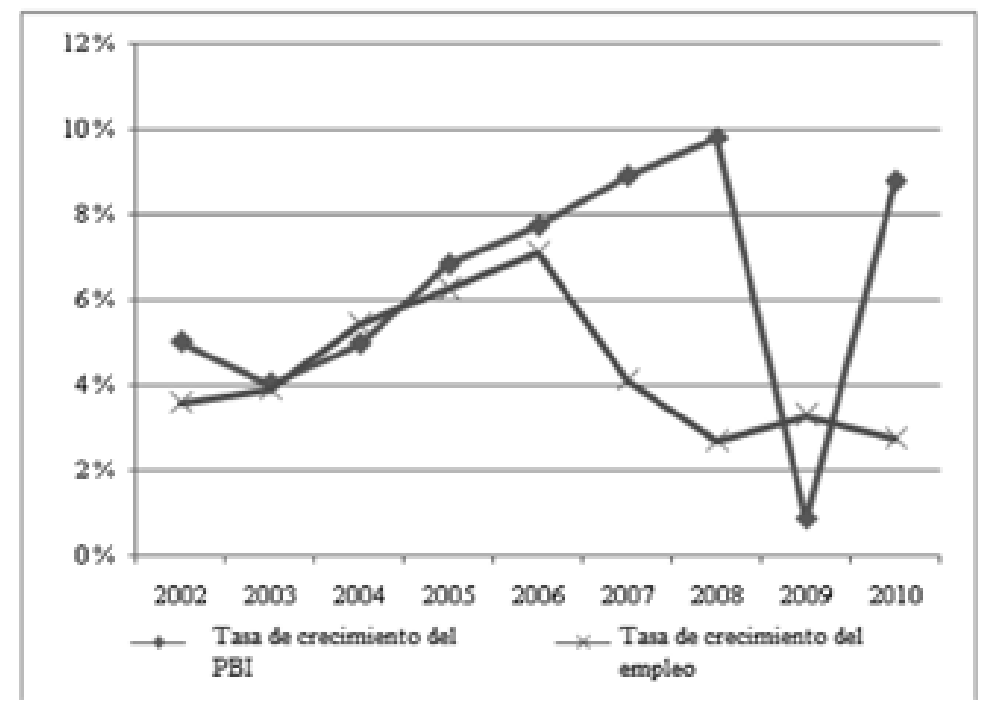

Figura 7 Crecimiento de PBI.

Tomado de "Perú: Perfil de pobreza por departamentos 2001-2010", por el Instituto Nacional de Estadística e Informática (INEI) 2011.Recuperado de https://www.inei.gob.pe/media/MenuRecursivo/publicaciones_digitales/Est/Lib0981/Libro.pdf

Dado los diversos factores analizados se puede decir que estos factores representan una oportunidad en el negocio, ya que la PEA va incrementándose, lo que significa que hay más jóvenes dispuestos a obtener un empleo. Sin embargo, debemos mantenernos cautos con el PBI, ya que, además, sumado a la inestabilidad, no es un escenario que invite a la inversión.

\subsubsection{Análisis legal.}

- Ley $\mathrm{N}^{\circ} 28518$. Ley sobre modalidades formativas laborales ${ }^{17 .}$

Perú es uno de los pocos países de América Latina que ha regulado las prácticas, por medio de esta ley y su reglamento. Regula las modalidades formativas laborales, con el fin de fomentar la capacitación laboral, desarrollar las capacidades para el trabajo,

${ }^{17}$ MINTRA (2014). Ministerio de trabajo. Recolectado de la página web: http://goo.gl/Z3Gqcr 
mejorar la empleabilidad y productividad. Para eso divide las diversas modalidades formativas en:

- De aprendizaje

○ Con predominio en la empresa

- Con el predominio en el centro de formación Profesional:

Prácticas pre profesionales

- De actualización para la reinserción laboral

- Pasantías

- Capacitación laboral juvenil

- Prácticas profesionales

En el caso de las prácticas pre-profesionales se deben tomar en cuenta los siguientes

puntos:

- Se realiza mediante un convenio de aprendizaje entre la empresa, el estudiante y el centro de estudios.

- Solo la pueden realizar personas que tengan la condición de estudiantes, en el caso de universitarios todos aquellos que no tengan la condición de egresados.

Esta ley establece que una empresa, sus practicantes, no pueden exceder más del $20 \%$ del total de trabajadores. 
Por medio de esta ley, el practicante gozará de los siguientes beneficios

- En el caso de las prácticas pre profesionales, la jornada de trabajo no debe ser mayor de 6 horas diarias o 30 semanales

- Si el practicante cumple la jornada máxima, la subvención económica mensual no debe ser menos que una Remuneración Mínima. Si su jornada es inferior, el pago es proporcional.

- Si la duración de la práctica es mayor a los 12 meses, la empresa deberá otorgar un descanso de 15 días.

- Se deberá entregar al practicante una subvención adicional equivalente a media subvención mensual, cada 6 meses de duración continua.

- El monto no está afecto al pago del Impuesto a la Renta (IR), ni a otros impuestos, contribuciones, ni aportaciones.

Esta ley regula directamente nuestra idea de negocio, la modificación de la misma afectaría nuestros parámetros de atención y perfil de postulantes.

- Convenio sobre el desarrollo de los Recursos Humanos y la Recomendación $\mathrm{N}^{\circ}$ 150 de la Organización Interamericana del Trabajo

Esta recomendación determina a la Formación Profesional como "todos los modos de formación que permitan adquirir o desarrollar conocimientos técnicos y profesionales, ya sea que se proporcione dicha formación en la escuela o en el lugar de trabajo", eso se refiere a que no solo el centro de estudios es primordial para entregar 
conocimientos, sino también el lugar de trabajo, donde el empleador busca formar al empleado para un cargo en un determinado tiempo.

Además, en esta recomendación, la OIT sugiere que se adopten medidas, y políticas para la orientación y formación profesional. E involucra no solo al Estado sino también al sector empresarial para que realice propuestas al Estado y cree sus propias estructuras formativas. Con esta recomendación la OIT busca asegurar empleos acordes a las aptitudes de los profesionales, incentivar la movilidad profesional, inclusión y formación laboral.

\section{- Constitución Política}

La Constitución Política del Perú, tiene como derechos fundamentales de los peruanos, el derecho a la educación y el derecho al trabajo, ambos derechos están estrechamente ligados a la temática de este plan de negocio.

Dentro del derecho a la educación, este es velado por el Ministerio de Educación y dentro de sus funciones se encuentra la realización de lineamientos generales para los planes de estudios, buscando que estos respondan a las necesidades del mercado y a las tendencias mundiales. Además, de supervisar y garantizar el cumplimiento y la calidad de la educación, entre otros.

En el caso del derecho al trabajo, es el Ministerio de Trabajo y Promoción Social el que se encarga de verlo, no solo fomentar el trabajo, sino también, la educación para el trabajo, es decir la formación profesional.

La legislación actual, da una plataforma de sustento para el negocio, ya que brinda 
las herramientas legales por la ley de modalidades formativas laborales, lo cual es una oportunidad.

\subsubsection{Análisis tecnológico.}

- $\quad$ Aumenta el acceso a Internet.

Según el Instituto Nacional de Estadística e Informática (INEI), en el último trimestre de 2014, el 50.9\% de los usuarios de 6 y más años accede a Internet todos los días, lo que representó un crecimiento de 2.5 puntos, en comparación con el trimestre octubre-diciembre de 2013. Las personas que usan Internet una vez por semana es el 42.5\%. El 94.5\% de la población que utiliza el Internet lo hace para obtener información, el $83 \%$ lo hace para comunicarse (correo o chat) y el $66 \%$ recurre a Internet para realizar actividades de entretenimiento como juegos de videos y obtener películas o música. Esta información crea escenarios donde los clientes potenciales, se encuentran en línea buscando diferentes necesidades en función a sus requerimientos. ${ }^{18}$

- $\quad$ Incremento en el uso de redes sociales.

Los servicios de redes sociales no están destinados únicamente a facilitar a los usuarios de Internet conversaciones en línea, también ayudan a seguir las noticias más actuales, estar en contacto con los amigos o colegas, contribuir a los debates en línea o aprender de los demás. En este proceso, los medios sociales están cambiando las expectativas del usuario en materia de privacidad, conductas aceptables en línea y reglas

\footnotetext{
18 Tomado del trabajo final del curso de Plan de Marketing "Plan de Marketing del Banco de Crédito del Perú. Caso: Tarjeta Solución Negocios" junio 2015
} 
de cortesía, y estos cambios se producen con rapidez. El uso de redes sociales hoy en día es un hecho muy común, un claro ejemplo es que los jóvenes han adaptado una nueva forma de comunicarse e informarse vía las redes sociales. Y para el caso de los empleadores, según un estudio de LHH-DBM Perú ${ }^{19}$ sobre el uso de las redes sociales en el ámbito laboral, determinó que un 52\% ejecutivos ha contratado por lo menos una vez a alguien que contactó a través de las redes sociales ${ }^{20}$ Esto refleja que los futuros profesionales deben cuidar su presencia en las redes sociales, al ser esta una plataforma importante al momento de postular a un puesto de trabajo. Adicionalmente, los jóvenes deben implementar en su rutina de búsqueda de prácticas pre profesionales a las redes sociales, por ejemplo, creando un perfil en LinkedIn y actualizarlo constantemente.

Nuestra estrategia de contacto a posibles candidatos es captarlos mediante redes sociales y páginas de interés.

Debido a los avances tecnológicos, estos se muestran como una gran oportunidad al negocio, siendo las redes sociales un aliado para poder llegar a nuestro público objetivo

\subsubsection{Análisis ecológico.}

El presente plan de negocios evalúa el impacto ecológico que tiene el negocio evitado que dañe al medio ambiente. La implementación del presente plan de negocios

\footnotetext{
${ }^{19}$ Gestión (2015). Ejecutivos de recursos humanos afirma contratado de personal a través de las redes sociales. Recolectado por la página web: http://goo.gl/zXz5Nm

${ }^{20}$ Tomado del trabajo final del curso de Plan de Marketing "Plan de Marketing del Banco de Crédito del Perú. Caso: Tarjeta Solución Negocios" junio 2015
} 
propone que la información se maneje información digital.

El manejo de la información en digital hace que, sumado al incremento al acceso al Internet y redes sociales, pueda manejarse una estrategia para tener un uso mínimo del papel. Este beneficiaría en costos, imagen proyectada, responsabilidad social del negocio e impacto en el medio ambiente.

\subsection{Oportunidades}

Las oportunidades del reclutamiento de talento humano se basan en cuatro tendencias mundiales: demografía / escasez, sofisticación de los empleadores, opciones individuales, y revoluciones tecnológicas.

Demografía / Escasez: La demografía, con el paso del tiempo, está sufriendo cambios (el promedio de edad será mayor) y los cambios sociales (mayor nivel de riesgo) son algunas barreras naturales, ya que no se cuenta con el suficiente personal para que cubran las vacantes disponibles, debido a la fuerza de trabajo mayor, migraciones, oferta y demanda desequilibrada. En el 2020, la población menor de 25 años será menos del 25\%, aumentará la expectativa de vida por 10 años más, los cambios en la estructura familiar serán menores, entre el 2020 y el 2025 la población en edad de trabajar representa el $67 \%^{21}$.

Empleadores más sofisticados. Las demandas en las especificaciones de cada puesto serán con habilidades "multitask". Debido que se están eliminando puestos de

21 Seminario, B., Sanborn, C., \& Alva, N. (2013). Cuando despertemos en el 2062: visiones del Perú en 50 años. Lima, Perú: Universidad del Pacifico.. 
trabajo rutinarios, la mayoría requiere que sean bilingües, certificados y con especialidad, con habilidades de interacción, y con ética y valores. A nivel internacional, el $31 \%$ de los empleadores se encuentran enfrentando dificultades para encontrar el talento humano

Siempre se busca al más calificado, se desea que tengan habilidades sociales, la jubilación de los baby boomers y el número limitado a trabajadores por resultados. La industria de bajo crecimiento: Falta de trabajadores calificados y no se puede cubrir vacantes debido a un esquema individualizado.

Talento individual. Identifica lo que sabe hacer mejor. Debido a que aprende a aprender, puede establecer relaciones de ganar-ganar. Entre estas características son: Conocimiento, habilidades, valores y actitud, rasgos de personalidad.

La integración al mercado laboral es: emprender, adaptarse, integrarse y vincularse.

Revoluciones tecnológicas. Las redes sociales Facebook, Twitter, LinkedIn, ayudan a mantener actualizado el currículo del talento humano de manera blanda.

Debido que transforma a la sociedad y a las instituciones educativas mejorando la difusión del conocimiento y del talento humano. Las redes sociales tienen un impacto en la forma de trabajar, además que mejora las reglas de conducta pensadas en la reputación, políticas y prácticas que permitan aprovechar las ventajas para la cultura de las redes.

Actualmente, las instituciones educativas mejorarían nuevas carreras, especializaciones y ofertas profesionales. El ofrecimiento de certificaciones es para trabajos específicos, además que la modificación de los planes de estudio debe ser ágil, 
recurrente y sistemática, los cuales deben usar tecnologías y métodos pedagógicos

modernos.

\subsection{Matriz EFE}

Tabla 8

Evaluación de los Factores Externos.

Factores determinantes de éxito

Peso Calificación Peso Ponderado

\section{Oportunidades}

1 Incentivo de la orientación vocacional en estudiantes de secundaria

$\begin{array}{lll}0.10 & 3.00 \quad 0.30\end{array}$

2 El Estado se encuentra enfocado en la inclusión en muchos aspectos, incluso en la laboral

$\begin{array}{lll}0.07 & 2.00 \quad 0.14\end{array}$

3 Expansión de universidades duplicando la capacidad instalada desde hace 13 años

$\begin{array}{lll}0.11 & 4.00 \quad 0.44\end{array}$

4 Expansión de la inversión del estado creando nuevos puestos especializados con mayor valor laboral

$\begin{array}{lll}0.11 & 3.00 \quad 0.33\end{array}$

5 Escasez del talento humano

$0.10 \quad 2.00$

6 Incremento de la tecnología a través de las redes sociales

$\begin{array}{lll}0.03 & 1.00 \quad 0.03\end{array}$

7 Mejora en el acceso a Internet

$0.08 \quad 1.00$

0.08

8 Alianza estratégica con universidades

0.03

2.00

0.06

\section{Amenazas}

1 Cambios en las costumbres de los jóvenes profesionales

$\begin{array}{lll}0.05 & 2.00 \quad 0.10\end{array}$

2 Regulación laboral se modifica incrementando la informalidad

$\begin{array}{lll}0.10 & 3.00 \quad 0.30\end{array}$

3 Informalidad en el reclutamiento de recursos humanos

$\begin{array}{lll}0.10 & 3.00 & 0.30\end{array}$

4 Reclutamiento de recursos humanos a nivel internacional

$\begin{array}{lll}0.07 & 2.00 \quad 0.14\end{array}$

5 Alianzas estratégicas entre la competencia

Nota: Elaboración propia. 
El análisis se ha realizado en base a la información del sector, debido a que la presente investigación es un plan de negocio de una empresa nueva.

El valor del promedio ponderado es 2.47. Esto nos indica que las estrategias del sector no están aprovechando las oportunidades existentes y reduciendo las amenazas.

El factor más importante que afecta a esta industria es la expansión de universidades duplicando la capacidad instalada desde hace 13 años como lo señala el peso de 0.44 .

La Matriz de Evaluación de los Factores Externos, el peso ponderado total de las oportunidades es de 1.58 y de las amenazas es 0.89 , lo cual puede ser interpretado como escenario favorable para el sector.

Se asignó un peso relativo a cada factor, de 0.0 (no es importante) a 1.0 (muy importante). La suma de todos los pesos asignados a los factores debe sumar 1.0

La calificación de 1 a 4 a cada uno de los factores determinantes para la implementación de las estrategias presentes en el plan de negocios están respondiendo con eficacia al factor, donde $4=$ una respuesta superior, $3=$ una respuesta superior a la media, 2 = una respuesta media y $1=$ una respuesta mala. 


\section{Capítulo III. Estudio de Mercado}

Este capítulo está dedicado al estudio de mercado del Plan de Negocio, se describirá el servicio brindado, y se detallará el proceso de investigación cuantitativa y cualitativa. Además de realizar el análisis de los resultados obtenidos para poder determinar el mercado objetivo del servicio.

\subsection{Descripción del servicio}

El servicio se brinda a través de un equipo de profesionales capacitados en el sector del talento humano, que se encargan de comprender requerimientos y necesidades de vacantes para los practicantes en empresas.

El intangible de la empresa se encuentra en la base de datos actualizada a través de perfiles de candidatos para procesos de reclutamiento y selección.

A continuación, se muestran los procesos del primer servicio ofrecido (ver Tabla 9):

Tabla 9

Servicio ofrecido a los practicantes.

Recepción de CV (Diferentes canales: web, referencia, ferias universitarias)

Análisis $\quad$ Validación de datos

Primer contacto $\quad$ Evaluación psicotécnica

Conclusiones Resultados del análisis y de la evaluación

Segundo contacto Se le confirman las prácticas con los que cumplen el perfil, de tener un resultado con competencias a potenciar se le ofrecen los contactos con el fin de pertenecer a la cartera en el futuro

Nota: Elaboración propia. 
En esta tabla muestra que el servicio que se brinda a los practicantes es la recepción de CV. Este puede ser enviado vía diferentes canales: Web, correo electrónico, referencias de terceros, ferias universitarias, de manera presencial.

Luego de obtener el CV de algún candidato, el primer paso es realizar un análisis, para esto se validarán datos: de estudios, dirección, edad, experiencia previa.

Luego del primer filtro, se convoca al alumno a realizar una evaluación psicotécnica, donde se evaluará su capacidad de adaptación al cambio, madurez, motivación, capacidad de iniciativa, tolerancia a la presión, estabilidad emocional, etc. Además de evaluar capacidades y aptitudes como memoria, capacidades verbales, numéricas, administrativas entre otras.

Después de estas evaluaciones se procesan los resultados detallados.

Por último, se realiza el contacto con el alumno, donde se le indica si tiene el perfil adecuado para algunas prácticas o, por el contrario, necesita mejorar algunas competencias.

Luego se brinda servicios a las empresas (ver Tabla 10):

Tabla 10

Servicio ofrecido a las empresas.

Primera reunión con la Definición de perfiles y vacantes solicitadas para los practicantes empresa

Tiempo para cubrir las vacantes

Firma del contrato formal con la consultora

Segunda reunión con la Presentación de CV propuestos empresa

Presentación de candidatos mediante un assesment

Tercera reunión con la Presentación del seleccionado (documentación y firma del contrato) empresa

Seguimiento de desempeño del practicante

Nota: Elaboración propia. 
En el caso de las empresas, se plantea realizar tres reuniones, para poder brindar el servicio.

La primera reunión tiene como objetivo la definición de los puestos de trabajo, conocer la cantidad de vacantes, el tiempo que disponemos para encontrar al candidato para el puesto. Además de definir los puntos del contrato, honorarios y firma de este.

En la segunda reunión, se presentan los CV elegidos previamente por la consultora, con un análisis de cada uno, resultado de las evaluaciones que se han realizado con los postulantes.

En la última reunión, se presenta a la persona seleccionada, para dar paso a su proceso de inducción y contratación por parte de la empresa.

Actualmente, según la legislación laboral ${ }^{22}$, las empresas pueden admitir a sus practicantes pre- profesionales de tres maneras:

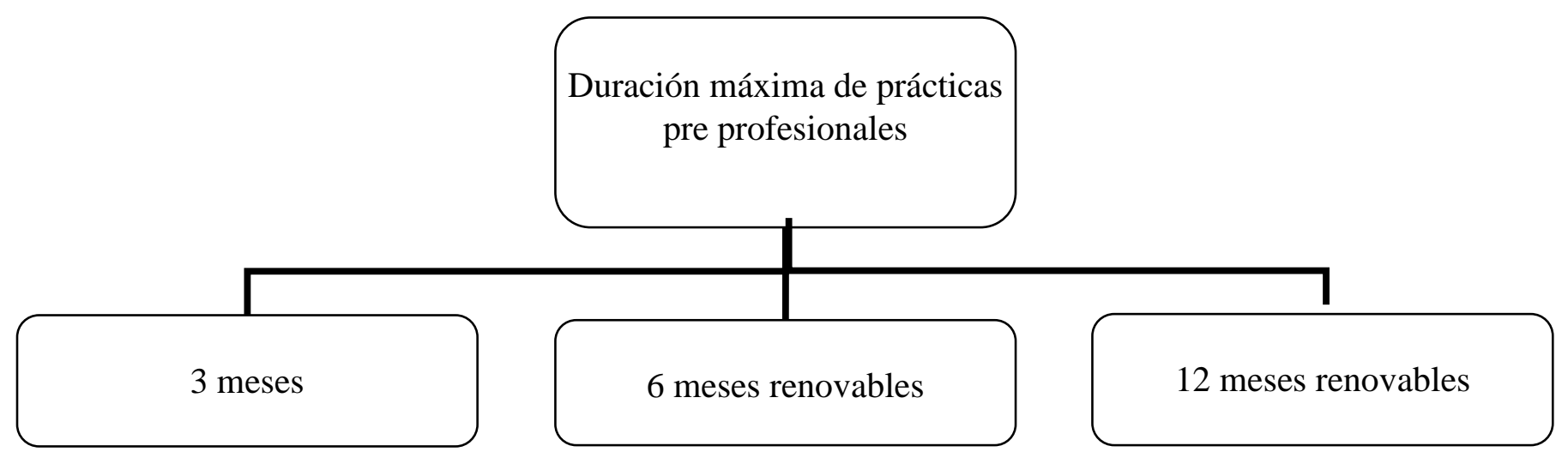

Figura 8 Tipos de prácticas pre profesionales.

Elaboración propia

${ }^{22}$ Ministerio del Trabajo (2014). Ley del trabajo profesional. 


\subsection{Selección del segmento de mercado}

Los segmentos de mercado que están comprendidos en este Plan de Negocio son dos:

- Alumnos universitarios

Alumnos de las universidades de Lima que tengan más de 1,500 matriculados, este grupo de jóvenes tiene un alto uso de internet. Según el Perfil del adulto joven 2011 de Ipsos, el $81 \%$ usa habitualmente el Internet, un $82 \%$ ve televisión todos los días.

Casi la totalidad del NSE A tiene una cuenta de correo electrónico, mientras en el B un $85 \%$ y en el C un 69\%. En el perfil realizado en el 2015, se determina que los jóvenes se conectan en promedio 5 días a la semana y lo hacen desde su computadora o smartphone. Además, el internet es el canal publicitario que más atención les presta.

Consideraremos alumnos universitarios de las universidades de Lima, que tengan más de 1,500 matriculados, esta información es tomada de la SUNEDU.

Las universidades consideradas son las siguientes:

1. Pontificia Universidad Católica del Perú

2. Universidad Alas Peruanas

3. Universidad Antonio Ruiz de Montoya 
4. Universidad Científica del Perú

5. Universidad de Lima

6. Universidad del Pacifico

7. Universidad Esan

8. Universidad Inca Garcilaso de la Vega

9. Universidad Nacional de Ingeniería

10. Universidad Nacional de Piura

11. Universidad de San Martin de Porres.

12. Universidad Nacional del Callao

13. Universidad Nacional Federico Villarreal

14. Universidad Nacional Mayor de San Marcos

15. Universidad Peruana de Ciencias Aplicadas

16. Universidad Privada Cesar Vallejo

17. Universidad Privada del Norte

18. Universidad Privada San Ignacio de Loyola

19. Universidad Privada San Juan Bautista

20. Universidad Ricardo Palma 
21. Universidad Tecnológica del Perú

- Empresas Medianas y Grandes:

Las empresas consideradas dentro de medianas empresas generan el 69.5\% de empleo directo en el año 2013.

Según el INEI, en el documento "Características Económicas y Financieras de las Empresas Comerciales en el Perú” ${ }^{23}$, señala que, de total de empleo generado por las empresas comerciales, el 49,0\% fueron ocupados por las empresas dedicadas al comercio al por mayor. Por ámbito geográfico, el 75,0\% del empleo se concentra en el departamento de Lima y la Provincia Constitucional del Callao, el restante 25,0\%, se encuentran en los demás departamentos; siendo los más importantes Lambayeque (7,7\%), Arequipa (3,6\%), La Libertad (3,0\%), y Piura con el 2,0\%. 11. El 66,9\% del personal ocupado por las empresas comerciales son cubiertos por hombres y el 33,1\% por mujeres. Esta distribución es similar por segmento empresarial. Cuando se mide por actividad económica, el mayor número de empleo ocupado por mujeres se encuentra en el comercio por menor con el 41,9\%

${ }^{23}$ INEI “Características Económicas y Financieras de las Empresas Comerciales en el Perú" (2015) 


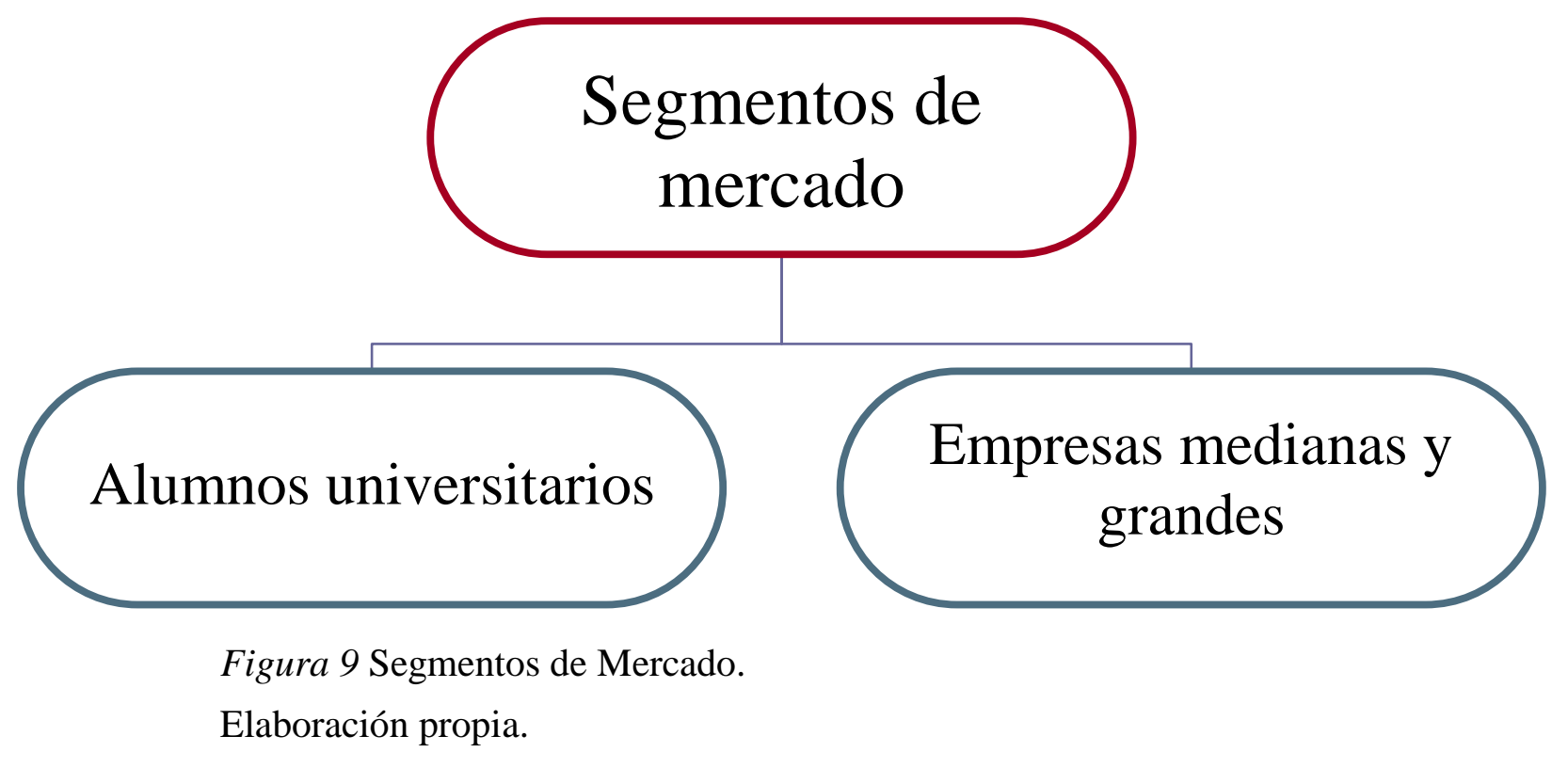

\subsection{Investigación Cualitativa}

Los objetivos de la investigación cualitativa, para el caso de los alumnos universitarios son los siguientes:

- Conocer la opinión de los alumnos de últimos ciclos con las prácticas pre profesionales

- Conocer cuáles serían las características de la práctica pre profesional ideal para los alumnos.

- Conocer cuál fue su experiencia con las prácticas pre profesionales.

- Conocer los hábitos de búsqueda de los alumnos para encontrar prácticas pre profesionales

- Determinar el conocimiento que tienen los alumnos en las consultoras de recursos humanos. 
- Establecer su interés en trabajar con una consultora de recursos humanos en su proceso de búsqueda de prácticas pre profesionales.

- Conocer cómo sería su consultora ideal.

Los objetivos de la investigación cualitativa, para el caso de las empresas medianas y grandes son los siguientes:

○ Conocer el interés de las empresas en contratar practicantes

- Determinar si las empresas cuentan con un equipo encargado de la contratación de practicantes

- Establecer si las empresas tienen una política de contratación de practicantes.

- Conocer si las empresas han trabajado con consultoras de recursos humanos

- Conocer su experiencia trabajando con consultoras de recursos humanos para la contratación de trainees.

- Establecer su interés de trabajar con consultoras de recursos humanos para la contratación de trainees,

- Determinar el precio estimado que las empresas podrían pagar a una consultora de recursos humanos.

○ Establecer la localización ideal de la consultora de recursos humanos.

En el anexo 1, podremos ubicar la guía del Focus Group y en el anexo 4 la guía de entrevista. 


\subsubsection{Proceso de muestreo.}

En el proceso de muestreo de la investigación cualitativa, utilizando el método de las sesiones grupales, se realizaron a los estudiantes Focus Group y entrevistas a los representantes del área de recursos humanos.

Se realizaron cuatro Focus Group a los alumnos de universidades limeñas. Cada focus se caracterizó por tener el siguiente tipo de alumnos:

- Focus uno: Alumnos de $5^{\circ}$ a $7^{\circ}$ ciclo que no han realizado prácticas, de los NSE A y B, que pertenecían a las siguientes universidades:

- PUCP

- Universidad de Lima

- UPC

- Universidad del Pacífico

- Universidad Cayetano Heredia

- Focus dos: Alumnos de $5^{\circ}$ a $7^{\circ}$ ciclo que ya han realizado prácticas de los NSE B y C que pertenecían a las siguientes universidades:

- PUCP

- USIL

- UNMSM 
- ESAN

- Universidad Nacional Agraria La Molina

- Focus tres: Alumnos de $8^{\circ}$ a $10^{\circ}$ ciclo que no han realizado prácticas de los NSE A y B que pertenecían a las siguientes universidades:

- PUCP

- Universidad de Lima

- UPC

- Universidad del Pacífico

- Focus cuatro: Alumnos de $8^{\circ}$ a $10^{\circ}$ ciclo que han realizado prácticas de los NSE B y C que pertenecían a las siguientes universidades:

- PUCP

- USIL

- UNMSM

- ESAN

- Universidad Ricardo Palma

La participación en cada focus fue alrededor entre ocho a diez personas. 
En el caso de las entrevistas, estas se realizaron 24 entrevistas a encargados del

área de Recursos Humanos, o departamentos a fines, de grandes empresas.

Tabla 11

Entrevistas a contactos en el área de RRHH

\begin{tabular}{|c|c|c|}
\hline $\begin{array}{c}\text { NUMERO DE } \\
\text { TRABAJADORES }\end{array}$ & RUBRO & PUESTO \\
\hline Mayor de 1000 trabajadores. & Empresa Asesora Empresarial & Analista de Selección \\
\hline Menor de 1000 trabajadores & Empresa Consultora de Recursos Humanos. & Asistente de Pagos \\
\hline Mayor de 1000 trabajadores. & Empresa de Servicios Bancarios & Analista de Selección \\
\hline Mayor de 1000 trabajadores. & Empresa de Seguros & Asistente de Planillas \\
\hline Mayor de 1000 trabajadores. & Empresa Minera & Jefe de Cuentas \\
\hline Menor de 1000 trabajadores & Empresa Consultora de Recursos Humanos. & Analista de RRHH \\
\hline Menor de 1000 trabajadores & Empresa de Fabricación Cerámica & Analista de Contratos \\
\hline Mayor de 1000 trabajadores. & Empresa Administradora de Fondo de Pensiones & Asistente de Planillas \\
\hline Mayor de 1000 trabajadores. & Empresa Cementera. & Jefe de Cuentas \\
\hline Menor de 1000 trabajadores & Empresa Retail & Gestor de Talentos \\
\hline Menor de 1000 trabajadores & Empresa Automotriz & Auxiliar de Procesos de Selección \\
\hline Menor de 1000 trabajadores & Empresa de Servicios Financieros & Asistente de RRHH \\
\hline Menor de 1000 trabajadores & Empresa Textil & Analista de Selección \\
\hline Mayor de 1000 trabajadores. & Empresa Pesquera & Analista de Planillas \\
\hline Mayor de 1000 trabajadores. & Empresa Constructora & Analista de Selección \\
\hline Mayor de 1000 trabajadores. & Empresa Retail. & Asistente de GDH \\
\hline Mayor de 1000 trabajadores. & Empresa de Energía & Asistente de Planillas \\
\hline Mayor de 1000 trabajadores. & Empresa de Consumo Masivo & Analista de Cuentas \\
\hline Mayor de 1000 trabajadores. & Empresa de Gas & Analista de Contratos \\
\hline Mayor de 1000 trabajadores. & Empresa de Servicios & Jefe de Compensaciones \\
\hline Mayor de 1000 trabajadores. & Empresa de Fabricación Cerámica & Analista de Selección \\
\hline Mayor de 1000 trabajadores. & Empresa Constructora & Coordinador de Capacitación \\
\hline Mayor de 1000 trabajadores. & Empresa Minera & Jefa de Planillas \\
\hline Mayor de 1000 trabajadores. & Empresa Minera & Secretaria de Gerencia \\
\hline
\end{tabular}

Nota: Elaboración propia. 


\subsubsection{Diseño de instrumento.}

- Focus Group

La guía que se estableció para el Focus Group está dividida en siete partes, la primera parte, es de introducción donde se explica el objetivo del focus y las reglas del mismo. Siempre utilizando un lenguaje casual y relajado, esto debido a que nos dirigimos a un público joven.

La segunda parte se enfoca en las prácticas pre profesionales en general, es decir que opinan los jóvenes de estas, cuál es la importancia que tienen estas para ellos, si están planificando una próxima búsqueda, cuál es su práctica ideal, dónde le gustaría que sea y qué labores le gustaría realizar. Y si ha realizado prácticas anteriormente, porqué lo realizó y cuál fue su balance el término de esta.

La tercera parte está destinada a la búsqueda de prácticas, sus hábitos de búsqueda, la frecuencia en que lo hacen, desde que ciclo han buscado o piensan hacerlo, cómo realizan la búsqueda, qué medios utilizan, por qué buscan. Además, se les solicitará que enumeren las ventajas y desventajas en cada medio de búsqueda.

La cuarta parte se refiere a sus experiencias en las consultoras y prácticas, si alguna vez han utilizado una consultora para conseguir prácticas y cómo fue su experiencia con esta. Y si no ha tenido experiencia alguna, se determinará el nivel de conocimiento de las consultoras en cada 
joven. Además de determinar los beneficios que ellos perciben en usar una consultora.

La prueba de concepto se realizará en la quinta parte, donde se les explicará sobre nuestra idea de negocio y se buscará determinar el nivel de necesidad que ellos puedan tener en este servicio.

La sexta parte consiste en la búsqueda de la consultora ideal, qué beneficios buscan, que monto pagarían, el qué lugar les gustaría que estuviéramos, qué medios serían los ideales para publicitar, y en qué tono.

Por último, la séptima parte consiste en la intención, ya sea de recomendación del servicio y uso del servicio.

- Entrevista

En el caso de la entrevista, el formulario cuenta con ocho preguntas, relacionadas a la experiencia previa que tiene el entrevistado para la contratación de practicantes, el proceso que realizan, si lo han realizado con alguna consultora, además de la percepción que tienen de las consultoras de Recursos Humanos.

\subsection{Investigación Cuantitativa}

Los objetivos de la investigación cualitativa, para el caso de los alumnos universitarios son los siguientes: 
- Conocer el nivel de importancia de las prácticas pre profesionales en los alumnos.

- Establecer los motivos que conllevan a los alumnos a realizar sus prácticas pre profesionales.

- Establecer la frecuencia y medio de búsqueda de prácticas pre profesionales.

- Conocer si los alumnos han tenido experiencias previas con consultoras de Recursos Humanos y su apreciación sobre el servicio.

- Determinar las expectativas que tienen los alumnos al utilizar una consultora de recursos humanos.

- Determinar si los alumnos están dispuestos a comprar los servicios de la consultora de recursos humanos.

- Determinar las características que deben tener la consultora ideal para los alumnos.

Los objetivos de la investigación cualitativa, para el caso de las empresas medianas y grandes son los siguientes:

- Conocer si las empresas cuentan como política la contratación de practicantes y determinar la frecuencia de contratación.

- Determinar los principales métodos de reclutamiento de practicantes. 
- Establecer la necesidad que las empresas contraten los servicios de una consultora de recursos humanos.

- Determinar si las empresas están dispuestas a tomar los servicios de la consultora de recursos humanos.

- Determinar las características que deben tener la consultora ideal para las empresas.

\subsubsection{Proceso de muestreo.}

El marco de muestreo se desarrolló usando información del Instituto Nacional de Estadística e Informática (para las estadísticas de las empresas), asimismo para el tema educativo, se utilizó información de la Superintendencia Nacional de Educación Superior Universitaria (para las estadísticas de los alumnos y universidades). El proceso de muestreo se desarrolló usando la probabilidad a través del muestreo aleatorio para los alumnos y empresas.

Tabla 12

Alumnos matriculados, según tipo de universidad-. Lima, 2015

\begin{tabular}{lrr}
\hline Tipo de & Pre grado & Distribución \\
universidad & & \\
\hline Total & 638,139 & $100.00 \%$ \\
Públicas & 77,843 & $12.20 \%$ \\
Privadas & 560,296 & $87.80 \%$
\end{tabular}

Nota: Adaptado de "Información Estadística de universidades (SUNEDU), información actualizada al 4 de mayo del 2017. 
Según información de SUNEDU, por el tamaño de la población escogida en la investigación, se considera realizar la técnica de cálculo de poblaciones finitas:

$$
n=\frac{N \times Z_{a}{ }^{2} \times p \times q}{d^{2} \times(N-1)+Z_{a}{ }^{2} \times p \times q}
$$

Dónde:

N = tamaño de la población (638 139)

$\mathrm{Z}=$ nivel de confianza $(90 \%, 1.65)$

$\mathrm{P}=$ probabilidad de éxito, o proporción esperada (50\%)

$\mathrm{Q}=$ probabilidad de fracaso $(50 \%)$

D = precisión (Error máximo admisible en términos proporción) (10\%)

Se utilizó el nivel de confianza más bajo, como 90\%, se obtiene un intervalo más estrecho y preciso.

La precisión fue definida en relación a un error máximo admisible definido por el índice promedio de deserción universitaria (10\%).

A un nivel de confianza del 90\%, considerando una probabilidad de éxito de $50 \%$ (alto nivel de incertidumbre), y una precisión de 10\%, a un tamaño de la población de 638139 se calculan 68 encuestas a realizar. 
Tabla 13

Cantidad de empresas en Lima, según segmento empresarial 2014

\begin{tabular}{lcc}
\hline Tipo de Empresa & Empresa & Distribución \\
\hline Total & 824501 & $100 \%$ \\
Micro Empresa & 770644 & $93.6 \%$ \\
Pequeña Empresa & 45167 & $5.3 \%$ \\
Mediana y Gran Empresa & 7801 & $1 \%$ \\
Administración Publica & 889 & $0.1 \%$ \\
\hline
\end{tabular}

Nota: Adaptado de "Directorio Central de Empresas y Establecimientos" por Instituto Nacional de Estadistica e Informatica (INEI), $2015^{24}$.

Por el tamaño de la población escogida en la investigación, se considera tomar la técnica de determinación del cálculo de poblaciones finitas:

$$
n=\frac{N \times Z_{a}{ }^{2} \times p \times q}{d^{2} \times(N-1)+Z_{a}{ }^{2} \times p \times q}
$$

Dónde:

\footnotetext{
${ }^{24}$ INEI, Directorio central de empresas y establecimientos. (2015, Setiembre).
} 
$\mathrm{N}=$ tamaño de la población $(7801)$

$\mathrm{Z}=$ nivel de confianza $(90 \%, 1.65)$,

$\mathrm{P}=$ probabilidad de éxito, o proporción esperada (50\%)

$\mathrm{Q}=$ probabilidad de fracaso $(50 \%)$

D = precisión (Error máximo admisible en términos proporción) (10\%)

Se utilizó el nivel de confianza más bajo, como 90\%, se obtiene un intervalo más estrecho y preciso.

A un nivel de confianza del $90 \%$, considerando una probabilidad de éxito de $50 \%$ (alto nivel de incertidumbre), y una precisión de $10 \%$, a un tamaño de la población de 7 801, se calculan 67 encuestas a realizar.

\subsection{Diseño de instrumento}

Se realizaron dos tipos de encuestas, las cuales van dirigidas a los alumnos universitarios y a los responsables de las áreas de Recursos Humanos.

- Encuesta a alumnos, está comprendida por 19 preguntas.

Las primeras preguntas sirven de filtro, como el nombre la universidad, y el ciclo que está cursando.

Luego, se preguntará al alumno cuál es su nivel de importancia hacia las prácticas pre-profesionales, si ya realizó alguna, y si la respuesta es afirmativa, porque 
lo ha hecho. Esto con el fin de poder conocer los motivos que llevan a los alumnos a practicar, más allá del hecho de ganar experiencia.

Luego de estas preguntas, queremos conocer cada cuánto tiempo busca prácticas y por qué medio, esto con el fin de saber la frecuencia de uso y si llega a utilizar nuestro servicio, saber cuántas veces lo utilizaría.

Queremos, además, conocer si ya ha tenido experiencias previas con consultoras de Recursos Humanos y qué le pareció la experiencia, para así poder saber sus expectativas al usar una consultora.

Las preguntas siguientes se desprenden de la prueba de concepto, se le explicará brevemente al encuestado sobre nuestra idea de negocio y seguidamente se le consultará por la ubicación, precio, servicios a utilizar. Para finalizar con la pregunta de disposición de compra.

- Encuesta a empresas, con 15 preguntas.

Tal como la encuesta para alumnos, las primeras preguntas son de filtro, donde se solicita los datos de la empresa, cargo y área donde el encuestado labora, esto para tener la seguridad que la persona forma parte del área de Recursos Humanos o sus similares.

Es importante saber si la empresa tiene como política la contratación de practicantes, cuántos de estos hay en la empresa y cada cuánto tiempo contrata nuevos, por eso las preguntas siguientes tratan sobre este tema. 
Luego se les preguntará sobre sus métodos de reclutamiento de practicantes, cómo realizan la búsqueda y si alguna vez han necesitado los servicios de una consultora, además de pedirles que califiquen su experiencia.

A partir de la siguiente pregunta, se realiza la prueba de concepto, explicándoles en qué consiste nuestro servicio y si están dispuestos a tomarlo, además de solicitarles su opinión sobre los servicios que podrían contratar, el precio que estarían dispuestos a pagar, así como el lugar donde estaría la empresa y los medios de comunicación.

\subsubsection{Análisis y procesamiento de datos.}

En el análisis y procesamiento de datos se utilizó el programa Excel, para ello se reflejó con gráficos la información obtenida.

La técnica estadística utilizada en el procesamiento de los datos en el estudio cuantitativo y cualitativo es la estadística descriptiva.

La estadística descriptiva es la técnica matemática que obtiene, organiza, presenta y describe un conjunto de datos con el propósito de facilitar su uso generalmente con el apoyo de tablas, medidas numéricas o gráficas.

\subsection{Estudio cualitativo}

Los resultados del estudio cualitativo realizado a los alumnos universitarios, que responden a nuestros objetivos planteados, son los siguientes: 
- Conocer la opinión de los alumnos de últimos ciclos con las prácticas pre profesionales.

Los alumnos consideran que las prácticas pre-profesionales son de suma importancia para su desarrollo profesional.

Si bien en algunas universidades es necesario sustentar que hayan realizado prácticas pre profesionales para poder obtener su Bachiller, por consenso, los alumnos consideran que realizar prácticas profesionales es parte fundamental de su formación.

"Creo que es un plus poder realizar prácticas pre profesionales, ya que me da una visión más clara de mi futuro ámbito laboral y qué necesito para mejorar mis habilidades"

Jorge, $7^{\circ}$ ciclo PUCP

- Conocer cuáles serían las características de la práctica pre profesional ideal para los alumnos.

En este punto, los alumnos tuvieron opiniones divididas, ya que consideraban que una práctica profesional ideal debería tener las siguientes características:

- Continuidad laboral

- Línea de carrera 
- Sueldo acorde al mercado

- Cerca de su centro de estudios

- Capacidad de entrenarlos para la vida laboral

- Poder poner en práctica sus conocimientos.

Las características más comunes son la de continuidad laboral y de poner en práctica sus conocimientos aprendidos en su universidad.

- Conocer cuál fue su experiencia con las prácticas pre profesionales.

Entre los alumnos que ya habían realizado prácticas pre profesionales, existen dos grupos: el primero de estos es de aquellos que han realizado prácticas sobre su carrera y han adquirido nuevos conocimientos y habilidades administrativas. Sienten una mejora en su perfil, luego de que las realizaron.

El segundo grupo, que eran la minoría, señalaba que no se sintieron conformes con la experiencia, ya que no realizaban labores propias de un practicante y concluyen que por medio de la práctica pre profesional no lograron adquirir habilidades adicionales.

- Conocer los hábitos de búsqueda de los alumnos para encontrar prácticas pre profesionales.

El medio más común que utilizan los alumnos para encontrar prácticas pre profesionales es la web, ya sea redes sociales (fan pages de empresas o de 
buscadores de empleos), en las webs institucionales de las empresas en las que desean practicar o en la bolsa de trabajo de su universidad, aunque esta última opción no es muy usada.

Otra vía para poder encontrar prácticas pre profesionales son las referencias de terceros como compañeros de clase o docentes.

- Determinar el conocimiento que tienen los alumnos en las consultoras de recursos humanos.

No existe mucho conocimiento de las consultoras, ya que ellos no las ven como algo cercano a su situación actual, las relacionan con la búsqueda de un empleo estable posterior a la obtención de su grado.

- Establecer su interés en trabajar con una consultora de recursos humanos en su proceso de búsqueda de prácticas pre profesionales.

Luego de la explicación de nuestra idea de negocio, muchos de los alumnos se sintieron próximos a la idea, ya que expresaron que les parece necesario e importante conocer sus habilidades y capacidades para hacer frente a un proceso de selección. Además de tener en un solo lugar donde se concentren muchas oportunidades de prácticas profesionales sin necesidad de utilizar varios métodos de búsqueda.

Además, opinaron que sería interesante que la consultora brinde asesorías y capacitaciones a los alumnos para prepararlos a hacer frente a un proceso de 
selección, como, por ejemplo, elaboración correcta de un CV, presentación en una entrevista, manejo del estrés, habilidades blandas, etc.

○ Conocer cómo sería su consultora ideal.

Los alumnos buscan una consultora que esté disponible siempre, ya sea vía web, mail, redes sociales, teléfono e incluso WhatsApp. Es decir, utilizando sus mismos medios para así poder tener inmediatez en la comunicación.

No les ponen mucho interés en el lugar donde estaría colocada la consultora, ya que esto se ve reemplazada por los medios de comunicación digitales.

Les gustaría que concentre la mayor cantidad de ofertas de prácticas y sobre todo de empresas medianas y grandes y que dentro de los puestos que ofrezcan tengan la posibilidad de realizar línea de carrera en dicha empresa.

Otra característica es que solicitan una retroalimentación luego de que concluyan sus prácticas. Esta retroalimentación puede ser realizada por la misma empresa o por la consultora, ya que consideran importante conocer su desempeño laboral con miras a ir mejorando sus capacidades y habilidades.

Teniendo en cuenta los resultados de los Focus Group realizados con alumnos, se reformula el concepto de negocio:

“El servicio propuesto es una consultora para que alumnos universitarios de últimos ciclos puedan acceder a prácticas pre 
profesionales en empresas idóneas para sus habilidades. La consultora evalúa la orientación vocacional, habilidades internas- externas y monitorea la colocación de los universitarios, además que preparará a través de talleres como liderazgo, motivación, plan de vida, así como capacitación en correcta presentación del currículo vitae y la entrevista personal- comunicación con jefes".

En el caso del estudio realizado a las empresas, los resultados, basados en los objetivos planteados, son los siguientes:

- Conocer el interés de las empresas en contratar practicantes

De las empresas entrevistadas, en su totalidad realizan la contratación de practicantes para el apoyo de diversas actividades, desde administrativas hasta las más detalladas.

Dentro de las políticas de varias empresas están la contratación de practicantes ya que lo ven como un tema formativo.

- Determinar si las empresas cuentan con un equipo encargado de la contratación de practicantes

Generalmente el área encargada de ver la contratación de practicantes es el área de Recursos Humanos o similares, muchas veces a petición de determinadas áreas. 
En algunos casos, el proceso de búsqueda, selección y contratación se realiza en la misma empresa, pero en la mayoría de casos se hace cargo una consultora, siendo el último filtro su departamento de Recursos Humanos.

- Establecer si las empresas tienen una política de contratación de practicantes.

La mayoría de las empresas tienen programas exclusivos de practicantes o trainees, los cuales varían según la empresa, estos programas tienen diversas características, como horarios flexibles, rotación por diversas áreas, contratos de poca duración, evaluación constante.

- Conocer si las empresas han trabajado con consultoras de recursos humanos

Varios de nuestros entrevistados han trabajado con consultoras de recursos humanos, no solo para la búsqueda de practicantes, sino para todos sus procesos de selección. Ya que de esa forma les permiten manejar tarifas corporativas, ser confidenciales, además la consultora ya conoce el clima laboral de la empresa.

- Conocer su experiencia trabajando con consultoras de recursos humanos para la contratación de trainees.

Las empresas al tener un programa especial para practicantes y al tener contratos de diversa duración, hacen que los requerimientos de búsqueda sean constantes.

Las empresas siempre están abiertas a nuevas alternativas, entienden que las características de búsqueda de practicantes son muy distintas a las de un 
empleo. Por eso, para ellas es importante trabajar con consultoras que sean próximas al público que desean llegar, en este caso practicantes, que sean próximas, usen su mismo lenguaje, sean más visuales.

- Establecer su interés de trabajar con consultoras de recursos humanos para la contratación de trainees,

Una gran parte de los entrevistados consideran importante tener practicantes en su empresa y, por ende, ven al proceso de selección clave para poder captar nuevo talento, que a la larga podría quedarse en la empresa en otros cargos. Si esta selección se realiza con una consultora que esté en la misma sintonía de los alumnos y que garantice captar a los mejores talentos según la convocatoria pueden trabajar con esta por mucho tiempo.

- Determinar el precio estimado que las empresas podrían pagar a una consultora de recursos humanos.

Esto depende mucho del tamaño de empresas, ya que los montos que nos indicaron oscilaban entre los 50 a 100 soles por practicante. Las variables para definir el precio dependen del tamaño de empresa, cantidad de practicantes a contratar por año.

○ Establecer la localización ideal de la consultora de recursos humanos.

La ubicación de estas empresas no les genera incertidumbre debido a que cuentan con amplias oficinas las cuales pueden ser utilizadas para sus reuniones. O en su defecto, realizar las coordinaciones vía correo electrónico. 


\subsubsection{Estudio cuantitativo.}

A continuación, se muestran las gráficas de los resultados de la encuesta a los estudiantes, agrupados según los objetivos de la investigación:

\section{Datos demográficos}

Los alumnos encuestados son de las universidades que tengan más de 1,500 matriculados (ver Figura 10)

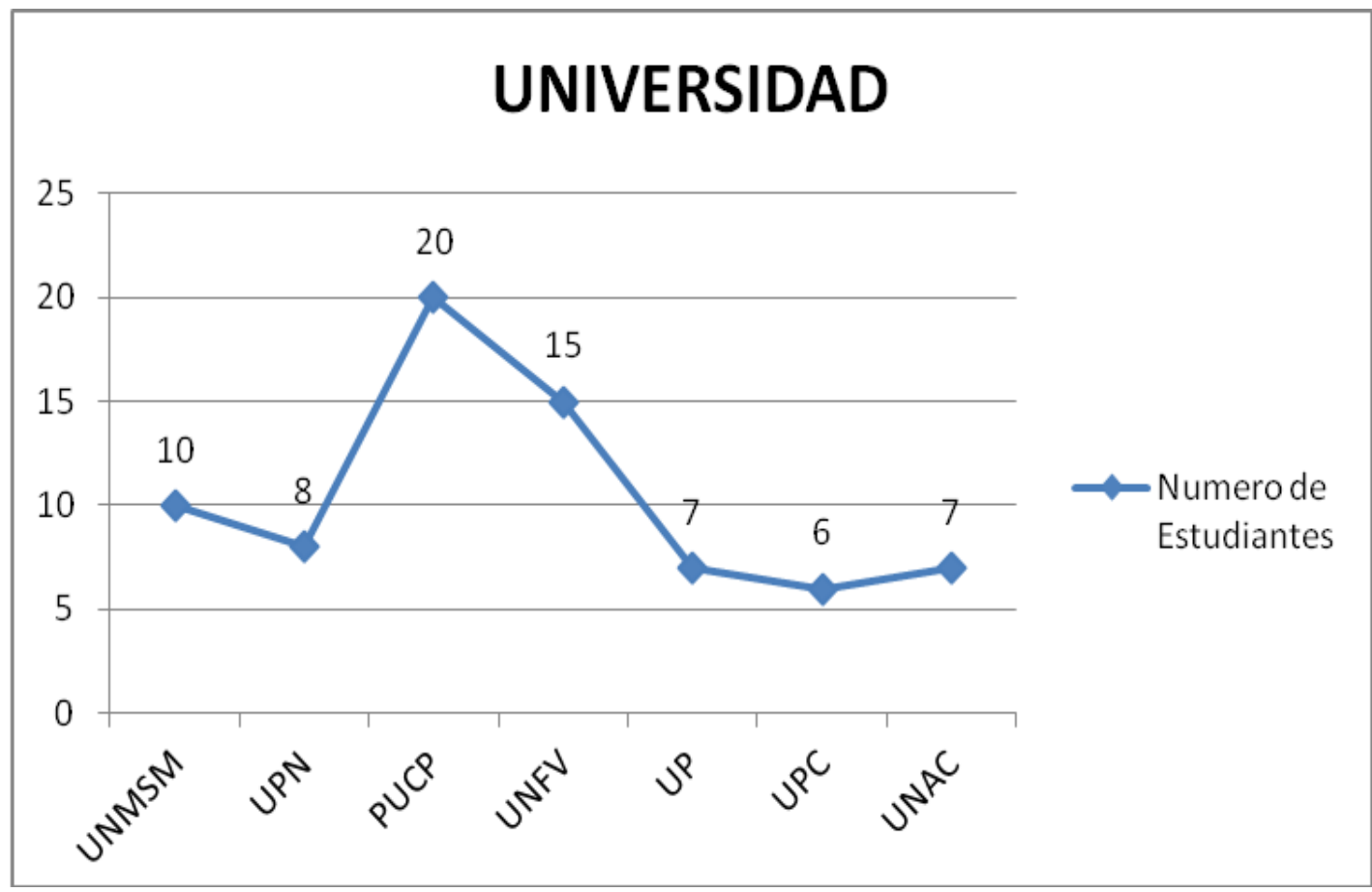


Figura 10. Cantidad de alumnos por universidad de procedencia.

Elaboración propia

En su mayoría, los entrevistados son del octavo, noveno y décimo ciclo. (Ver

Figura 11)



Figura 11. Ciclo que está cursando.

Elaboración propia

- Conocer el nivel de importancia de las prácticas pre profesionales en los alumnos.

Más del $50 \%$ de los encuestados considera importante realizar prácticas pre-profesionales. (Ver Figura 12) 


\section{¿Qué tan importante considera realizar prácticas pre-profesionales?}

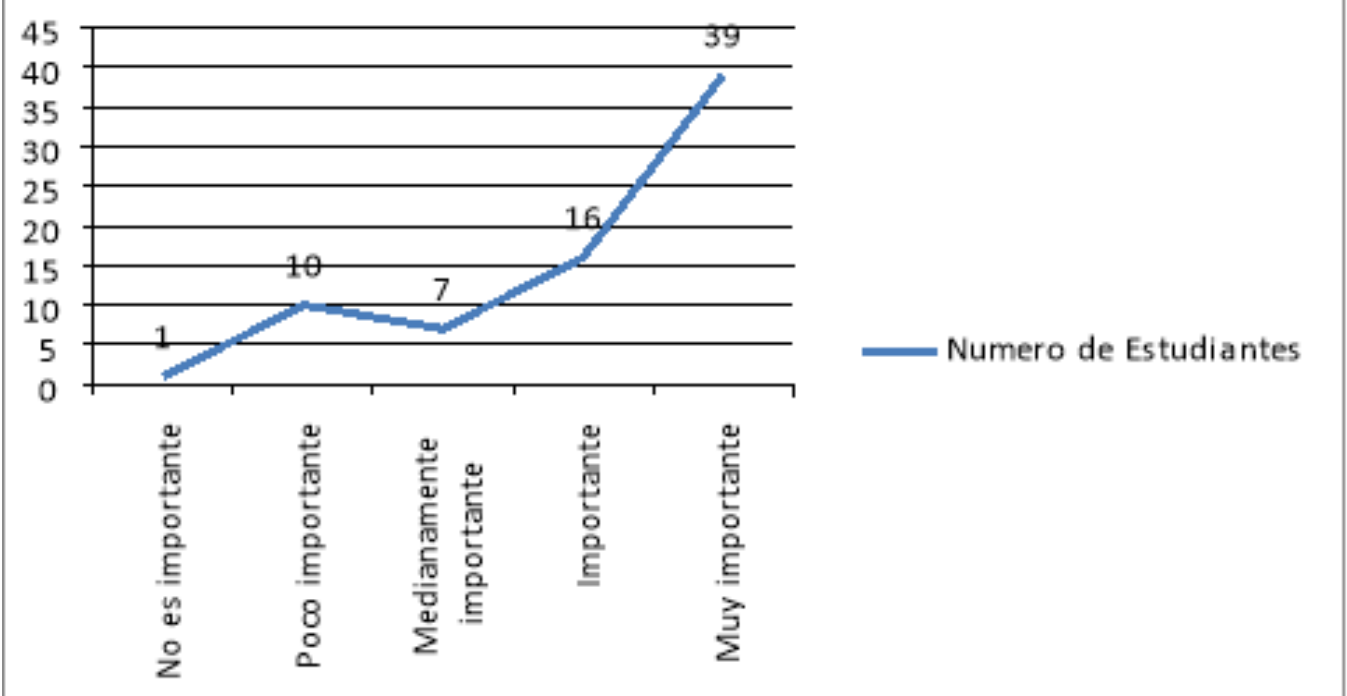

Figura 12. Importancia de realizar prácticas pre - profesionales.

Elaboración propia

- Establecer los motivos que conllevan a los alumnos a realizar sus prácticas pre profesionales

De los 60 encuestados que dijeron que habían realizado prácticas pre profesionales, más del $40 \%$ indica que conseguir más experiencia fue su principal motivación.

Los alumnos ubican tres razones importantes para poder realizas las prácticas pre profesionales, siendo la primera razón poder ganar experiencia en el plano laboral, seguido de poder tener ingresos económicos. 
En un tercer lugar ubican la exigencia de la malla curricular, ya que en algunas universidades tiene como requisito para obtener el Bachillerato, sustentar prácticas pre profesionales por un determinado tiempo. Ver Figura 13.

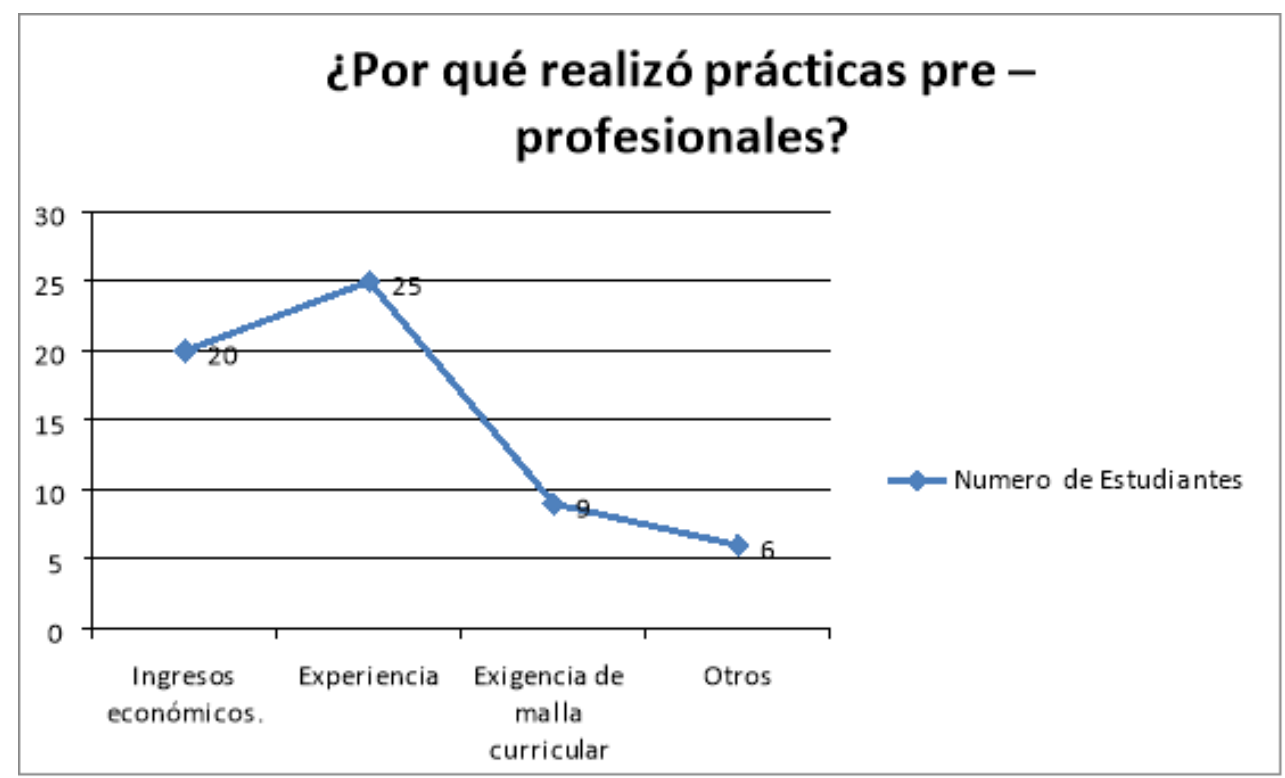

Figura 13. Motivaciones que llevan a realizar las prácticas. Elaboración propia

- Establecer la frecuencia y medios de búsqueda de prácticas pre profesionales.

La herramienta más usada para la búsqueda de oportunidades de prácticas son las páginas web de las empresas seguidas de las publicaciones realizadas en las universidades donde estudian. Ver Figura 14. 


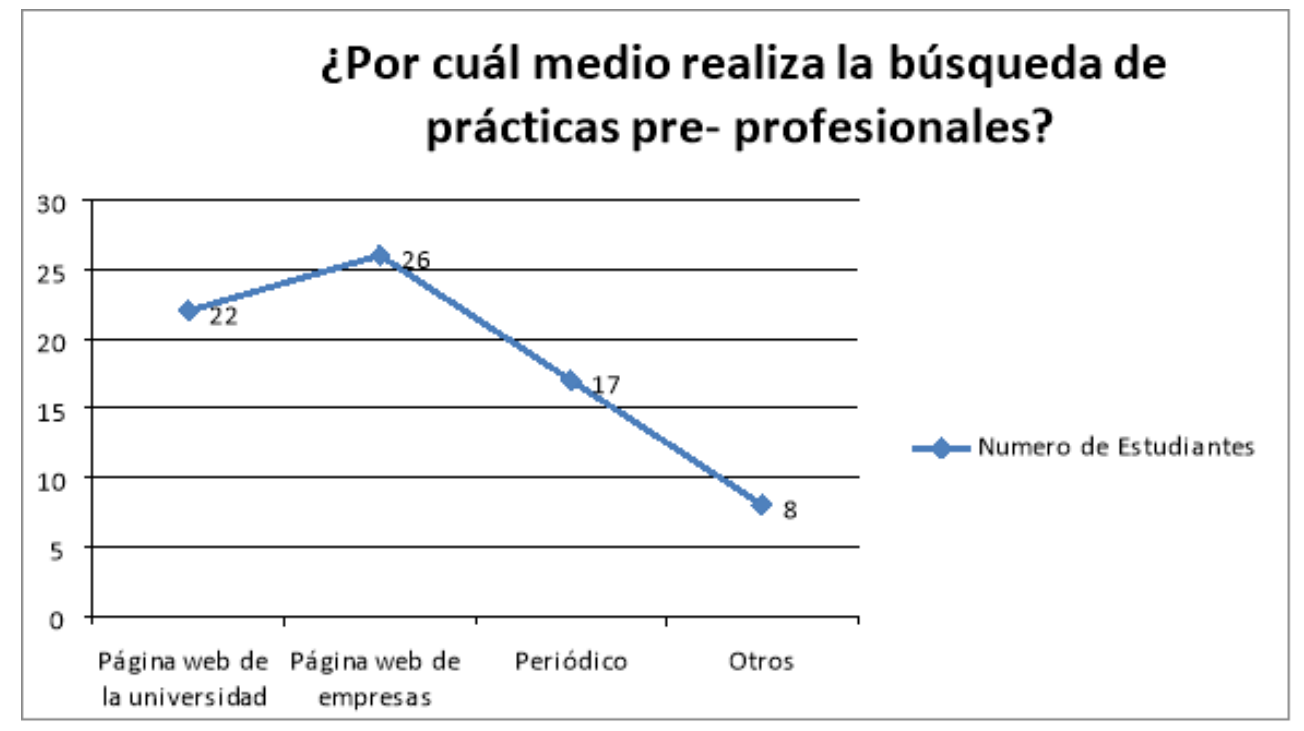

Figura 14. ¿Por cuál medio realiza la búsqueda de prácticas pre-profesionales? Elaboración propia

Las búsquedas se realizan de manera semanal de acuerdo con lo indicado por nuestros encuestados. Ver Figura 15.

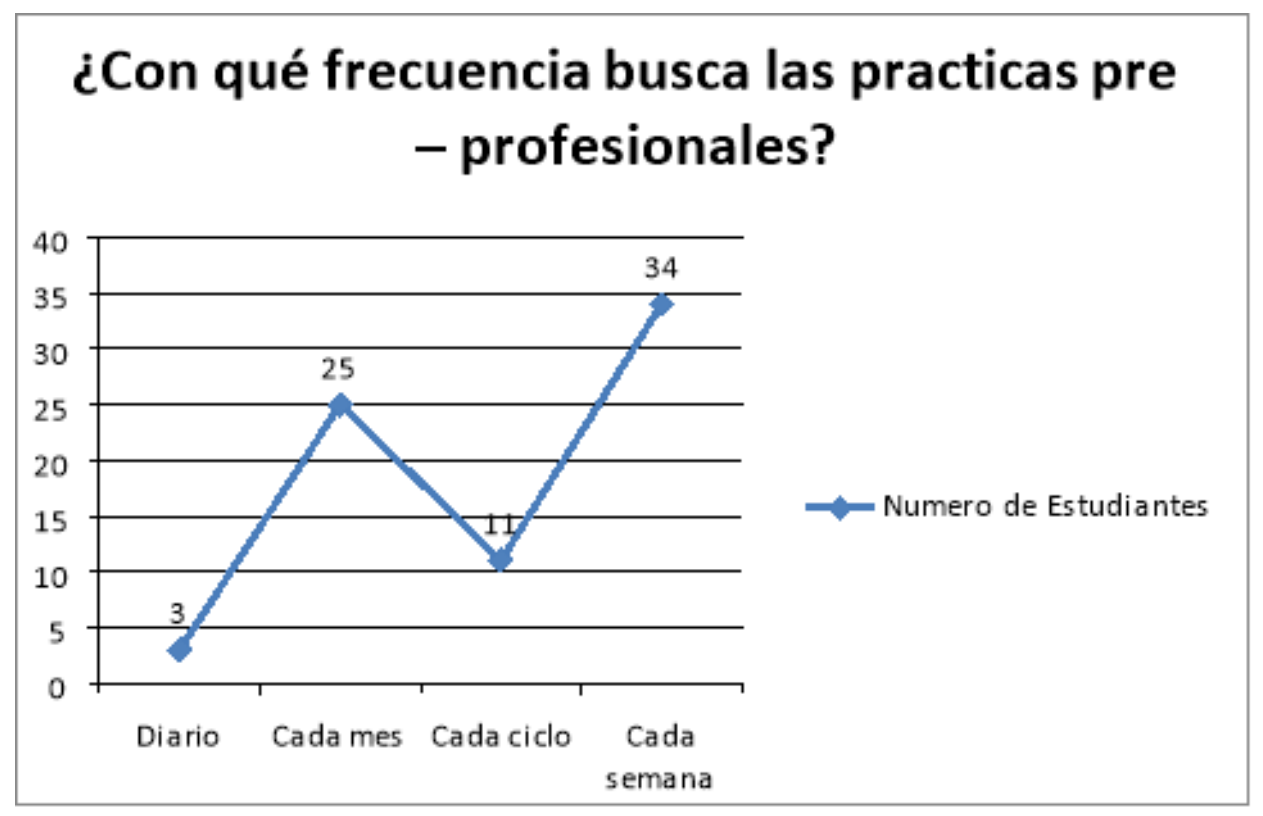

Figura 15. ¿Con qué frecuencia busca las practicas pre - profesionales?

Elaboración propia 
- Conocer si los alumnos han tenido experiencias previas con consultoras de

Recursos Humanos y su apreciación sobre el servicio

Este resultado demuestra que la mayoría de encuestados ya han pasado por al menos un proceso de selección por medio de una consultora. Ver Figura 16.

\section{¿Alguna vez ha utilizado una consultora para acceder a un proceso de selección?}

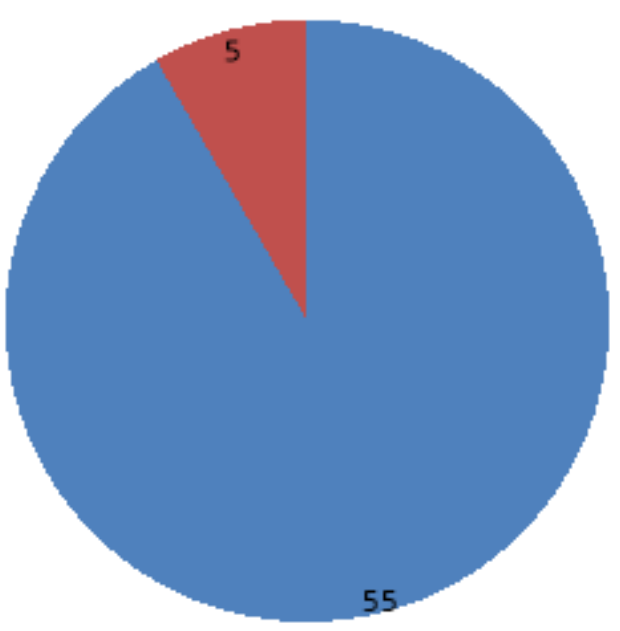

Figura 16 ¿Alguna vez ha utilizado una consultora para acceder a un proceso de selección? Elaboración propia

Sin embargo, su experiencia la califican entre regular a buena, que es un término medio. Ver Figura 17. 


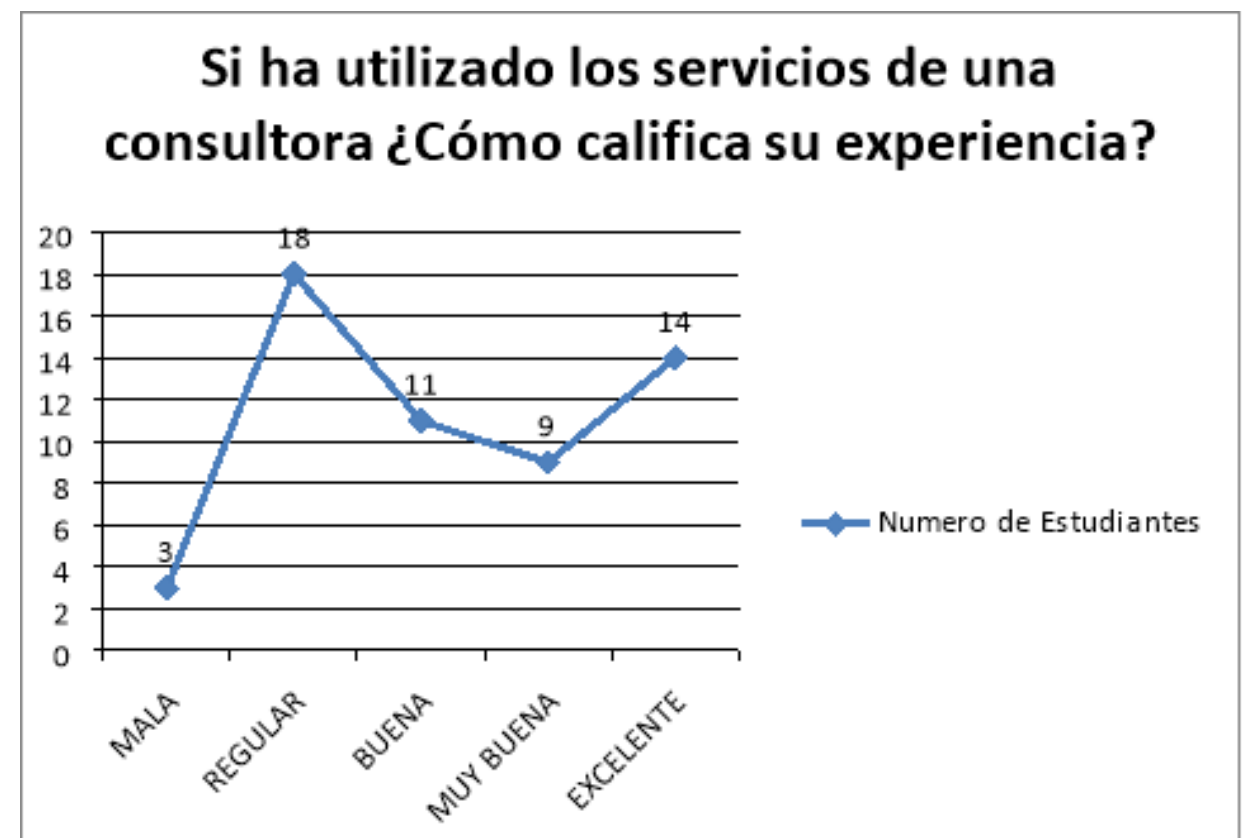

Figura 17. Si ha utilizado los servicios de una consultora ¿Cómo califica su experiencia? Elaboración propia

○ Determinar las expectativas que tienen los alumnos al utilizar una consultora de recursos humanos.

Los alumnos buscan una consultora que tenga un proceso transparente, esta ventaja va ligada con que tenga una buena comunicación con los participantes en el proceso. Ver Figura 18. 


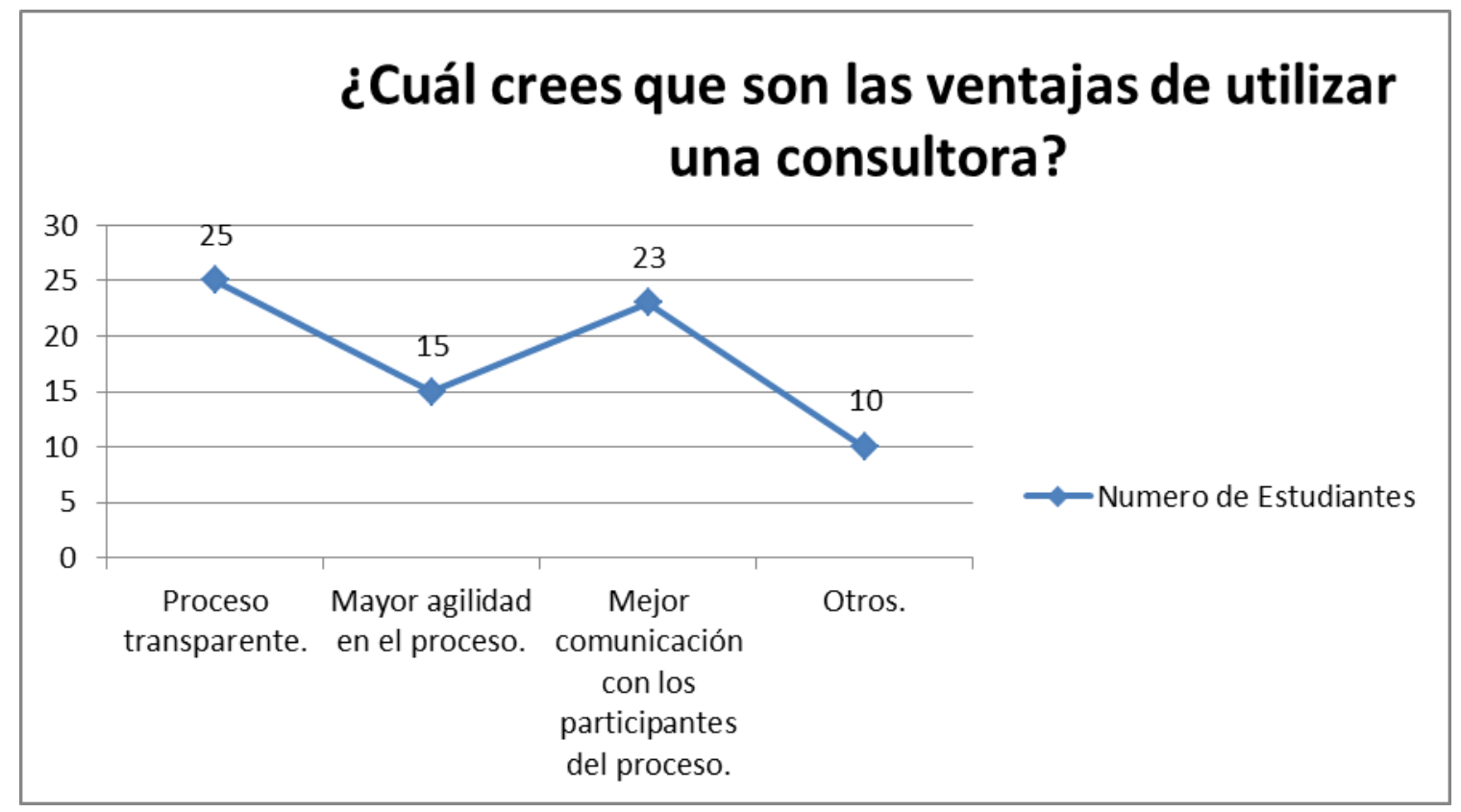

Figura 18.¿Cuál crees que son las ventajas de utilizar una consultora? Elaboración propia

- Determinar si los alumnos están dispuestos a comprar los servicios de la consultora de recursos humanos

En esta pregunta, la mitad de encuestados no ven probable utilizar una consultora de recursos humanos para poder acceder a prácticas pre profesionales, y la otra mitad lo ven entre indiferente, probable y muy probable. Es factible que aquellos jóvenes que no ven probable adquirir los servicios de una consultora, es porque no se encuentran familiarizados con los beneficios de estas. Ver Figura 19. 


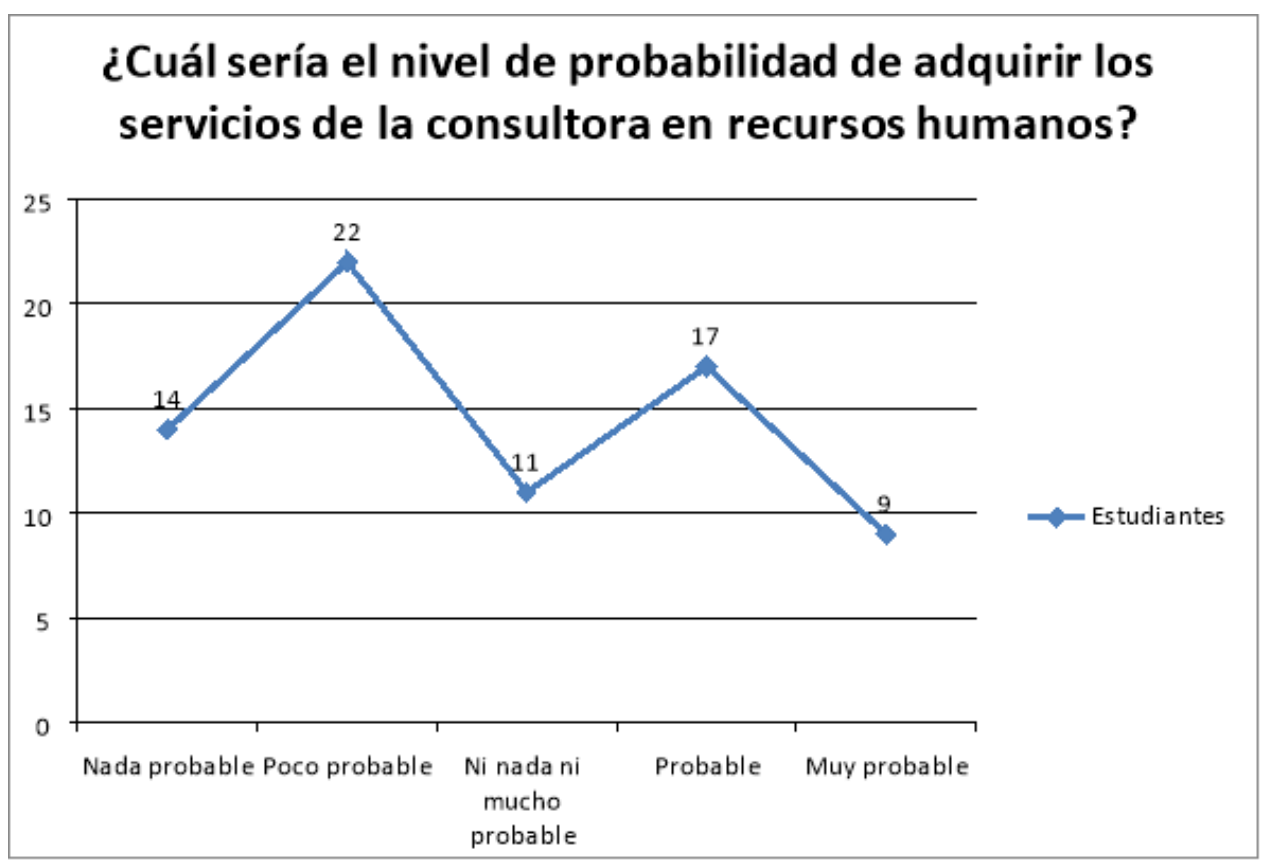

Figura 19. ¿Cuál sería el nivel de probabilidad de adquirir los servicios de la consultora en recursos humanos?

Elaboración propia

- Determinar las características que deben tener la consultora ideal para los alumnos

En el caso del precio la mayoría de alumnos pueden pagar por los servicios de la consultora menos de 50 soles. Nadie pagaría más de 200 soles. Ver Figura 20.

La mayoría de entrevistados les gustaría que la oficina de la consultora se ubique en San Isidro, sin embargo, tengamos en cuenta que ellos buscan la inmediatez, vía internet. Ver Figura 21.

Un gran porcentaje les gustaría tener información por medio de las redes sociales, como Facebook, LinkedIn. Ver Figura 22. 
A pesar de la inmediatez en la comunicación, tener información en redes sociales, los alumnos prefieren que la consultora tenga oficinas físicas, cerca de un $23 \%$ prefieren oficinas virtuales. Ver Figura 23.

Dentro de los servicios que los alumnos están dispuestos a comprar a estos les interesan las asesorías en orientación vocacional, seguido de un acceso a data Premium de convocatoria. Ver Figura 24.

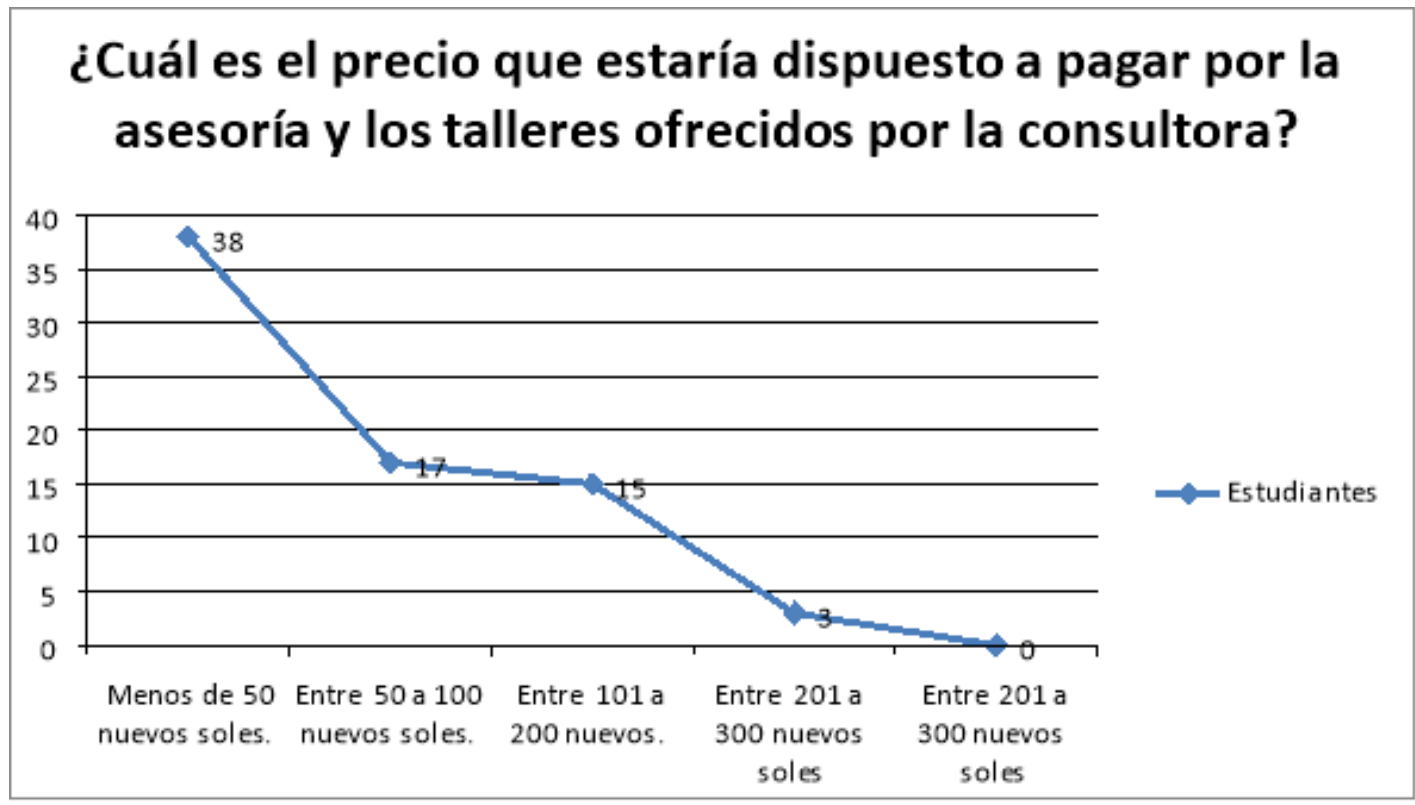

Figura 20. ¿Cuál es el precio que estaría dispuesto a pagar por la asesoría y los talleres ofrecidos por la consultora?

Elaboración propia 


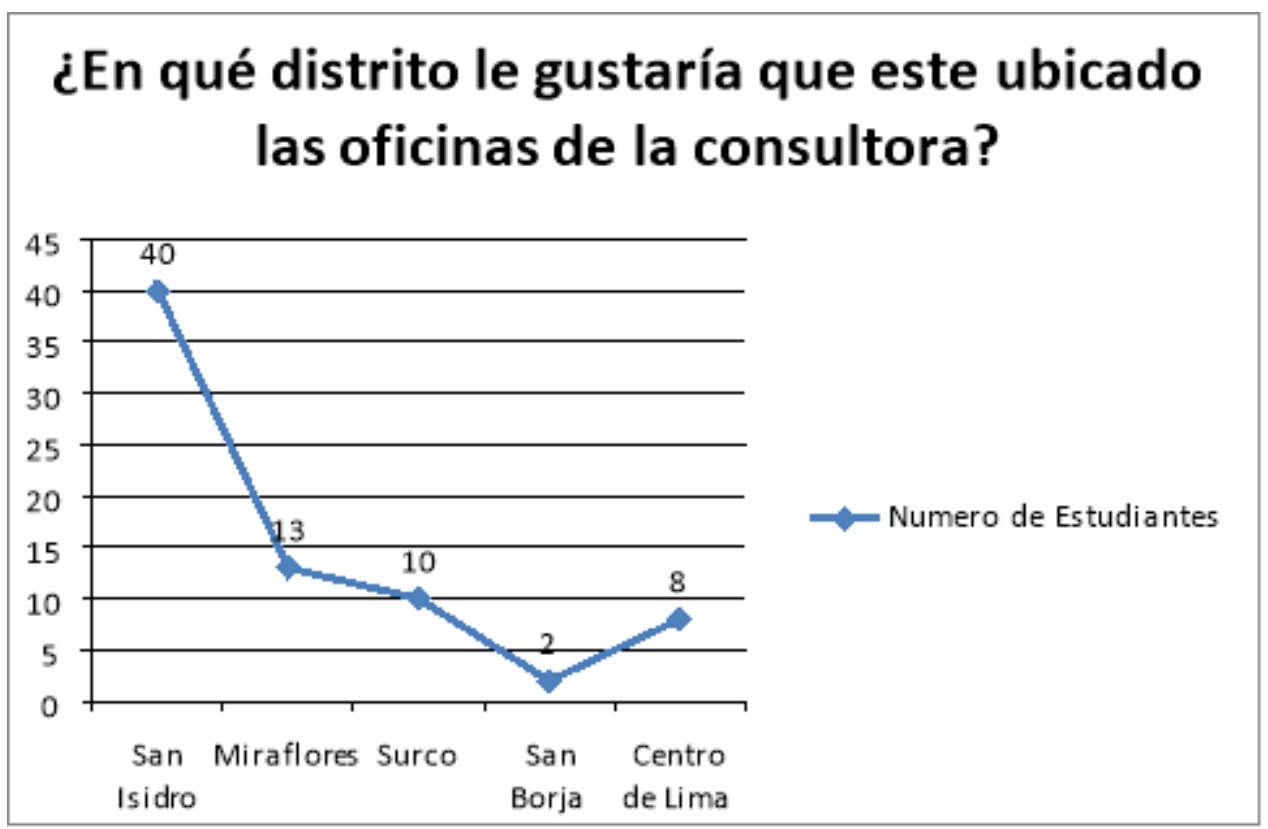

Figura 21. ¿En qué distrito le gustaría que estén ubicadas las oficinas de la consultora? Elaboración propia



Figura 22. ¿Por qué medio le gustaría tener información de la consultora? Elaboración propia 


\section{¿Qué tipo de presentación le gustaría tener de la empresa consultora?}

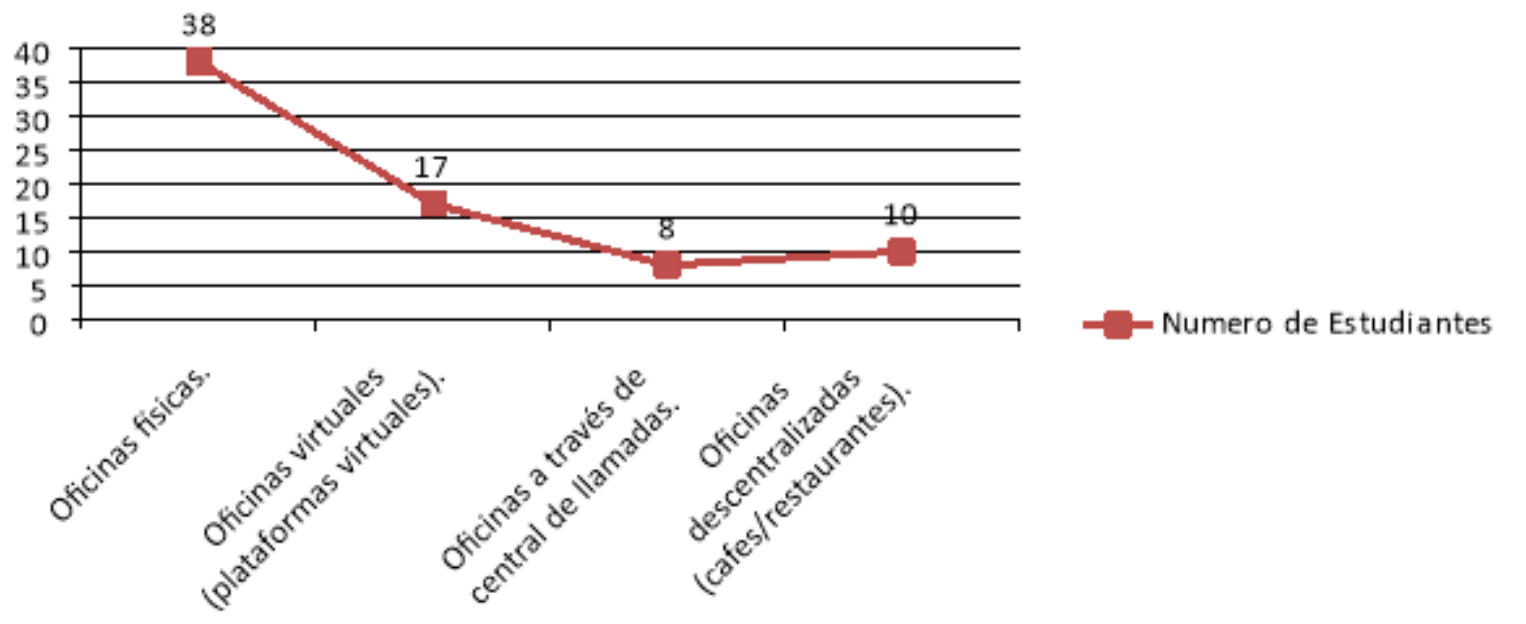

Figura 23.¿Qué tipo de presentación le gustaría tener de la empresa consultora? Elaboración propia

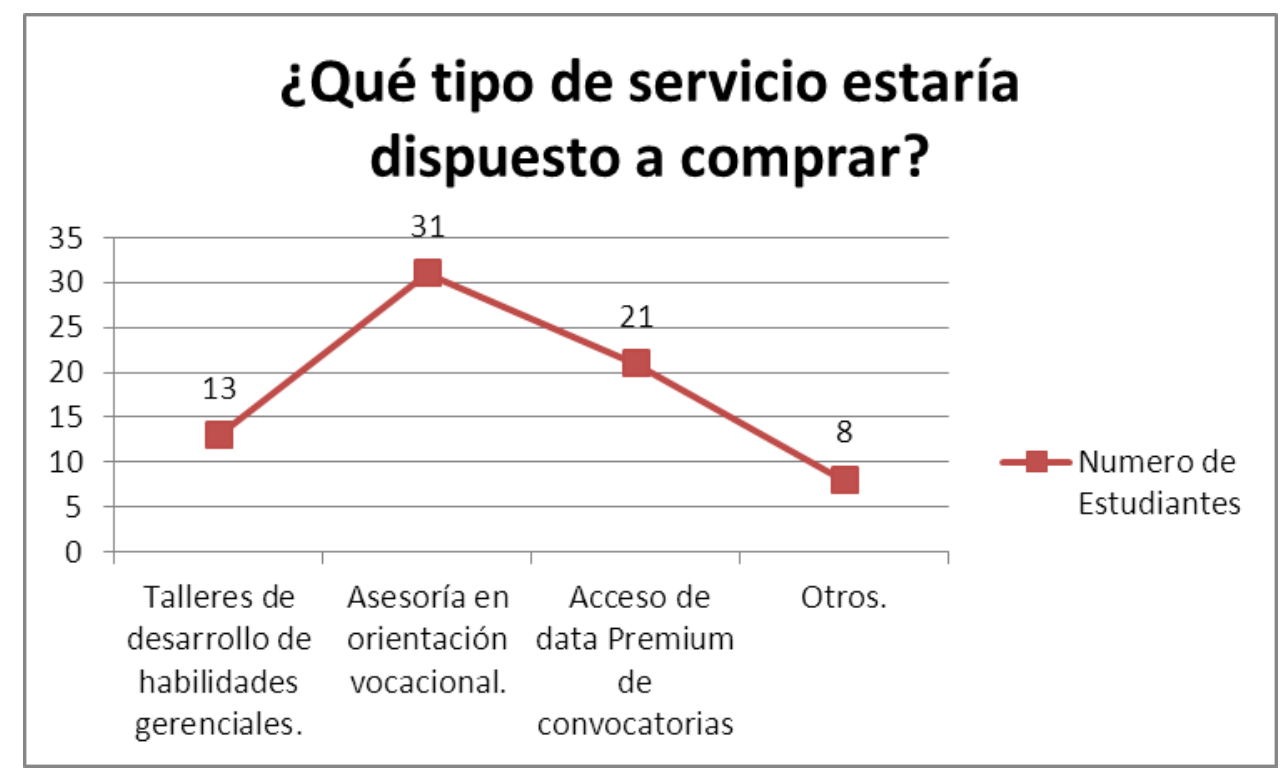

Figura 24. ¿Qué tipo de servicio estaría dispuesto a comprar? ¿Qué tipo de servicio estaría dispuesto a comprar?

Elaboración propia 
En el caso de las empresas, a continuación, se muestran los resultados obtenidos:

- Conocer si las empresas cuentan como política la contratación de practicantes y determinar la frecuencia de contratación.

Ante la pregunta de cuántos practicantes contrastan al año su empresa, más de la mitad de encuestados contratan más de 30 practicantes al año. Ver Figura 25.

Treinta y tres empresas contratan de manera anual, y solo nueve empresas cada dos meses. Ver Figura 26.

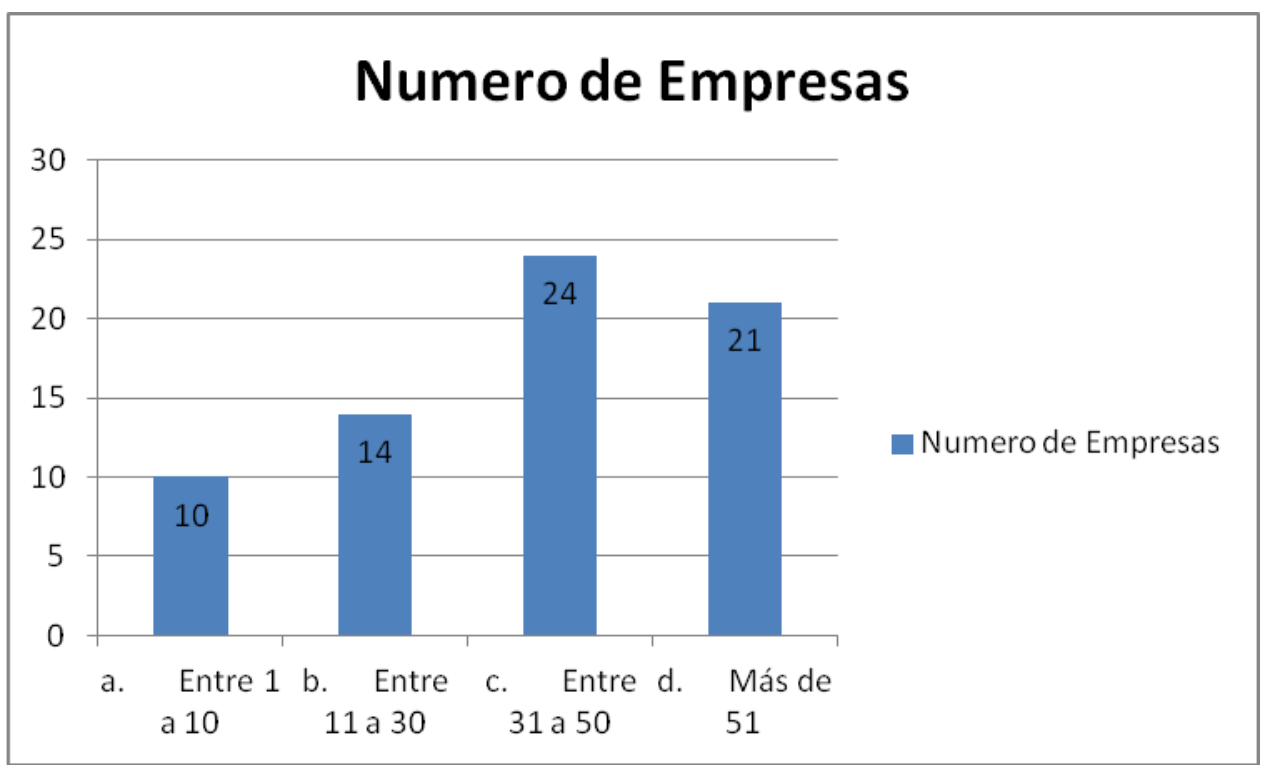

Figura $25_{i}$ Cuántos practicantes contratan al año en su empresa? Elaboración propia 


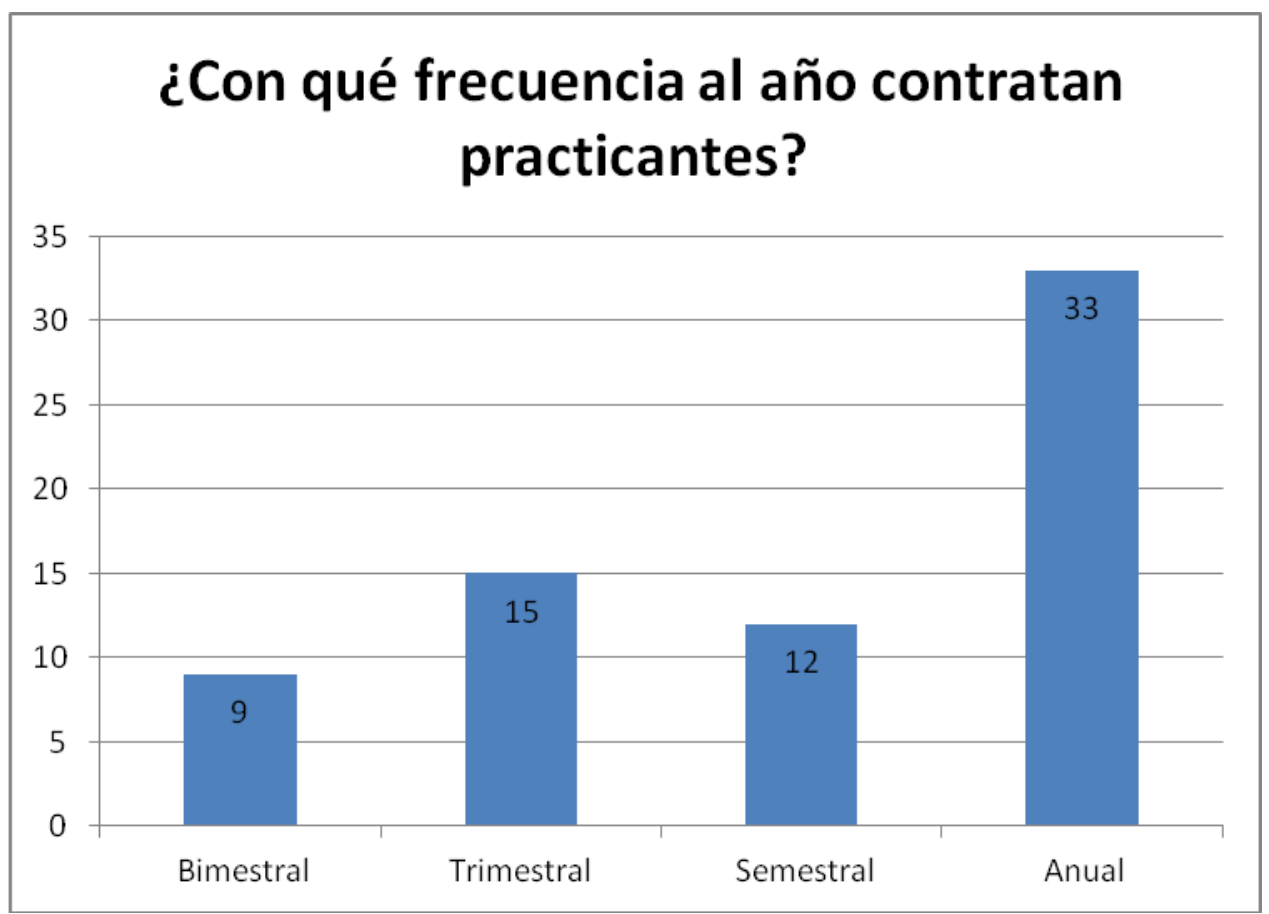

Figura 26. ¿Con qué frecuencia al año contratan practicantes? Elaboración propia

- Determinar los principales métodos de reclutamiento de practicantes.

La mayoría de empresas buscan practicantes pre-profesionales por medio de las universidades. Este resultado dista un poco de lo que opinan los alumnos, ya que el primer lugar de búsqueda para ellos son las páginas web de las empresas. Ver Figura 27. 


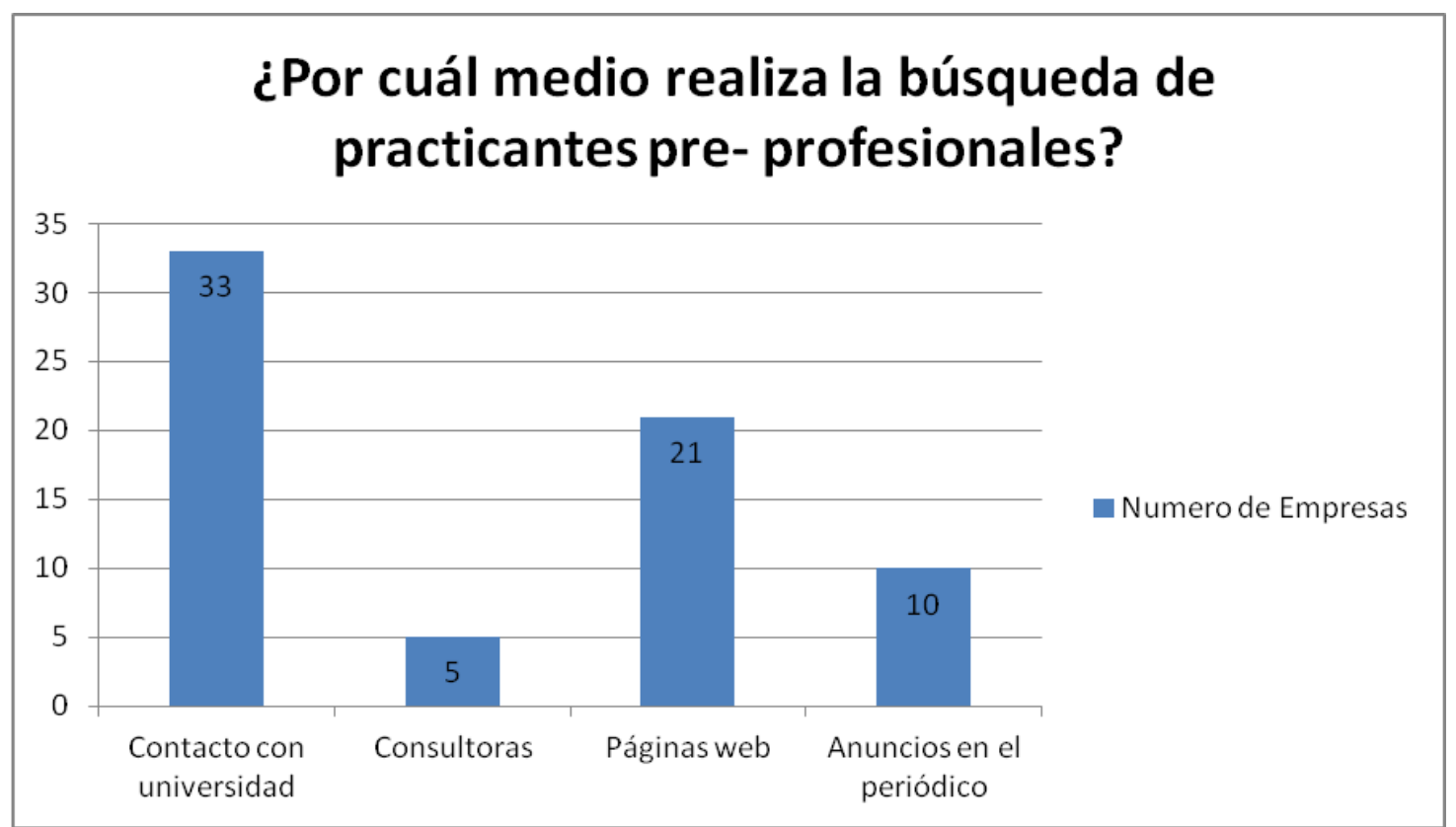

Figura 27. ¿Por cuál medio realiza la búsqueda de practicantes pre- profesionales? Elaboración propia

- Establecer la necesidad que las empresas contraten los servicios de una consultora de recursos humanos.

La gran mayoría de empresas contratan consultoras para que puedan administrar su proceso de selección, y califican su experiencia entre buena y muy buena. Ver Figura 28 y 29. 


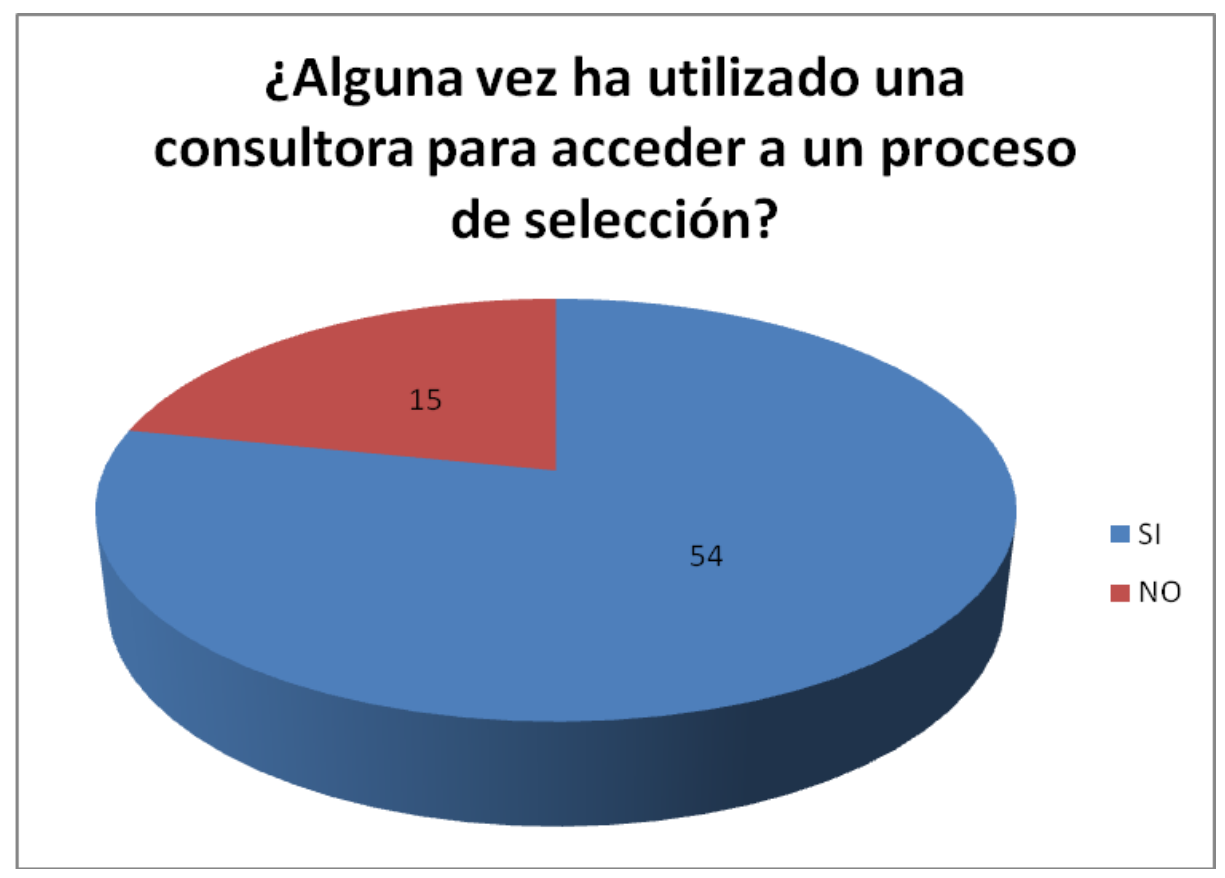

Figura 28. ¿Alguna vez ha utilizado una consultora para acceder a un proceso de selección?

Elaboración propia

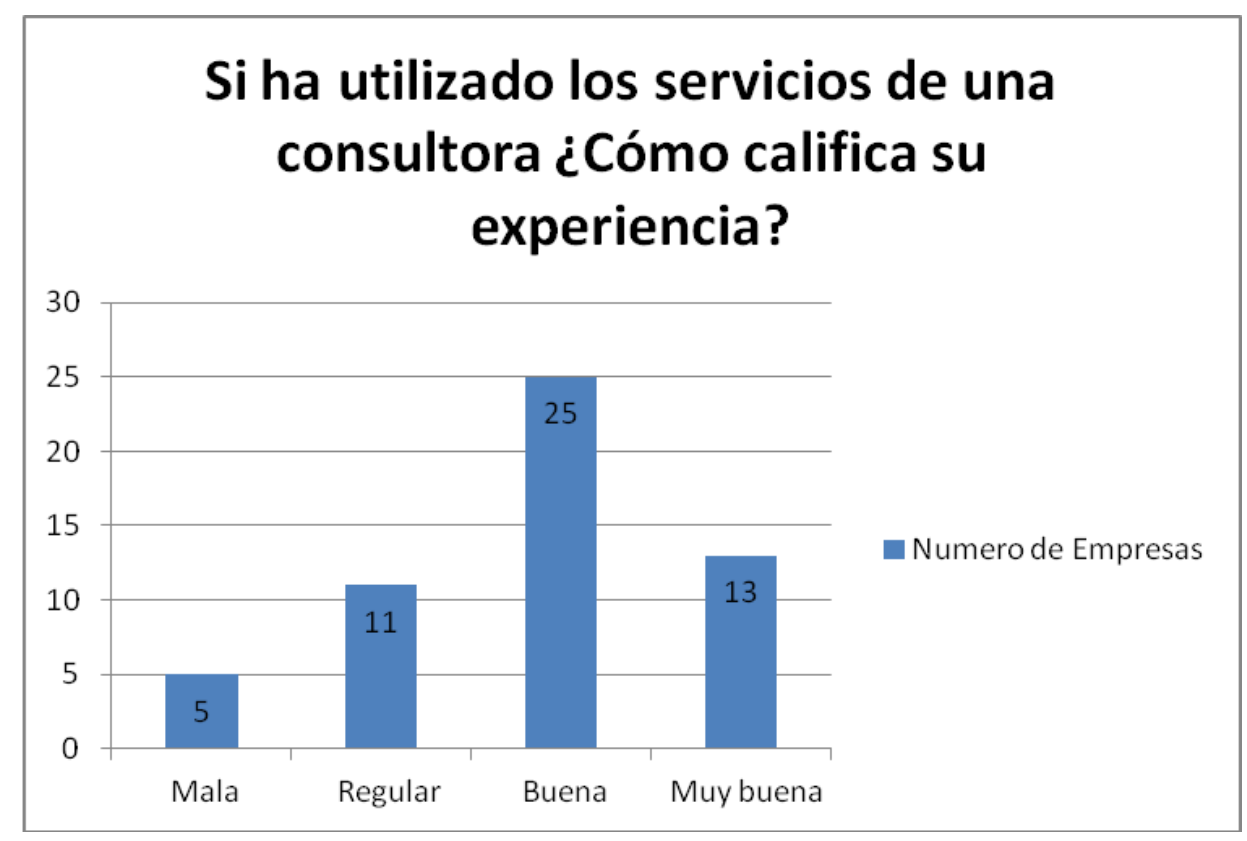

Figura 29. Si ha utilizado los servicios de una consultora ¿Cómo califica su experiencia? Elaboración propia 
- Determinar si las empresas están dispuestas a tomar los servicios de la consultora de recursos humanos.

Al tener ya experiencia previa en trabajar con consultoras, las empresas consideran probable que trabajen con consultoras para la búsqueda de talento. Ver Figura 30.

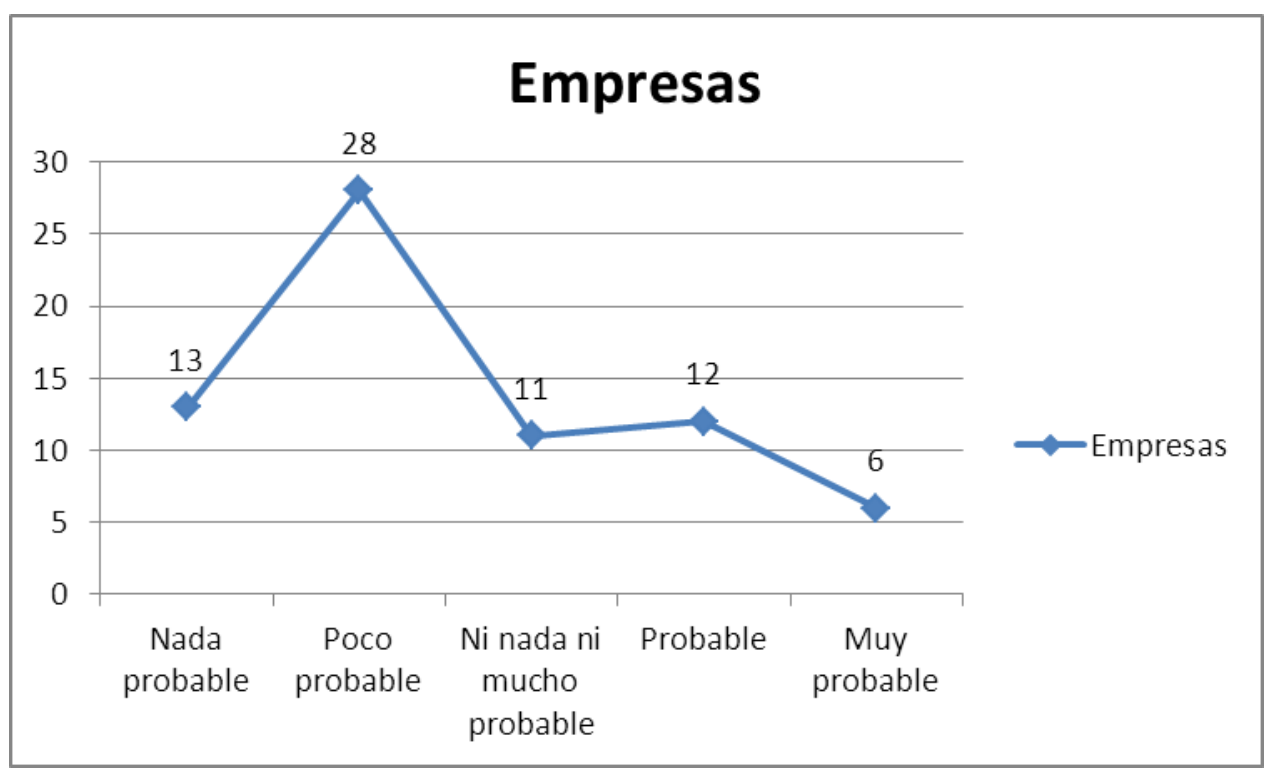

Figura 30. ¿Cuál sería el nivel de probabilidad de adquirir los servicios de la consultora en recursos humanos?

Elaboración propia

- Determinar las características que deben tener la consultora ideal para los alumnos

Las empresas están dispuestas a pagar entre 101 soles hasta 300 soles por los servicios de la consultora (ver Figura 31). Además, al igual que los estudiantes, prefieren al distrito de San Isidro como el más idóneo para que las oficinas de la consultora estén ubicadas (ver Figura 32 y 34).

Les gustaría informarse de la consultora por medio de las redes sociales, de 
preferencia LinkedIn y luego vía correo electrónico (ver Figura 33).

Para las empresas la selección del personal, base de datos y proceso de selección son las tres alternativas de compra (ver Figura 35).

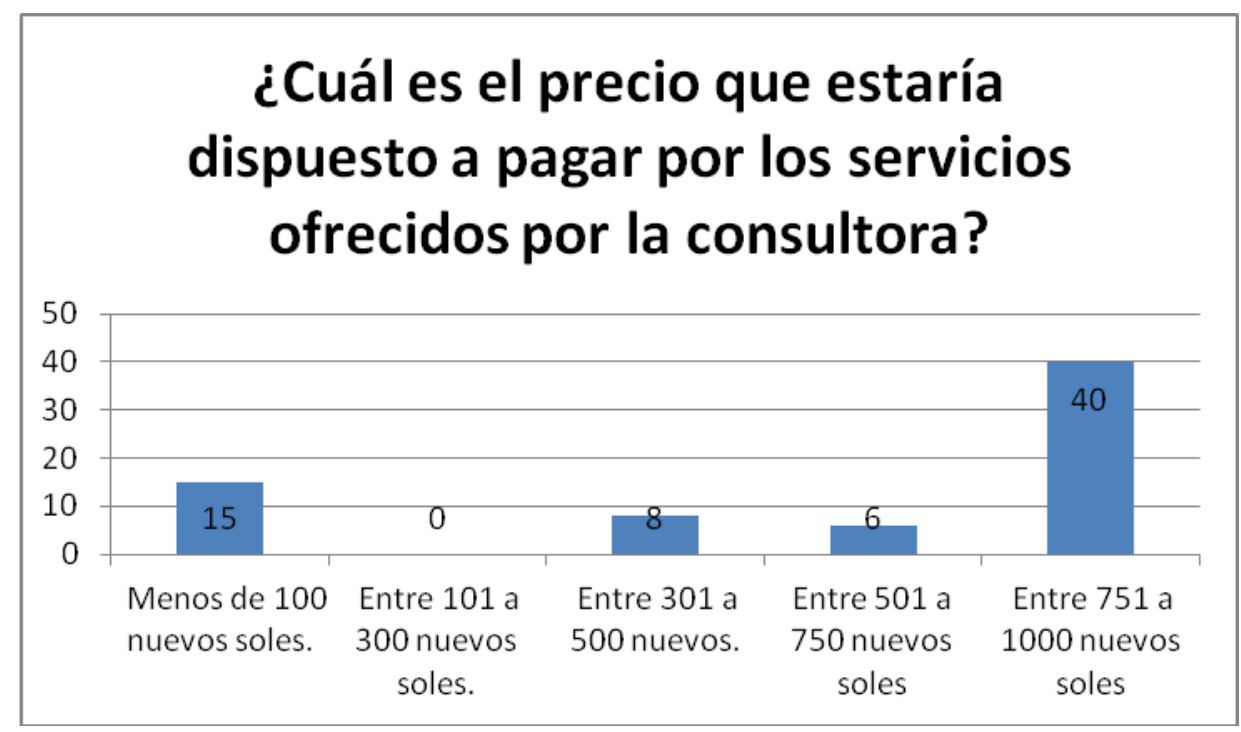

Figura 31. ¿Cuál es el precio que estaría dispuesto a pagar por los servicios ofrecidos por la consultora?

Elaboración propia 


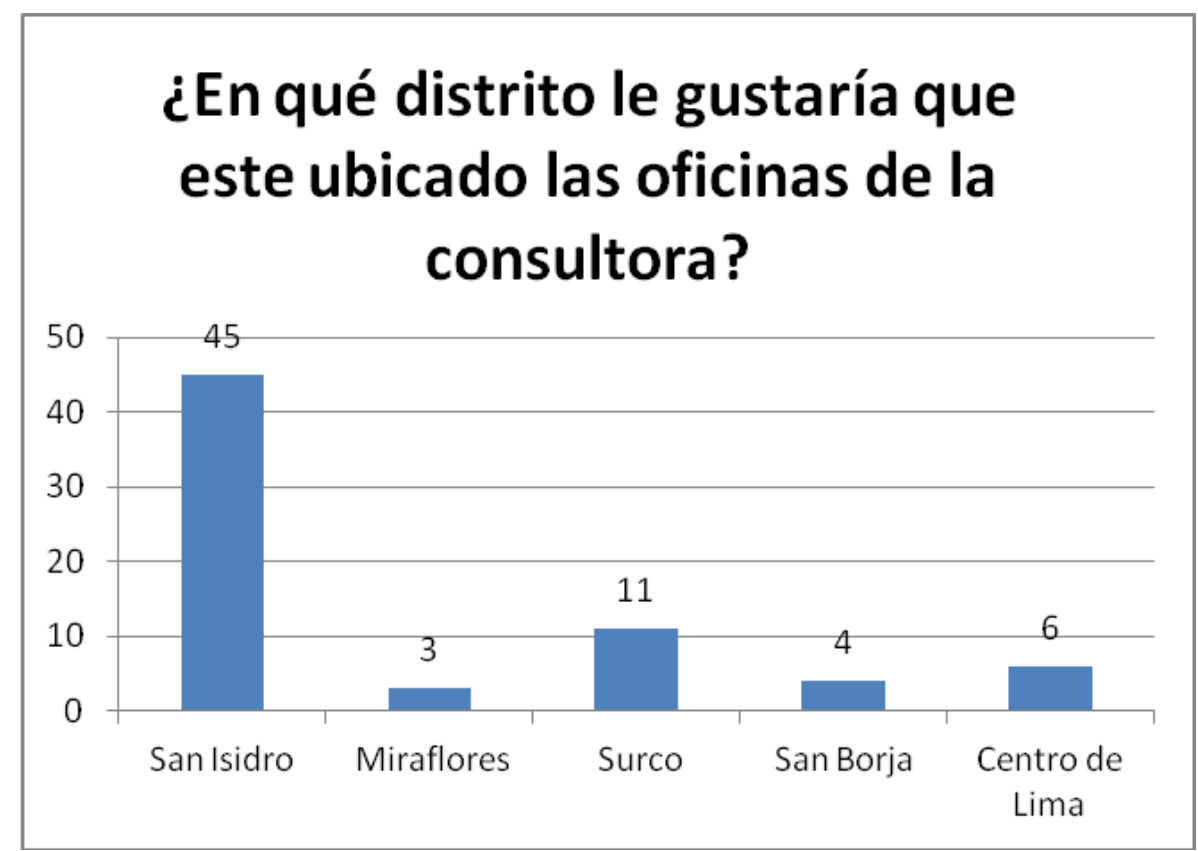

Figura 32. ¿En qué distrito le gustaría que este ubicado las oficinas de la consultora? Elaboración propia

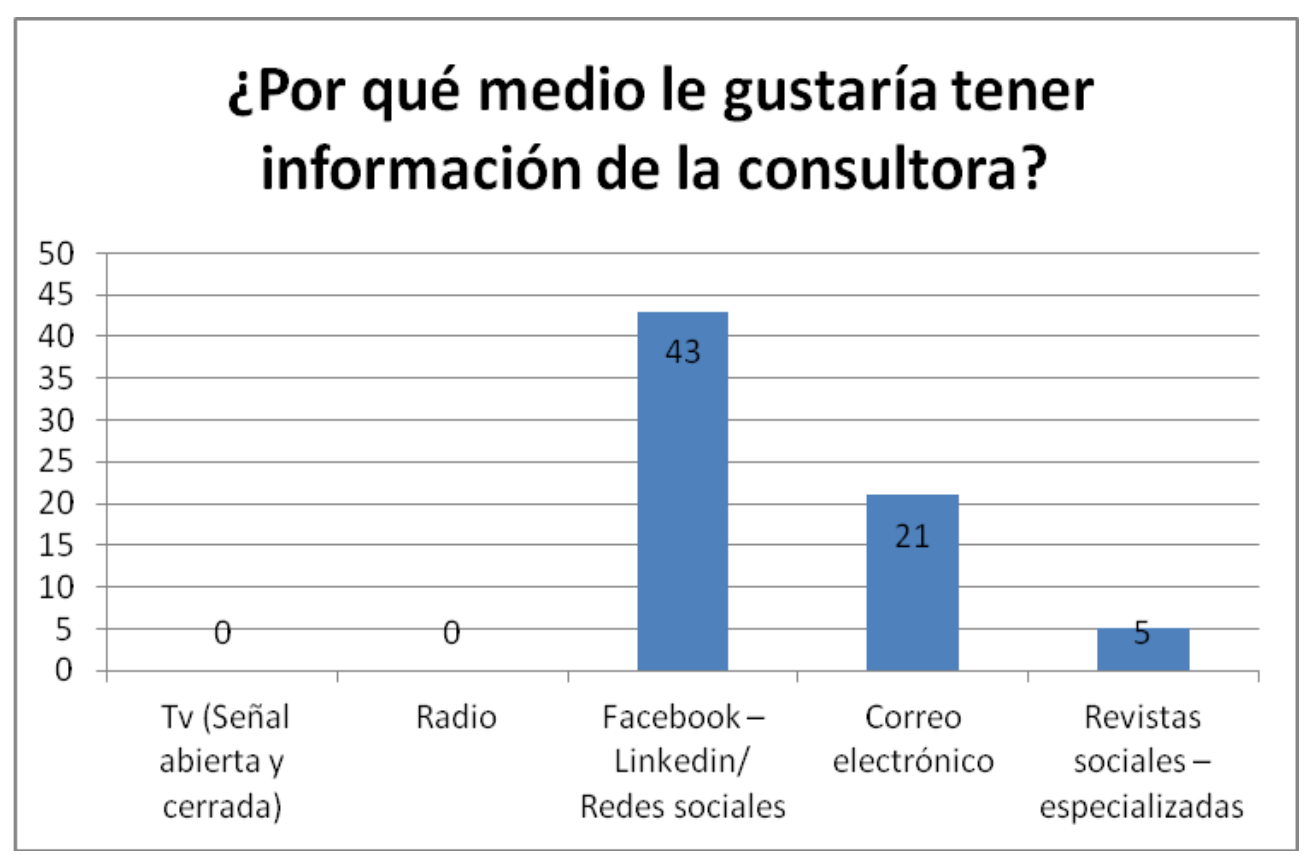

Figura 33. ¿Por qué medio le gustaría tener información de la consultora? Elaboración propia 


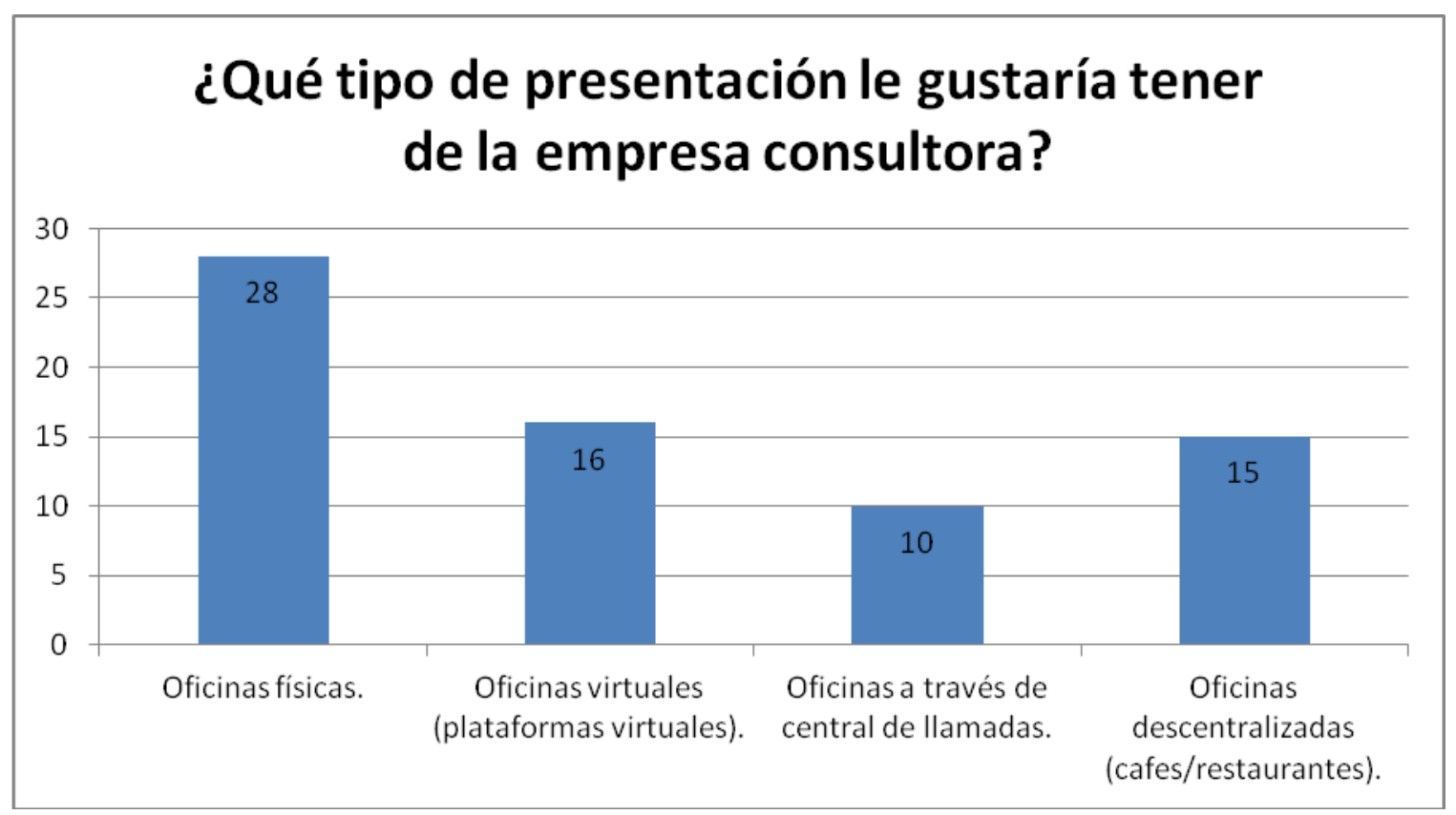

Figura 34. ¿Qué tipo de presentación le gustaría tener de la empresa consultora? Elaboración propia



Figura 35 ¿Qué tipo de presentación le gustaría tener de la empresa consultora? Elaboración propia

\subsection{Perfil del consumidor tipo y sus variantes}

A continuación, se presenta los dos tipos de consumidores:

Empresario: En su mayoría pueden ser empresas corporativas (Bancos, AFP, 
Alicorp y Backus \& Johnston, entre otras), las cuales les brinda mayor satisfacción debido que a su constante búsqueda del talento humano.

Es importante mencionar, que estas empresas tienen procesos de aprendizaje para el personal nuevo, sin embargo, muchas veces no logran comunicar a todos los colaboradores el enfoque del negocio. Por ello, es importante que la empresa consultora capacite a los practicantes para que ayude a ampliar mejor el desarrollo y diseño del negocio.

Muchos estudiantes que realizan prácticas son buenos prospectos para las empresas, pero éstas pueden perder un potencial colaborador debido a la falta de seguimiento en el desarrollo de actividades propias del negocio. Si bien, algunas universidades han creado filosofías de estudios ligados a la aplicación de herramientas para la mejora de procesos internos de una empresa, estos no se relacionan directamente con las relaciones interpersonales del practicante y la empresa (comunicacionales).

Estudiantes. Este perfil es básicamente a los estudiantes de los últimos ciclos que buscan interactuar con profesionales especializados en para mejorar las relaciones comunicacionales entre practicante y empleador, estos pueden ser universitarios en su mayoría del sector privado, donde valoriza el tiempo de aprendizaje (brecha entre universidad - empresa), para desarrollar experiencia comunicacional entre su empleador.

El estudiante valora realizar prácticas pre profesionales en el sector y especialidad, debido que es importante para su desarrollo profesional, esto marcará los siguientes trabajos orientados a la especialidad y sector en que se especializa. 


\section{Capítulo IV. Proyección del Mercado Objetivo}

Este capítulo se dedica a las proyecciones y determinación de la posible cantidad de usuarios del servicio, ya sean alumnos universitarios como empresas.

\subsection{El ámbito de la proyección}

El ámbito de proyección se calculó usando dos tipos diferentes de públicos objetivos: Estudiantes universitarios y Empresas. Al ser un servicio que su desarrollo está condicionado a la economía del país, se utilizará la tasa de crecimiento del PBI para realizar la proyección económica del presente negocio. Según el Banco Central de Reserva, este método es el más utilizado para obtener proyecciones, ya que incorpora cambios en las tendencias macro y microeconómicas, así como también se toma en cuenta la volatilidad en la política interna y externa.

\subsection{Selección del método de proyección.}

\subsubsection{Mercado potencial.}

Para este plan de negocios se trabajará con los estudiantes de las universidades de Lima, que tengan más de 1,500 matriculados. Según la SUNEDU en el 2015 se matricularon al redor de 638,139 alumnos.

Se consideró como tamaño de la población a 7801 (mediana y grandes empresas). 
Tabla 14

Mercado potencial

\begin{tabular}{lrc}
\multicolumn{2}{c}{ Unidad } & $\%$ \\
\hline Estudiantes & 638139 & $93 \%$ \\
Empresa & 7801 & $7 \%$ \\
Total & 645940 & $100 \%$
\end{tabular}

Nota. Elaboración propia

Considerando los dos sectores, existe un mercado potencial de 645940 entre estudiantes y empresas.

\subsubsection{Mercado disponible.}

Sin embargo, en la encuesta realizada al grupo objetivo, en la pregunta 11, se pudo detectar que existe un $59.69 \%$ de estudiantes que gustaron y estarían dispuestos a comprar el servicio. Esto hace un total de 331,236 (mercado disponible).

En relación con el análisis de la empresa se validó que un 42\%, es decir 3,355 de empresas con las características descritas de nuestro servicio. 
Tabla 15

Intención de compra (estudiantes)

¿Cuál sería el nivel de probabilidad de adquirir $\quad$ Estudiantes $\%$

los servicios de la consultora en recursos

humanos?

Nada probable

14

19.18

Poco probable

22

30.14

Ni nada ni mucho probable

11

Probable

17

Muy probable

9

12.33

Total

73

100

Nota: Elaboración propia - Muestra efectiva: 73 
Tabla 16

Disponibilidad de adquirir el servicio (empresas)

¿Cuál sería el nivel de probabilidad de adquirir $\quad$ Empresas $\quad \%$

los servicios de la consultora en recursos

humanos?

Nada probable

Poco probable

Ni nada ni mucho probable

Probable

Muy probable

Total
13

28

11

$16 \%$

12

$17 \%$

6

$9 \%$

70

$19 \%$

$40 \%$

$9 \%$

$100 \%$

Nota: Elaboración propia - Muestra efectiva: 70

\subsubsection{Mercado Efectivo.}

Una vez que el mercado disponible es calculado, se plantea la pregunta

$\mathrm{N}^{\circ} 11$, la cual sirve para sincerar al consumidor. Se preguntó qué tan probable es que adquiera el servicio, resultando que el $35.62 \%$ de estudiantes considera muy probable la adquisición del servicio. El mercado objetivo es de 117986 estudiantes. 
El análisis realizado a las empresas nos da un total de $26 \%$ corresponde a 872 empresas como mercado efectivo.

Tabla 17

Disponibilidad de adquirir el servicio (estudiantes).

¿Cuál sería el nivel de probabilidad de adquirir los Estudiantes \%

servicios de la consultora en recursos humanos?

Nada probable

14

19.18

Poco probable

22

30.14

Ni nada ni mucho probable

11

15.07

Probable

17

Muy probable

9

12.33

Total

73

100

Nota: Elaboración propia - Muestra efectiva: 73 
Tabla 18

Disponibilidad de adquirir el servicio (empresas).

¿Cuál sería el nivel de probabilidad de adquirir los servicios Empresas \% de la consultora en recursos humanos?

Nada probable

Poco probable

Ni nada ni mucho probable

Probable

Muy probable

Total
13

28

$40 \%$

11

$16 \%$

12

$17 \%$

6

$9 \%$

70

$100 \%$

Nota: Elaboración propia - Muestra efectiva: 70

Una vez evaluados los criterios de mercados, se realiza un resumen del mismo buscando establecer la metodología más exacta posible.

\subsubsection{Mercado Objetivo.}

Se consideró como mercado objetivo un $12.33 \%$ (14 548 estudiantes) estimación de demanda de estudiantes y para las empresas se consideró un 9\% (79 empresas). 
Para el mercado objetivo se tiene que definir la cantidad de servicios que se deben realizar para poder satisfacer la demanda del mercado limeño. Es en ese sentido, que es necesario tener como estrategia del negocio el establecer pautas de crecimiento según el porcentaje de este en el área del negocio. Teniendo en cuenta un crecimiento del PBI de $3 \%$ anual en un escenario estable

Tabla 19

Mercado objetivo

\begin{tabular}{|c|c|c|}
\hline & Mercado Objetivo & $\%$ \\
\hline Empresas & 79 & $9 \%$ \\
\hline Estudiantes & 14548 & $12.33 \%$ \\
\hline
\end{tabular}

Nota. Elaboración propia 


\section{Capítulo V. Localización}

En el presente capítulo se determinan los factores principales para poder definir la localización ideal para la creación de la sede de la consultora.

\subsection{Estudio de localización}

\subsubsection{Definición de factores locales.}

Las principales universidades públicas y privadas de Lima Metropolitana se encuentran en diferentes conglomerados geográficos, sin embargo, hemos identificado 03 puntos clave (ver Figura 36):

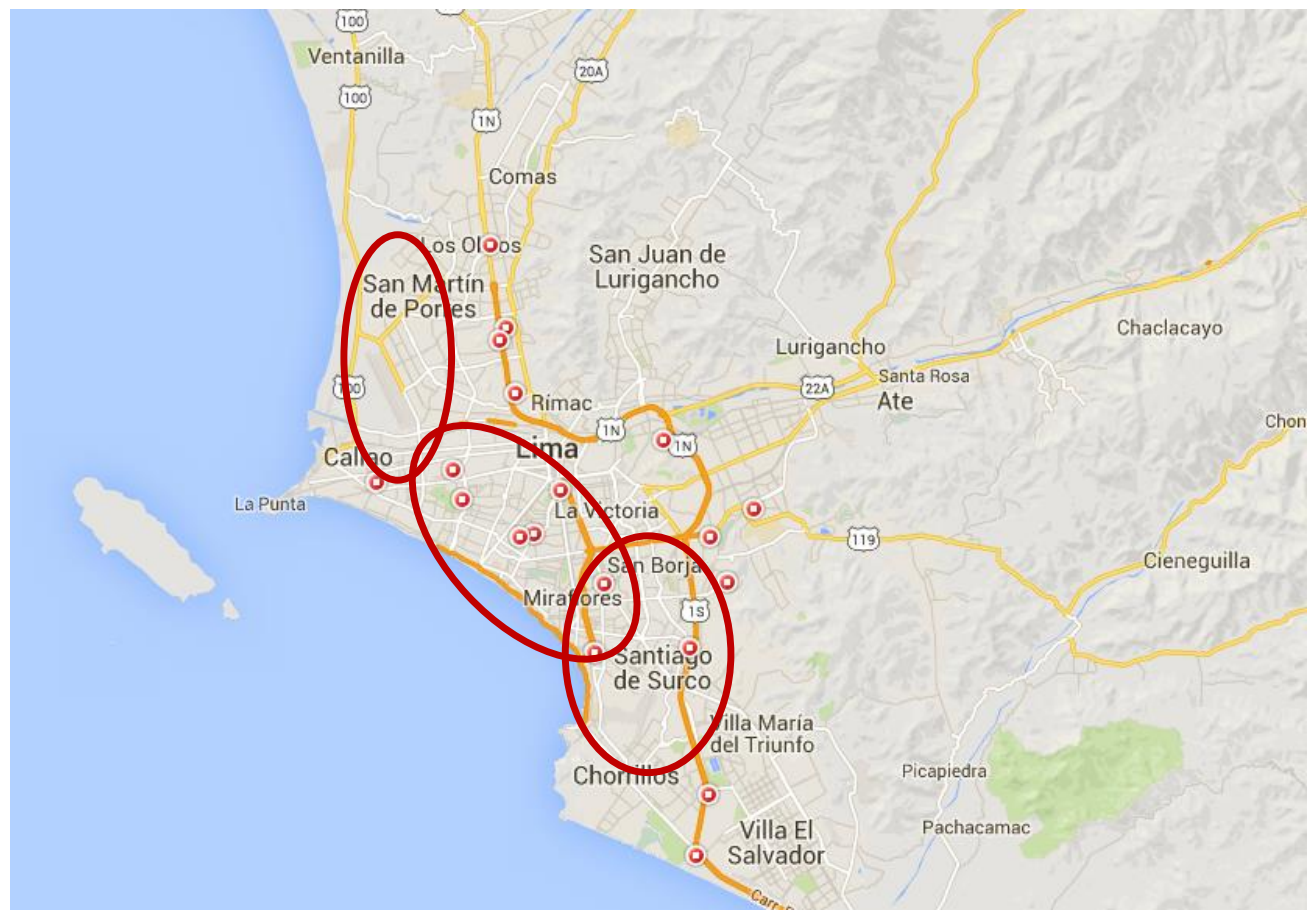

Figura 36. Ubicación de principales universidades públicas y privadas de Lima Metropolitana Fuente. Google maps. Recolectado de la página. https://goo.gl/TsemFx

Estas zonas se pueden caracterizar de la siguiente manera: 
- Conglomerado $\mathrm{N}^{\circ}$ 1. Lima Moderna (Universidad San Ignacio de Loyola, Universidad de Lima, Universidad Peruana de Ciencias Aplicadas, Universidad Ricardo Palma)

- Conglomerado $\mathrm{N}^{\circ}$ 2. Lima Norte (Universidad Privada del Norte, Universidad Católica Sede Sapientae, Universidad Peruana Cayetano Heredia, Universidad Tecnológica del Perú, Universidad Federico Villarreal)

- Conglomerado $\mathrm{N}^{\circ}$ 3. Lima Este (Universidad Nacional del Callao, Universidad Nacional Mayor de San Marcos, Pontifica Universidad Católica del Perú, Universidad San Juan Bautista, Universidad del Pacífico)

\subsection{Determinación de la localización óptima.}

\section{Factores de la macro localización}

En el siguiente resumen, se observa que el conglomerado $\mathrm{N}^{\circ} 3$, presenta las mejores condiciones cuantitativas, esto debido a que en dicho cuadrante la concentración de la Universidad Nacional Mayor de San Marcos y Pontificia Universidad Católica del Perú no tienen la misma cantidad de alumnos que los otros conglomerados. 
Tabla 20

Resumen de conglomerados

\begin{tabular}{lcccc} 
Propuestas & \# Universidades & $\begin{array}{c}\text { \# empresas - } \\
\text { clientes }\end{array}$ & \# Alumnos & Resultado \\
\hline Conglomerado $\mathbf{N}^{\circ} \mathbf{1}$ & 9 & 31,200 & 168,620 & Regular \\
Conglomerado $\mathbf{N}^{\circ} \mathbf{2}$ & 5 & 34,032 & 232,237 & Buena \\
Conglomerado $\mathbf{N}^{\circ} \mathbf{3}$ & 7 & 43,435 & 237,282 & Muy buena \\
\hline
\end{tabular}

Nota: Elaboración propia - Validado por un experto.

El método de ponderación de factores ha sido determinado por el costo de ubicación ya que es un factor que influye en el diseño de negocio, seguido de la disponibilidad de ubicación. A continuación, se muestra el ranking de factores según los resultados de la matriz para ponderar los factores: 
Tabla 21

Ranking de Factores - Macro Localización

Conglomerado Conglomerado Conglomerado

\begin{tabular}{ccccc} 
& $\mathbf{N}^{\circ} \mathbf{1}$ & $\mathbf{N}^{\circ} \mathbf{2}$ & $\mathbf{N}^{\circ} \mathbf{3}$ \\
\hline Peso Calif. Pond. Calif. Pond Calif Pond.
\end{tabular}

Cercanía de las fuentes de

abastecimiento

$\begin{array}{lllllll}14.3 \% & 5 & 0.715 & 5 & 0.715 & 3 & 0.429\end{array}$

$\begin{array}{llllllll}\text { Disponibilidad de Ubicación } & 28.6 \% & 1 & 0.286 & 2 & 0.572 & 3 & 0.858\end{array}$

$\begin{array}{llllllll}\text { Acceso a servicios } & 14.3 \% & 3 & 0.429 & 4 & 0.572 & 5 & 0.715\end{array}$

$\begin{array}{llllllll}\text { Costo de la Ubicación } & 42.9 \% & 2 & 0.858 & 4 & 1.716 & 5 & 2.145\end{array}$

$\begin{array}{lllll}\text { Total } & 100.0 \% & 2.288 & 3.575 & 4.147\end{array}$

Nota: Elaboración propia - Validada por un experto. Tener en consideración que 5 es la más importante y 1 la menos importante. Ver Anexo 6

\section{Factores de macro localización}

Se realizó para cada conglomerado, una lista de variables cuantitativas importante para el giro del negocio, además se fijó una puntuación por factores cualitativos. Las variables utilizadas son: cercanía de las fuentes de abastecimientos, disponibilidad de ubicación, accesibilidad de servicios y costo de la ubicación. 


\section{Cercanía a fuentes de abastecimientos (A)}

Las tres propuestas tienen un similar nivel de abastecimiento, ya que, al ser zonas de alto tránsito, son los proveedores que se ubican o están disponibles en estos distritos, debido a la gran concentración de personas y de negocios similares. Por lo que la competencia entre estos es atractiva y la cantidad de proveedores es alta.

\section{Disponibilidad de ubicación (B)}

El conglomerado $N^{\circ} 3$ presenta una mejor disponibilidad en la ubicación, ya que el tiempo de alquiler en esta zona es mayor (alrededor de 5 años).

\section{Accesibilidad de servicios (C)}

Cada conglomerado dispone de su propia zona comercial, lo cual es muy importante para poder estar en una zona céntrica y con la disponibilidad de poder contar con servicios de manera inmediata.

\section{Costo de la ubicación (D)}

Los conglomerados 1 y 2 tienen un precio de alquiler por metro cuadrado ligeramente mayor que el conglomerado $\mathrm{N}^{\circ} 3$. Esto se debe a que los dos primeros tienen a distritos con mayor poder adquisitivo.

Tanto en el ranking general como en el de factores, el conglomerado $\mathrm{N}^{\circ} 3$ es la zona indicada, ya que tiene mejores factores cuantitativos y cualitativos. El conglomerado $\mathrm{N}^{\circ} 3$, es el más óptimo, ya que tienen mayor concentración de oficinas y universidades, se optará por el alquiler de una oficina en el distrito de San Isidro 
De acuerdo al análisis la oficina en alquiler presenta las siguientes características $50 \mathrm{~m}^{2}, 2$ ambientes, 1 baño, vista a la calle, segundo piso, sin ascensor, sin cochera, mucha facilidad para parquear en la zona, ubicada en Calle Burgo a 1 cuadra de Real Plaza de Salaverry (San Isidro) siendo el alquiler de US\$ $620^{25}$ (Información validada por Agente Inmobiliaria).

${ }^{25}$ Ver Anexo 7 


\section{Capítulo VI. Aspectos Organizacionales}

En este capítulo se definen las bases para la creación de la empresa, definiendo la misión, visión, principios, determinando la estrategia, así como el FODA, cadena de valor, organigrama y la descripción de los puestos claves.

\subsection{Caracterización de la cultura organizacional deseada}

\subsubsection{Visión}

Una visión debe responder a la pregunta ¿En qué queremos convertirnos?, ya que ésta sienta las bases de manera clara y concisa sobre lo que queremos ser a un futuro. Una visión debe ser breve y debe contar con el aporte de los directivos y, si es posible, del personal de confianza. Una visión clara es importante para poder desarrollar una misión detallada.

Para construir esta visión adecuada, se realizaron las siguientes preguntas ${ }^{26}$ :

Tabla 22

Preguntas claves para la construcción adecuada de la visión ¿Qué imagen deseas? Consultora para prácticas pre profesionales

¿Cómo será el futuro? Ser una importante consultora a nivel regional.

¿Qué se hará en el Trabajar con socios estratégicos de diferentes

futuro? niveles de atención

Nota: Elaboración propia.

${ }^{26}$ Idalverto Chiavenato, Planeación estratégica fundamentos y aplicaciones. Pág. 53. 
Luego de responder dichas preguntas se llegó a la siguiente visión:

"Ser una consultora peruana de recursos humanos competitiva, generando alianzas con nuestros socios estratégicos para la mejora en la calidad de nuestro servicio”.

\subsubsection{Misión}

La misión es un enunciado que debe durar en el tiempo, además de distinguir a una organización de las demás empresas similares. Es la "razón de ser” de una organización y debe responder a la pregunta ¿Cuál es nuestro negocio? Una misión clara es fundamental para poder establecer los objetivos y estrategias de manera efectiva.

Según Hamel (2006), la misión es la declaración de la empresa al accionar y esta parte del supuesto que toda la organización se compromete a cumplir la misión.

Para construir esta misión se realizó las siguientes preguntas, que satisfacen la necesidad del análisis ${ }^{27}$ :

\footnotetext{
${ }^{27}$ Idalverto Chiavenato, Planeación estratégica fundamentos y aplicaciones. Pag 53.
} 
Tabla 23

Preguntas claves para la construcción adecuada de la misión

¿Quiénes somos? Consultora especializada en reducir el

tiempo de inserción laboral para jóvenes

para practicas pre profesionales

¿Qué buscamos?

¿Por qué lo hacemos?

¿Cuáles son los fines y objetivos Reducir el tiempo de inserción laboral
Para mejora la calidad de vida profesional de

los jóvenes y empresas

Ser la primera opción

\section{que queremos alcanzar?}

¿Para quienes trabajamos? Para los jóvenes universitarios

Nota: Elaboración propia

Luego de responder dichas preguntas se llegó a la siguiente misión:

"Somos la opción efectiva en el campo de gestión de desarrollo humano, brindamos a jóvenes universitarios y empresas soluciones para reducir su tiempo de inserción laboral y mejorar la calidad de vida profesional”

\subsubsection{Principios.}

Según la Real Academia de la lengua, define a los principios como:

- m. Base, origen, razón fundamental sobre la cual se procede discurriendo en cualquier materia.

- m. Causa, origen de algo. 
- m. Cada una de las primeras proposiciones o verdades fundamentales por donde se empiezan a estudiar las ciencias o las artes.

Los principios son los pilares de la empresa, más allá de definirlos, la empresa debe vivirlos y estar desarrollándolos continuamente, los debe promover, promulgar y mantener diariamente. Estos valores no solo se refieren a la actitud que adoptan los trabajadores, sino en todos los actores que intervienen en la empresa: los productos, comunicación, etc.

Los valores son las propiedades, cualidades o características de una acción, una persona o un objeto considerados típicamente positivos o de gran importancia. Los valores son objeto de estudio de la Axiología.

Los valores de la empresa son los pilares más importantes de cualquier organización. Con ellos en realidad se define a sí misma, porque los valores de una organización son los valores de sus miembros, y especialmente los de sus dirigentes.

Los principios de la organización son los siguientes:

- Responsabilidad

- Honestidad

- Respeto,

- Solidaridad,

- Mantener la ética profesional por encima de los intereses personales 


\subsection{Formulación de estrategias del negocio}

Para la formulación de estrategias del negocio se ha visto la necesidad de desarrollar la estrategia de enfoque (concentración), ya que el público objetivo del negocio son los alumnos universitarios de los últimos ciclos las empresas medianas grandes. Ante este público se debe ajustar una estrategia que se considere óptima para responder las necesidades de ambos públicos. Es decir, no se trata de ser los mejores del mercado, pero si en el segmento donde trabajaremos.

El público objetivo es:

- Estudiantes universitarios que requieren de prácticas pre profesionales

- Empresas que requieren de estudiantes universitarios para cubrir prácticas pres profesionales.

\subsubsection{FODA.}

En el análisis FODA (ver Figura 37), se han elegido los principales factores que afectan directa e indirectamente al negocio, con el fin de generar estrategias y planes de trabajo acorde a las circunstancias, al ser un negocio nuevo solo se considerarán las oportunidades y amenazas 


Oportunidades
•Incentivo de la
orientación
vocacional de los
estudiantes en
secundaria
-Enfoque del estado a
la inclusión laboral.
- Gran número de
universidades.
-Escasez del talento
humano
- Mejora en el acceso
de Internet
-Incremento de uso de
redes sociales.



Figura 37. Análisis FODA.

Elaboración propia

\subsubsection{Análisis de estrategias - PEYEA.}

A través de la herramienta PEYEA se puede elaborar la siguiente estrategia que se diseña en función al FODA encontrado. La descripción del análisis de la matriz lo encontramos en el Anexo 3. 


\section{Matriz de Posición Estratégica y Evaluación de la Acción (PEYEA)}

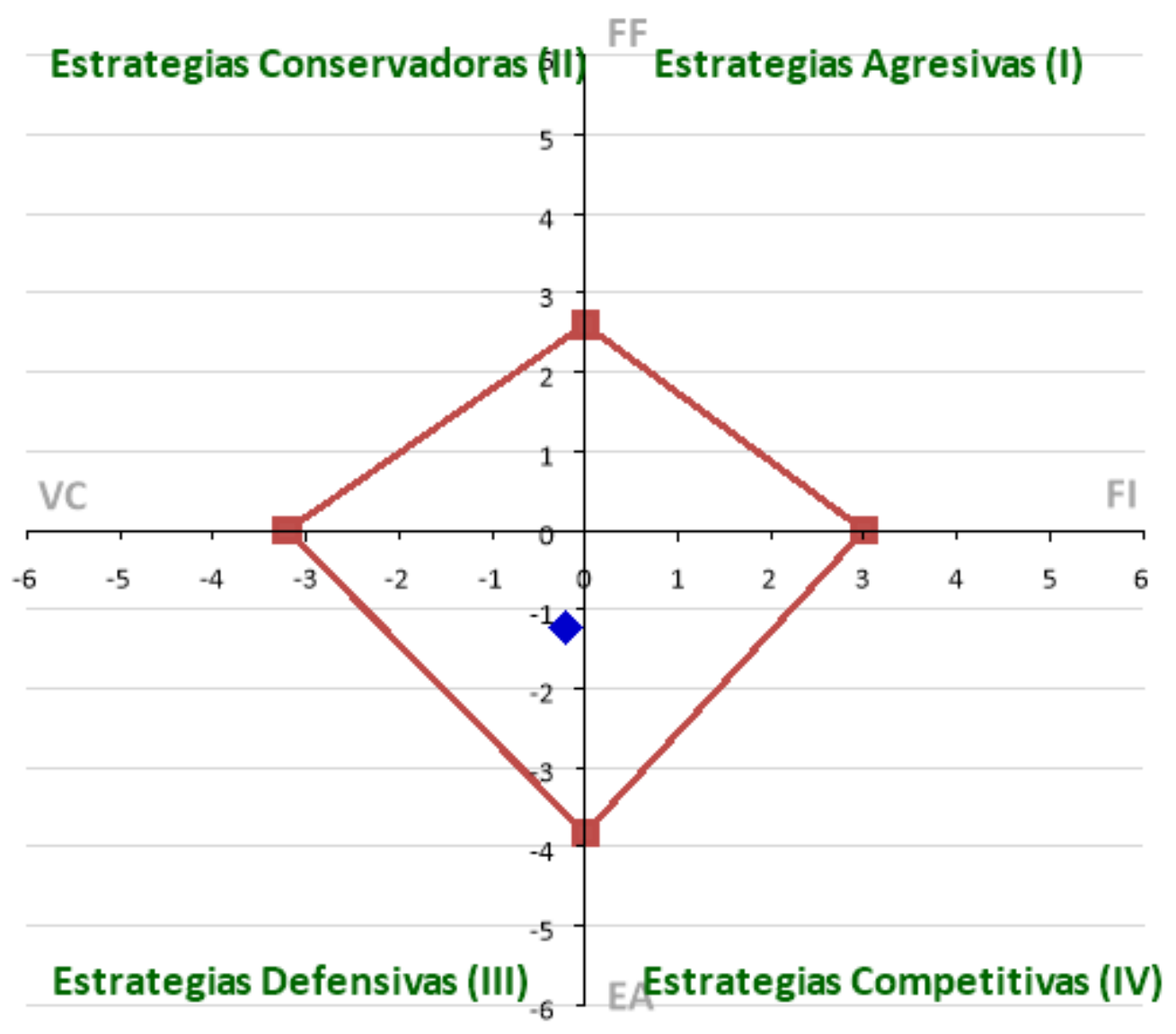

Figura 38. Matriz de posición estratégica de la acción (PEYEA). Elaboración propia

El cuadrante que sale en el análisis PEYEA son las estrategias defensivas, siendo estas pueden usarse este cuadrante III en 04 tipos de estrategias. Se observa que la diversificación concéntrica (venta de varios servicios relacionados a uno mismo) es una característica de alto nivel de competitividad que ayuda en la diferenciación en la categoría. 
Tabla 24

Estrategias de Defensivas

III Cuadrante Defensivo

Atrincheramiento

Desinversión

Liquidación

\section{Diversificación concéntrica}

Nota: Elaboración propia

Por ello, debido a esta conclusión se observa que el negocio debe orientarse en dos tipos de clientes en las cuales les permita obtener mejores beneficios.

\subsection{Determinación de las ventajas competitivas críticas}

Para determinar las ventajas competitivas se ha utilizado el enfoque de la cadena de valor de (Porter M. ${ }^{28}$ ) la consultora. Bajo este enfoque se busca visibilizar las actividades principales de la empresa y de esta manera obtener mejores resultados. En la cadena de valor se definen las actividades clasificadas como primarias y de apoyo, donde dentro de ellas se definen el proceso productivo:

Actividades primarias.

\footnotetext{
${ }^{28}$ Porter M. (2010), Ventaja competitiva. Editorial Continental. México pág. 51
} 
1. Logística de entrada: Implementación de una plataforma informática que permita obtener el perfil de los estudiantes con prácticas pre profesional, con cv actualizados, asimismo un análisis de las tendencias de requerimientos de los clientes (empresa).

2. Producción: Desarrollo de actividades a través de herramientas de psicología, búsqueda en sistemas alternativos como redes sociales, análisis de producción de tiempos por analista.

3. Logística de salida: Desarrollo de actividades monitoreando los resultados.

4. Marketing y ventas: Se diseña de manera digital utilizando herramientas como Facebook, LinkedIn

5. Servicio post -venta: Desarrollo de trabajos adicionales a las Universidades a través de informes mensuales de reportes de tendencia laboral a nivel nacional y mundial por especialidad.

Actividades de apoyo

6. Abastecimiento: Se refiere a los recursos humanos que tiene la consultora

7. Investigación y desarrollo: La creación, uso y actualización de bases de datos, la creación o implementación de una plataforma de comunicación interna.

8. Administración de recursos humanos: Administración de los requerimientos de colocación de personal, que tengan el perfil y reúna los requisitos necesarios. 
9. Infraestructura: Implementación de oficinas cumpliendo los requerimientos del giro de la empresa, con oficinas amplias y que incentiven el trabajo.

Ventaja competitiva basada en diferenciación. La consultora en su diseño original tiene atributos similares a los que se encuentran en el mercado limeño, pero posee dos aspectos importantes: el coaching a practicantes pre profesionales y el estudio de tendencias de las especialidades según el requerimiento laboral. En ambos servicios se diferencia de otras consultoras. A continuación, se muestra los atributos de diferenciación:

1. Activos tangibles. Los activos tangibles de la empresa se basan en el capital social de la empresa.

2. Activos intangibles. Los activos intangibles de la empresa se basan en el conocimiento del postulante, la capacitación a este y la respuesta acertada que se da a las empresas

3. Capacidades organizacionales. En esta se avoca al conocimiento del negocio.

Creación de valor de la consultora. La consultora adquiere valor agregado a través de tres puntos específicos:

1. Demanda de clientes. El servicio que se ofrece es innovador, puesto que no existe consultora que realice exclusivamente un servicio para alumnos universitarios. 
2. Escasez. Si bien, existen diferentes consultoras especializadas, la escasez de recursos humanos es un factor clave en las organizaciones y donde adquieren conocimiento y experiencia desde muy jóvenes (practicas pre profesional).

3. Apropiabilidad.

Infraestructura. Oficinas con herramientas tecnológicas

Gestión de recursos humanos. Requerimiento alineados a los objetivos estratégicos del plan. Especialistas en RRHH

Desarrollo de tecnología. Desarrollo de bases de datos y aplicación de plataformas informáticas

Compras. Adquisición de talento humano.
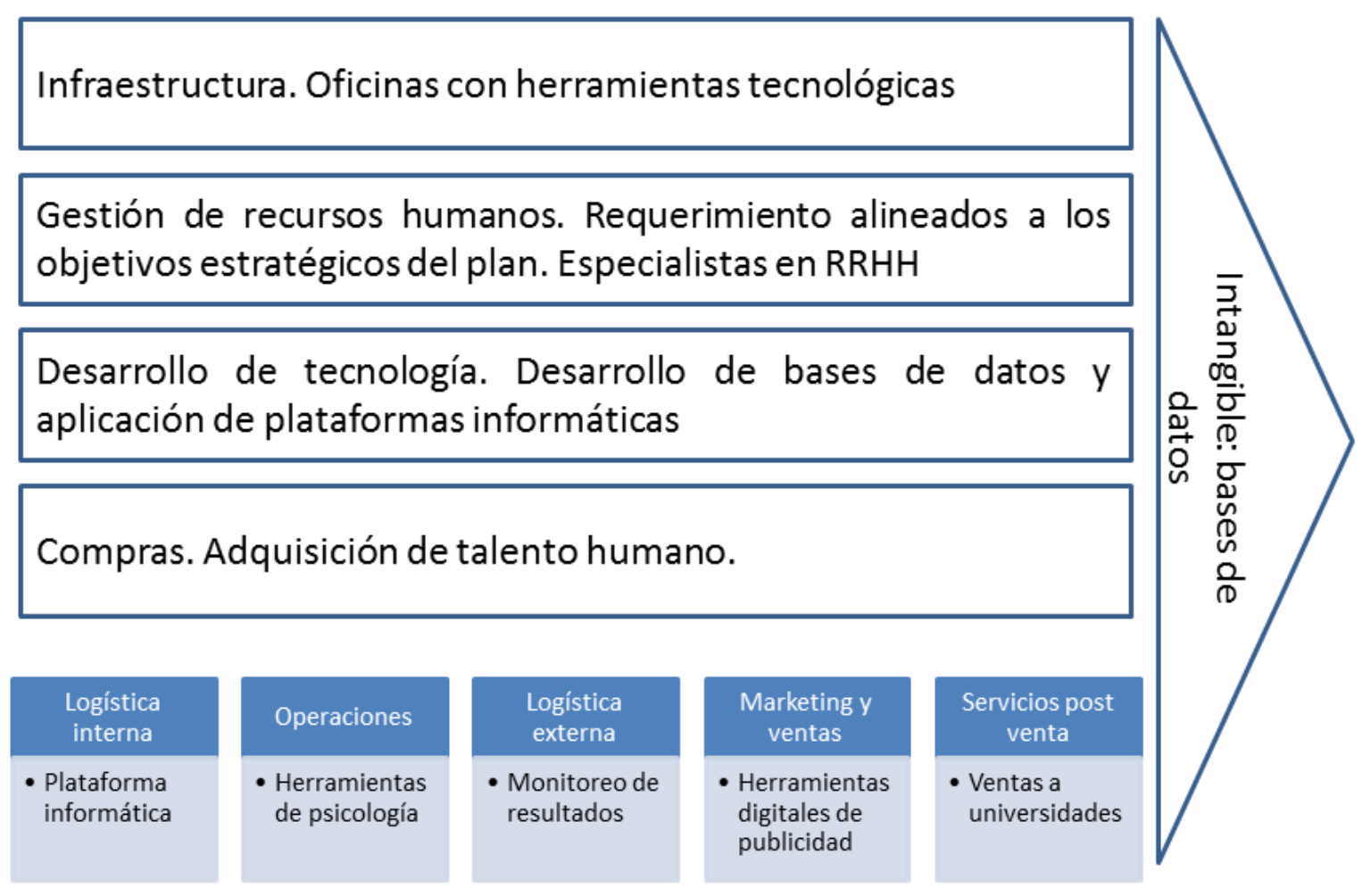

Figura 39 Cadena de valor del negocio.

Elaboración propia

\subsection{Diseño de la estructura organizacional deseada}

A continuación, se muestra el organigrama de la organización. 


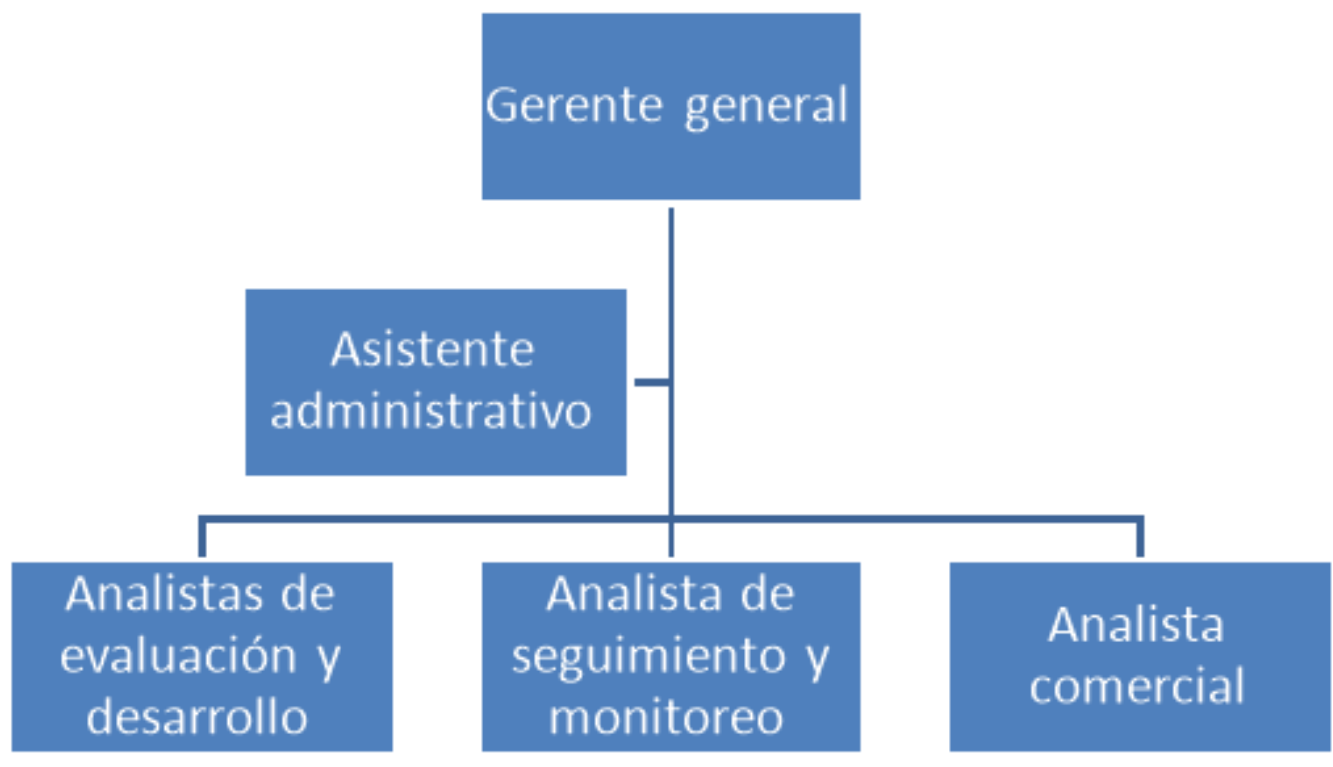

Figura 40. Organigrama.

Elaboración propia

La empresa se encuentra diseñada de manera horizontal con áreas claves para el

desarrollo del negocio. El organigrama consta de un gerente general, el cual se encargará del seguimiento de los analistas mediante indicadores de productividad.

\subsection{Diseño de los perfiles de puestos clave}

Gerente General. El perfil es para un profesional en Administración con una maestría en Gestión de Servicios, que disponga de experiencia en la administración de recursos humanos para diferentes entidades públicas y privadas. Los deberes son coordinar con las demás gerencias la realización del proceso de venta, contratación de personal y supervisión de los ingresos y egresos de la consultora con la finalidad de obtener rentabilidad para la empresa y para los accionistas.

Analista de Evaluación y Desarrollo. El perfil es para un Psicólogo o Administrador con especialidad en recursos humanos, que disponga de experiencia en desarrollo e implementación de personal para prácticas pre profesionales en empresas 
industriales y de servicios. Se encargará de la evaluación de competencias de los practicantes.

Analista de Seguimiento y Monitoreo. El perfil es para un Administrador, con experiencia en Recursos Humanos. Deberá encargarse de los proyectos empresas de manera que pueda controlar los plazos de los contratos, asimismo debe asegurarse de buscar la satisfacción del cliente con indicadores de post venta.

Analista Comercial. El perfil es de un Economista o Administrador especializado en las ventas especializadas y enfocadas a mantener la cantidad de proyectos ganados sean en licitaciones públicas y privadas, además de buscar clientes tanto en universidades como institutos privados. Debe coordinar con las gerencias para llevar a cabo el trabajo el servicio de consultoría.

Asistente Administrativo. El perfil es para un técnico en Administración con experiencia en Recursos Humanos. Se encargará de la atención al cliente (llamadas y correos de la consultora).

\subsection{Remuneraciones, compensaciones e incentivos}

Las remuneraciones fueron calculadas en función al promedio del sector y del mercado, considerando las funciones y experiencia laboral de los mismos. El detalle se encuentra en las siguientes tablas: 
Tabla 25

Remuneraciones de los empleados

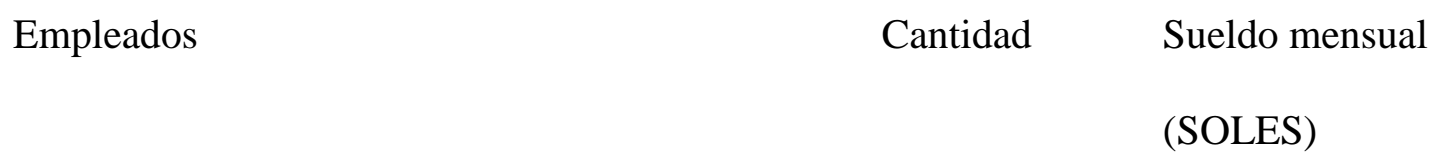

Gerente general

$1 \quad$ S/. $4,500.00$

Asistente de administración

$1 \quad$ S/. $1,500.00$

Analista de evaluación y desarrollo de proyectos

3

S/. 3,000.00

Analista de seguimiento y monitoreo

$1 \quad$ S/. $2,500.00$

Analista comercial

1

S/. 2,500.00

Nota. Elaboración propia

Tabla 26

Costo de mano de obra directa

Empleados Cantidad Sueldo mensual (SOLES)

$\begin{array}{lll}\text { Limpieza } & 2 & \text { S/. } 850.00\end{array}$

$\begin{array}{lll}\text { Seguridad } & 3 & \text { S/. } 1,000.00\end{array}$

Mantenimiento (jardines, entre otros) $\quad 1 \quad$ S/.850.00

Nota. Elaboración propia 


\section{Políticas de Recursos Humanos}

\section{Política de Ingreso}

La consultora mantiene contratos a plazo fijo de 6 meses para todo el personal que cumpla con el perfil descrito de manera previa.

\section{Política General del Desarrollo de los Recursos Humanos}

- $\quad$ Política de Capacitación y Perfeccionamiento

La consultora se responsabiliza de ofrecer como mínimo una capacitación al año. Esta se encontrará a cargo de un tercero y será costeada en su integridad por la consultora para todo el personal relacionado con el core business.

\section{- Política de Remuneraciones}

La consultora mantiene sueldos fijos y se otorgara un incentivo en el caso se excedan el $120 \%$ de metas comerciales en el mes de abril.

\section{- Política de Evaluación de Desempeño}

La consultora realiza una evaluación de desempeño al año, la cual consiste en una entrevista de feedback del gerente general a cada uno de los colaboradores. Los indicadores son $50 \%$ cuantitativos y $50 \%$ cualitativos.

\section{- Política de Calidad de vida laboral}

La Consultora promueve el flex -time con el fin que pueda cumplir con el $60 \%$ de horas semanales en la oficina y el $40 \%$ desde su domicilio.

\section{Política de Desvinculación}

La consultora respeta lo indicado en nuestra legislación laboral se ocupa del tema en los artículos $16^{\circ}$ y $18^{\circ}$ del Texto Único Ordenado de la Ley de Fomento del 
Empleo: Ley de Productividad y Competitividad Laboral (Decreto Supremo N ${ }^{\mathrm{a}} 003$ 97-TR) cuando señala lo siguiente:

Artículo 16.- Son causas de extinción del contrato de trabajo: (...)

b) La renuncia o retiro voluntario del trabajador;

Artículo 18.- En caso de renuncia o retiro voluntario, el trabajador debe dar aviso escrito con 30 días de anticipación. El empleador puede exonerar este plazo por propia iniciativa o a pedido del trabajador; en este último caso, la solicitud se entenderá aceptada si no es rechazada por escrito dentro del tercer día.

A partir de los 65 años se considera apto al trabajador para el cese laboral por jubilación. 


\section{Capítulo VII. Plan de Marketing}

\subsection{Segmentación}

\subsubsection{Estudiantes.}

Alumnos de los últimos ciclos las siguientes universidades:

1. Pontificia Universidad Católica del Perú

2. Universidad Alas Peruanas

3. Universidad Antonio Ruiz de Montoya

4. Universidad Científica del Perú

5. Universidad de Lima

6. Universidad del Pacifico

7. Universidad Esan

8. Universidad Inca Garcilaso de la Vega

9. Universidad Nacional de Ingeniería

10. Universidad Nacional de Piura

11. Universidad de San Martin de Porres.

12. Universidad Nacional del Callao

13. Universidad Nacional Federico Villarreal 
14. Universidad Nacional Mayor de San Marcos

15. Universidad Peruana de Ciencias Aplicadas

16. Universidad Privada Cesar Vallejo

17. Universidad Privada del Norte

18. Universidad Privada San Ignacio de Loyola

19. Universidad Privada San Juan Bautista

20. Universidad Ricardo Palma

21. Universidad Tecnológica del Perú

Que tengan entre 18 a 25 años, radiquen en Lima, pertenezcan a los NSE A, B y C y deseen realizar prácticas pre profesionales relacionadas a su carrera para adquirir conocimientos, mejorar su perfil profesional y estar en contacto con su próximo ambiente de trabajo.

- Segmentación Geográfica

Alumnos que radiquen en Lima.

- Segmentación Demográfica

Estudiantes de ambos sexos que tengan entre 18 a 25 años de los NSE A.

B y C 
- Segmentación Psicográfica - conductual:

Según el perfil del adulto joven según IPSOS Apoyo (promedio) ${ }^{29}$

- $5 \%$ tiene vehículo

- $62 \%$ no tiene ningún producto bancario

- $36 \%$ tiene laptop

- $18 \%$ tiene Tablet

- $61 \%$ usan Facebook

- $14 \%$ tiene Twitter

Además, dentro de un estudio realizado por IPSOS ${ }^{30}$ sobre las características de cada generación, determina que los de la Generación Y, los que actualmente tienen entre 21 y 35 años tienen las siguientes similitudes:

- $47 \%$ son solteros.

- $82 \%$ son digitales

- $64 \%$ usa smartphone

- $93 \%$ cuenta con redes sociales

${ }^{29}$ Tomado de: http://www.ipsos.pe/sites/default/files/marketing_data/Perfil_Adulto_Joven-2014.pdf

${ }^{30}$ https://www.ipsos.com/sites/default/files/2017-03/Generaciones\%202016.pdf 
Los jóvenes tienen un gran acceso a las redes sociales, lo que permite que se encuentren conectados en casi todo momento.

\subsubsection{Empresas.}

Empresas medianas y grandes de Lima que deseen contar con practicantes pre profesionales en sus diversas áreas y que tengan o deseen implementar un programa de capacitación laboral. Su ámbito de trabajo debe estar en Lima.

- Segmentación Geográfica

Empresas medianas o grandes que trabajen en Lima, ya sea como sede principal o alterna.

- Segmentación Demográfica

Empresas medianas y grandes de Lima, de todos los rubros.

- Segmentación Psicográfica - conductual:

La mayoría de medianas y grandes empresas tienen un programa de prácticas pro y profesionales.

\subsection{Estrategias de marketing}

La estrategia de marketing que se utilizará para el negocio es la de enfoque, ya que el servicio que brindamos es único en el mercado, somos la única consultora de recursos humanos dirigida exclusivamente a alumnos de universitarios de últimos ciclos que estén interesados en realizar prácticas pre profesionales. 
En base a esta estrategia, y dado que brindamos es un servicio, desarrollaremos la diferenciación enfocada en el marketing mix.

\subsubsection{Estrategia de producto.}

Para los estudiantes, el producto principal que se brinda es la colocación de practicantes en empresas, además se ofrecerá la orientación laboral, mediante charlas y talleres, como la ayuda en la elaboración de CV y la entrevista personal. Es decir, poder brindarles las herramientas necesarias para que su inserción laboral sea exitosa.

Los productos brindados en la consultora son los siguientes:

- Revisión de CV

- Taller de preparación de entrevista personal

- $\quad$ Taller de Habilidades Gerenciales

Estos productos serán ofrecidos a los estudiantes, quienes podrán participar para mejorar su desempeño en las entrevistas de trabajo y procesos de selección.

En el caso de las empresas, el producto que se ofrece es realizar el proceso de selección de practicantes, bajo el manejo de una base de datos y garantizando que el candidato tengas las habilidades y conocimientos necesarios e idóneos para el puesto. 
Para esto, se realizarán tres reuniones con la empresa, donde se definirán los perfiles y las vacantes para los puestos. Luego se presentarán los CV de los candidatos óptimos para lo solicitado, en esa reunión recibiremos un feedback sobre lo presentado para luego seleccionar al practicante elegido.

Luego de haber seleccionado al practicante se realizará un monitoreo de sus actividades y desempeño en el puesto, con el fin de tener una retroalimentación sobre el trabajo realizado con miras de realizar los ajustes necesarios para una segunda oportunidad.

Dimensiones del producto

Para los estudiantes:

- Beneficio básico: Es el servicio básico que busca el estudiante. En este caso es tener acceso a propuestas de prácticas pre-profesionales.

- Producto Genérico: Tener acceso a propuestas de prácticas preprofesionales de acuerdo con su perfil académico

- Producto Esperado: Poder obtener las prácticas pre-profesionales en una empresa reconocida en el mercado laboral.

- Producto aumentado: Atributos diferenciadores, como los talleres donde el estudiante podrá desarrollar o incrementar sus capacidades y aptitudes. 
- Producto potencial Son los atributos que debemos incorporar en un futuro para adaptarnos a las nuevas tendencias y cambios del mercado, como posibilidad de generar una aplicación de búsqueda basada en la geo localización, o que los estudiantes cuenten con algunos beneficios adicionales bajo una suscripción.

Para las empresas:

- Beneficio básico: Es el servicio básico que buscan las empresas. En este caso es poder cubrir sus plazas de prácticas pre-profesionales.

- Producto Genérico: Cubrir sus plazas con practicantes pre-preprofesionales capacitados correctamente para las labores.

- Producto Esperado: Contratar a un practicante pre-profesional que supere sus expectativas del puesto buscado.

- Producto aumentado: Seguimiento constante al practicante para poder conocer más a fondo la cultura de la empresa, lo que ellos buscan realmente y así poder ir ofreciendo cada vez más al candidato ideal.

- Producto potencial, podremos brindar a las empresas la posibilidad de ampliar la búsqueda de nuevos practicantes a nivel nacional.

La marca de N\&M Consultores

Según la Asociación Americana de Marketing, la marca es un nombre, un término, una señal, un símbolo, un diseño, o una combinación de alguno de ellos 
que identifica productos y servicios de una empresa y la diferencia de los competidores.

Es así que la marca para N\&M Consultores es la siguiente:

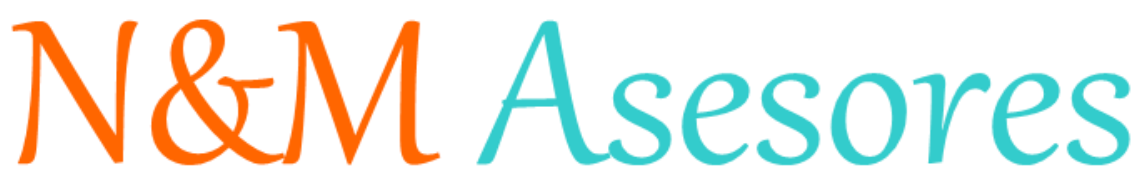

Figura 41. Logo del negocio.

Elaboración propia

Utilizamos estos colores: Naranja y Turquesa, ya que estos colores son vibrantes, atractivos a la vista y dinámicos. Características de la marca. Estos mismos colores los usaremos para toda nuestra decoración, folletería y comunicaciones.

\subsubsection{Estrategia de personas.}

Para el caso de los estudiantes, recibirán el servicio de personas capacitadas, y especializadas en recursos humanos como psicólogos, coachs. Los cuales deben manejar un lenguaje claro, fresco, empático y juvenil para poder llegar a los jóvenes.

En el caso de las empresas, tendrán más cercanía con los analistas de comerciales y de seguimiento y monitoreo, quienes deberán brinda un servicio de respuesta rápida, con datos precisos y comunicación asertiva. 
Cada puesto cuenta con requisitos básicos para poder asumirlo, así como una lista de funciones detallada, ubicación en el organigrama, deberes y derechos de cada trabajador.

Acciones para la estrategia de personas

- Capacitación inicial realizada por los directivos de la empresa donde se explica la cultura de la empresa y lineamientos generales.

- Reuniones semanales donde se evaluarán las acciones realizadas por cada área y se verán mejoras.

- Capacitación en servicio al cliente y ventas.

- Elaboración de un protocolo de atención con tiempos de respuesta.

\subsubsection{Estrategia de procesos.}

Se elaborarán procesos por cada servicio que se brinda y por cada público objetivo.

En el caso de los estudiantes, vía web, correo electrónico o de manera presencial, llenarán una ficha con sus datos personales actualizados, como su nombre completo, DNI, universidad de origen, carrera que estudian, ciclo cursado, dirección, correo, edad, área de interés. Además, adjuntarán su Currículum Vitae para poder armar su file personal 
Luego pasarán por las pruebas psicotécnicas y talleres, estos como un servicio adicional, y al final se les entregarán información sobre su situación.

Para las empresas, se realizará una ficha técnica donde se colocarán los datos principales de la empresa y del puesto requerido (misión, visión, valores, cultura organizacional) que servirá de una guía para la consultora. Además, luego de cada reunión realizada con la empresa se realizará un acta de cada una y se tendrá la conformidad de ambas partes.

Acciones para la estrategia de procesos

- Se realizará un manual de procesos, donde se detalle los flujogramas, el tiempo para cada uno, acciones de contingencia para cualquier caso.

- Manual de uso del logo o la empresa, en el cual se determinará dónde y cómo utilizarlo.

\subsubsection{Estrategia de precio}

Siendo un servicio, donde depende de muchos segmentos, se ha dispuesto elaborar los precios en función a los servicios especializados:

Tabla 27

Precios propuestos

\begin{tabular}{ll} 
& Precios \\
\hline Estudiantes & S/. 50.00 \\
Empresas & S/ 850.00
\end{tabular}

Nota. Elaboración propia 
Con respecto al precio de los estudiantes, es el costo que pagarían por los talleres adicionales que se realizan.

En el caso de las empresas, este es el costo que deberá cancelar por puesto de practicante pre-profesional.

Estos precios han salido de la investigación del mercado y teniendo en cuenta los diversos grupos objetivos a los que va dirigido el negocio. Sin embargo, manejaremos una estrategia de precios dinámicos, ya que estos podrían variar de la demanda, de la temporada y de paquetes empresariales.

\subsubsection{Estrategia de plaza.}

Este negocio busca tener oficinas descentralizadas, es decir que la consultora pueda acudir al lugar de preferencia. Además de tener oficinas semi virtuales, con el fin de tener una comunicación y conexión en cada momento con los interesados.

El distrito donde les gustaría que se ubique la consultora es San Isidro, debido que contiene elementos diferenciadores de ubicación, prestigio y seguridad.

En el caso de los estudiantes, la idea del negocio es tener inmediatez en las comunicaciones, dado que los jóvenes tienen un rápido acceso al internet. Por ende, se tendrá varios canales de comunicación además de la oficina, podrán comunicarse con nosotros vía correo electrónico, Facebook y WhatsApp. 
En el caso de las empresas, la consultora está dispuesta a movilizarse a las empresas para poder tener las reuniones de coordinación, así como, tener comunicación vía correo electrónico y teléfono.

\subsubsection{Estrategia de promoción.}

El medio por donde la consultora se comunicará y promocionará son las redes sociales (Facebook, Twitter y LinkedIn

En el caso de los jóvenes se realizará una mayor promoción en las siguientes plataformas:

- Facebook, mediante anuncios pagados y utilizando la segmentación que realiza esta red social.

- Instagram, es una de las redes más usadas de los jóvenes. Al ser más visual, se contará con una cuenta en esta plataforma, donde se publicarán imágenes y/o fotos motivando a los jóvenes a enviar sus CV y a participar en los talleres.

- Ferias laborales en las universidades, se buscarán hacer alianzas con las universidades para que estas nos inviten a sus ferias laborales con el fin de hacer conocida a la consultora, recabar data de los alumnos y motivar su participación en los talleres.

En el caso de las empresas se utilizará las siguientes plataformas para la promoción de la consultora. 
- Cartas de presentación a los responsables de las áreas de recursos humanos, con el fin de poder concretar una cita y así mostrarles nuestra oferta.

- Llamadas telefónicas, de recordación y reforzamiento a la carta de presentación.

- Avisos en el Linkedin, al ser esta una plataforma de búsqueda de empleo donde está nuestro mayor público objetivo que son las empresas que buscan practicantes, tendremos un perfil en esta red social donde haremos publicidad sobre nuestros servicios además de publicar noticias de interés.

- Envío de correo electrónico con información de nuestros servicios.

\subsubsection{Estrategia de Evidencia Física}

La consultora busca tener una uniformidad en el concepto, desde sus oficinas, folletos, color, etc.

Buscamos tener una oficina moderna, con áreas colaborativas, para facilitar el coworking, con una sala de reuniones adaptadas a nuestras necesidades.

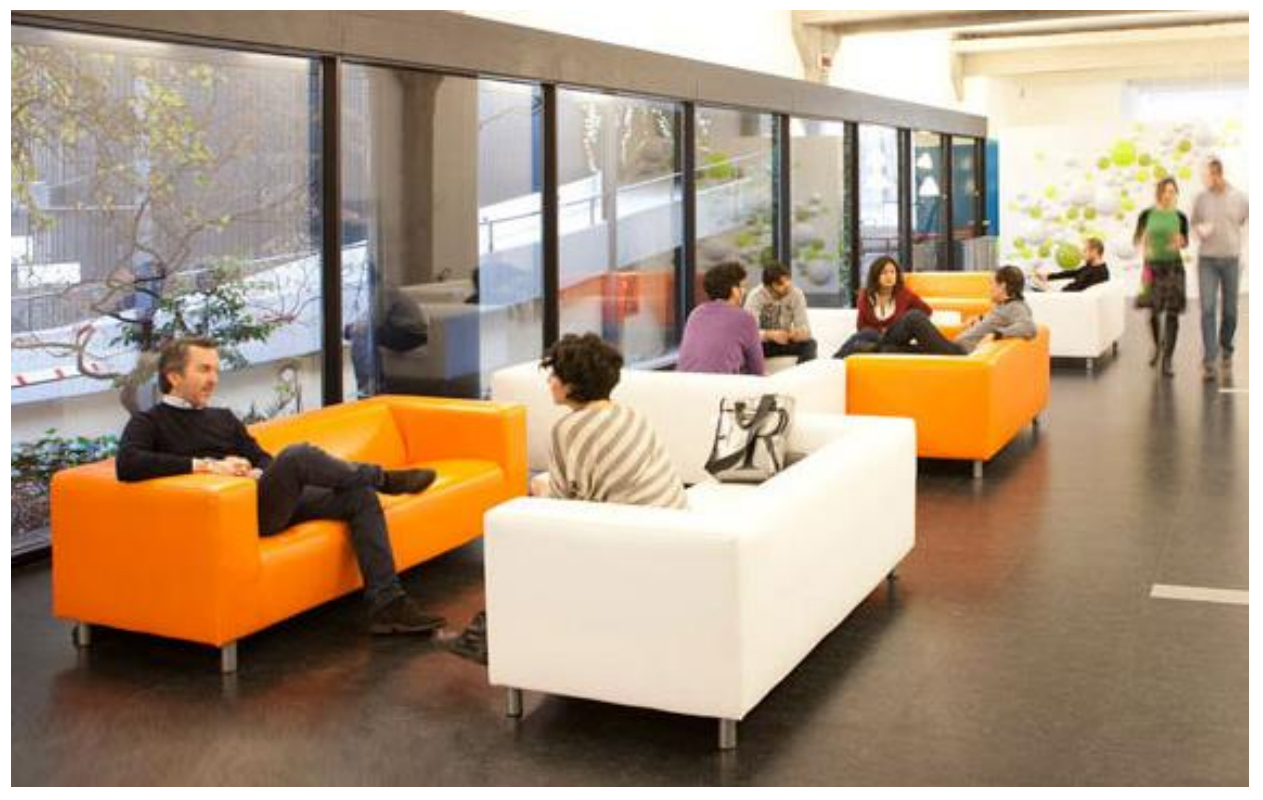




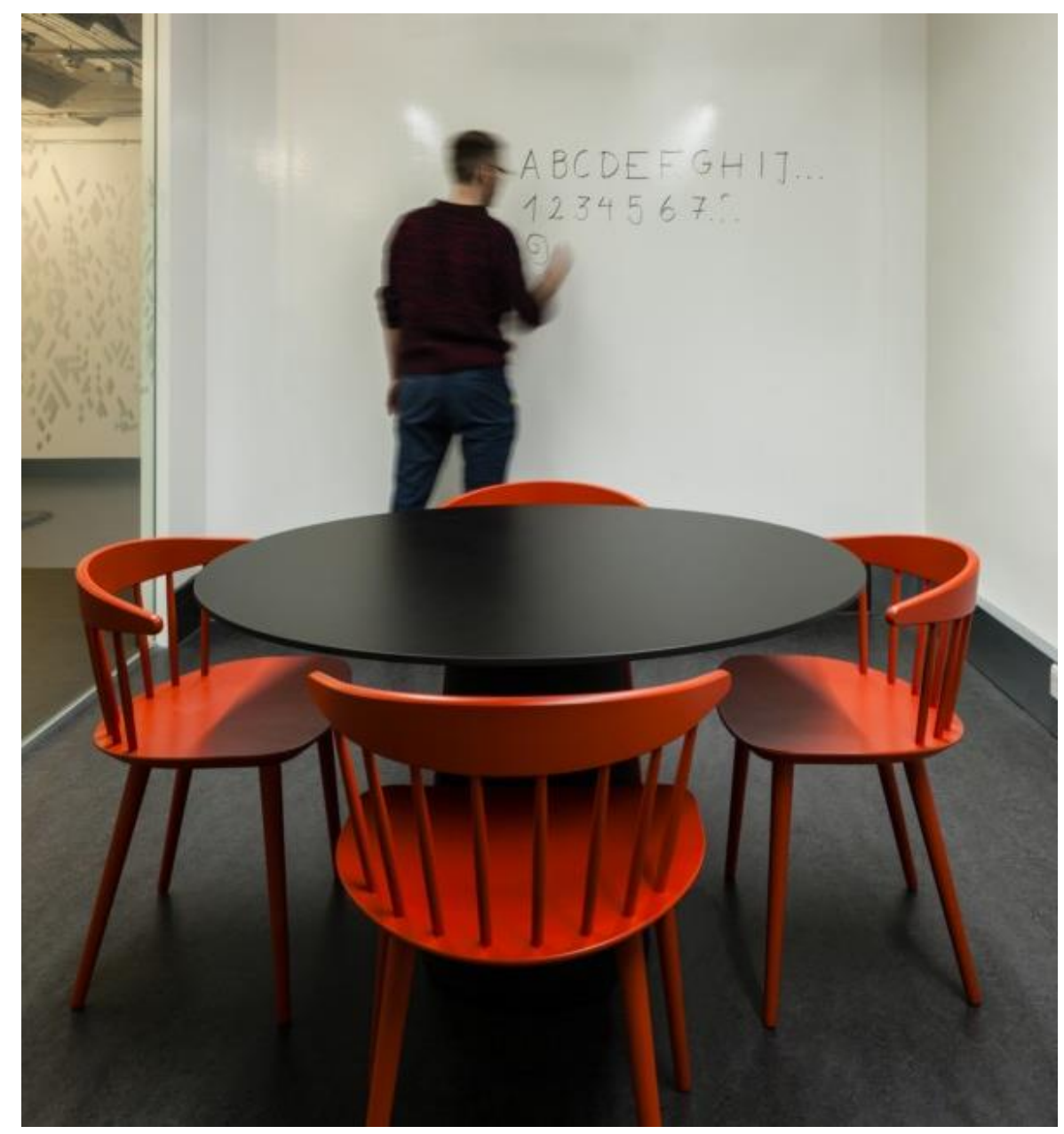

\subsection{Estrategia de ventas}

Las ventas deben realizarse usando estrategias segmentadas:

Para estudiantes. Campañas en ferias de estudiantes para orientación vocación, congresos de estudiantes y actividades relacionadas al reclutamiento de talento humano.

Para Empresas. Se realiza usando un sistema de llamadas telefónicas, usando base de datos del top 10,000 del latín panel (mejores empresas mejor cotizadas según SUNAT), de manera de emplear un sistema directo de venta, usando la estrategia de una cita comercial para explicar los beneficios del sistema de reclutamiento. 


\title{
7.4 Evaluación
}

\author{
Marketing y Ventas
}

Para reducir la probabilidad de riesgo o error, se establecen indicadores de control, con el objetivo de monitorear los resultados esperados de la empresa y tomar medidas rápidas para revertir los procesos.

Tabla 28

Seguimiento de indicadores de control

$\begin{array}{lll}\text { Área de Riesgo } & \text { Indicador } & \text { Frecuencia de Seguimiento }\end{array}$

Calidad de servicio Nivel de rotación de practicantes

Trimestral

Tiempos promedio de atención

Mensual

Rotación de empleados

Mensual

Marketing y ventas Tasa de crecimiento de facturación

Mensual

Ticket promedio por cliente

Mensual

Rentabilidad por segmento

Mensual

Nota. Elaboración propia

A continuación, se muestra las estrategias:

1 Evaluación de la cadena de valor por los precios promedios

2 Revisión de promociones para así de mejorar la relación con el cliente. 
3 Calidad de Servicio: por medio de encuestas (físicas, telefónicas, buzón de sugerencias)

4 Nivel de satisfacción de los clientes - empresas: por medio de encuestas (físicas, telefónicas, buzón de sugerencias)

Finalmente, la empresa debe tener planes de contingencia usando el valor agregado del servicio en la calidad de la base de datos, por ello es importante establecer socios comerciales como universidades para establecer la fortaleza en la renovación del talento humano. 


\section{Capítulo VIII. Planificación Financiera}

\subsection{La Inversión}

\subsubsection{Inversión Pre - Operativa (Tangible e Intangible).}

Para el desarrollo de este capítulo se ha considerado que la empresa es una Sociedad Anónima Cerrada (SAC) y el financiamiento es 100\% capital propio.

El análisis desarrollado en el presente capitulo destaca la viabilidad del proyecto.

La inversión del plan de negocios se encuentra en 86, 000 nuevos soles.

Tabla 29

Inversión

Inversión Monto $\quad \%$

$\begin{array}{lll}\text { Accionista } 1 & \text { S/. } 43,000.00 \quad 50 \%\end{array}$

Accionista 2

S/. 43,000.00

$50 \%$

Total

S/. 86,000.00

$100 \%$

Nota. Elaboración propia

El detalle de la tabla 30 corresponde a las inversiones realizada en activos tangibles al inicio de las operaciones, esta va a aumentar en el tiempo debido a la calidad de la base de datos, conocimiento en el sector y las especialidades de los practicantes. 
Tabla 30

Inversión activos tangibles

\section{Inversión en Activos Tangible}

\begin{tabular}{|c|c|c|c|}
\hline & Cantidad & V. Unitario & V. Total \\
\hline \multicolumn{4}{|l|}{ Equipos } \\
\hline Computadoras & 4 & S/. $1,999.00$ & S/. 7,996.00 \\
\hline Teléfono & 4 & S/. 249.00 & S/. 996.00 \\
\hline Total Equipos & & & S/. 8,992.00 \\
\hline \multicolumn{4}{|l|}{ Muebles } \\
\hline Escritorios & 4 & S/. 499.90 & S/. $1,999.60$ \\
\hline Sillas para escritorio & 4 & S/. 89.90 & S/. 359.60 \\
\hline Sillas fijas & 8 & S/. 59.90 & S/. 479.20 \\
\hline Archivador & 1 & S/. 159.90 & S/. 159.90 \\
\hline Juego de Muebles & 1 & S/. 999.00 & S/. 999.00 \\
\hline Extintor & 1 & S/. 69.90 & S/. 69.90 \\
\hline Total Muebles & & & $\mathrm{S} / .4,067.20$ \\
\hline Total de Activos Tangibles & & & $\mathrm{S} / . \mathbf{1 3 , 0 5 9 . 2 0}$ \\
\hline
\end{tabular}

Nota: Elaboración propia. 
En la tabla 31 se detalla los activos intangibles y gastos de constitución para el inicio de operaciones.

Tabla 31

Inversión en Activo intangibles

Inversión en Activos Intangibles

\begin{tabular}{lll}
\hline Cantidad & Unitario & V. Total
\end{tabular}

Licencia

Licencia Office

$1 \quad$ S/. 290.00

S/. 290.00

Total Equipos

S/. 290.00

Nota. Elaboración propia

Los gastos de constitución se realizan antes del inicio de las operaciones es considerada como la inversión pre operativa. El cuadro detalla que el gasto mayor es en el de remodelación de la oficina que fue seleccionada para alquilar, esto se debe a que tenía un diseño muy clásico debido a que anteriormente había sido un estudio contable y se vio en la necesidad de actualizar la presentación ya que nuestra propuesta está dirigida para un público diferente. 
Tabla 32

Gastos de Constitución

Gastos de Constitución

\begin{tabular}{|c|c|c|c|}
\hline Registro de marca (INDECOPI) & 1 & S/. 535.00 & S/. 535.00 \\
\hline Licencia de Funcionamiento & 1 & S/. 100.00 & S/. 100.00 \\
\hline Minuta & 1 & S/. 300.00 & S/. 300.00 \\
\hline Compra y legalización de libros contables & 1 & S/. 100.00 & S/. 100.00 \\
\hline Certificado de Defensa Civil & 1 & S/. 189.00 & S/. 189.00 \\
\hline Total de Gastos de Constitución & & & $\mathrm{S} / . \mathbf{1 , 2 2 4 . 0 0}$ \\
\hline \multicolumn{4}{|l|}{ Remodelación } \\
\hline Adecuación de Infraestructura & 1 & S/. 3,000.00 & $\mathrm{S} / .3,000.00$ \\
\hline Total de Remodelación & & & $\mathrm{S} / . \mathbf{3 , 0 0 0 . 0 0}$ \\
\hline Total de Activos Intangibles & & & $\mathrm{S} / . \mathbf{4 , 5 1 4 . 0 0}$ \\
\hline
\end{tabular}

Nota. Elaboración propia

\subsection{Inversión en capital de trabajo}

La siguiente tabla detalla la estructura de inversiones, siendo un $79.23 \%$ destinado para capital de trabajo. 
Tabla 33

Estructura de Inversiones

Estructura de inversiones

$\begin{array}{lcc}\text { Ítems } & \text { En soles } & \text { En Porcentaje } \\ \text { Activo Fijo } & \text { S/. 13,059.20 } & 15.19 \% \\ \text { Activo Intangible } & \text { S/. } 4,804.00 & 5.59 \% \\ \text { Capital de Trabajo } & \text { S/. 68,136.80 } & 79.23 \% \\ \text { Total Inversión inicial } & \text { S/. 86,000.00 } & 100.00 \%\end{array}$

Nota. Elaboración propia

\subsection{Financiamiento.}

Se ha previsto tener dos accionistas en el plan de negocios, y se considera financiamiento propio.

Tabla 34

Financiamiento

\begin{tabular}{llll}
\hline Ítems & En S/. & En Porcentaje \\
\hline Accionista 1 & S/. & 43,000 & $50.0 \%$ \\
Accionista 2 & S/. & 43,000 & $50.0 \%$ \\
& & & \\
Total & S/. & 86,000 & $100.0 \%$ \\
\hline
\end{tabular}

Nota. Elaboración propia 


\subsection{Presupuestos Base}

Los presupuestos detallados a continuación se encuentran proyectados a cinco años.

\subsubsection{Presupuesto de Gastos Administrativos.}

La tabla 35, muestra los costos que se generan por servicios con cargo al titular del departamento, debido a que se está detallado en el contrato nosotros en nuestra calidad de arrendatario asumimos el pago. 
Tabla 35

Presupuestos de Gastos Administrativos

Presupuesto de Gastos Administrativos

\begin{tabular}{|c|c|c|c|c|c|c|}
\hline & Mensual & Año1 & Año2 & Año3 & Año4 & Año5 \\
\hline Alquiler & S/. 2,026 & S/. 24,312.00 & S/. 24,312.00 & S/. 24,312.00 & S/. 24,312.00 & S/. $24,312.00$ \\
\hline Energía eléctrica & S/. 120 & S/. 1,440 & S/. 1,440 & S/. 1,440 & S/. 1,440 & S/. 1,440 \\
\hline Telefonía e internet & S/. 200 & $\mathrm{~S} / .2,400$ & S/. 2,400 & S/. 2,400 & $\mathrm{S} / .2,400$ & S/. 2,400 \\
\hline Agua & S/. 300 & S/. 3,600 & S/. 3,600 & S/. 3,600 & S/. 3,600 & S/. 3,600 \\
\hline Limpieza & S/. 850 & S/. 10,200.00 & S/. $10,200.00$ & S/. $10,200.00$ & S/. $10,200.00$ & S/. $10,200.00$ \\
\hline Seguridad & S/. 1,000 & $\mathrm{S} / .12,000.00$ & S/. 12,000.00 & $\mathrm{S} / .12,000.00$ & $\mathrm{~S} / .12,000.00$ & S/. $12,000.00$ \\
\hline $\begin{array}{l}\text { Mantenimiento (jardines, entre } \\
\text { otros) }\end{array}$ & S/. 850 & S/. $10,200.00$ & S/. $10,200.00$ & S/. $10,200.00$ & S/. $10,200.00$ & S/. $10,200.00$ \\
\hline Total de Gastos Administrativos & S/. 5,346 & S/. 64,152.00 & S/. $64,152.00$ & S/. $64,152.00$ & S/. $64,152.00$ & S/. $64,152.00$ \\
\hline
\end{tabular}

Nota. Elaboración propia 


\subsubsection{Presupuesto de Marketing y Ventas}

Los costos de materiales se diferencian entre el servicio ofrecido para los estudiantes y para las empresas.

Tabla 36

Presupuesto de Marketing y Ventas

Presupuesto de Marketing y Ventas

\begin{tabular}{|c|c|c|c|c|c|c|}
\hline Concepto & Costo (SOLES) & 2017 & 2018 & 2019 & 2020 & 2021 \\
\hline Estudiantes & 30 & 438,988.41 & $452,158.06$ & $465,722.80$ & $479,694.48$ & $494,085.32$ \\
\hline Merchandising & & $1,734.00$ & $1,734.00$ & $1,734.00$ & $1,734.00$ & $1,734.00$ \\
\hline Gastos de Venta & & $437,254.41$ & $450,424.06$ & $463,988.80$ & $477,960.48$ & $492,351.32$ \\
\hline Empresas & 450 & $35,535.72$ & $36,601.80$ & $37,699.85$ & $38,830.84$ & $39,995.77$ \\
\hline Tarjetas de presentación & & 700 & 700 & 700 & 700 & 700 \\
\hline Documentación corporativa & & 960 & 960 & 960 & 960 & 960 \\
\hline Merchandising & & 13770 & 13770 & 13770 & 13770 & 13770 \\
\hline Gasto de Ventas & & $20,105.72$ & $21,171.80$ & $22,269.85$ & $23,400.84$ & $24,565.77$ \\
\hline $\begin{array}{l}\text { Total de Presupuesto de Mar } \\
\text { Ventas }\end{array}$ & & $474,524.13$ & $488,759.85$ & $503,422.65$ & $\mathbf{5 1 8 , 5 2 5 . 3 3}$ & $534,081.09$ \\
\hline
\end{tabular}




\subsubsection{Presupuesto de Sueldos.}

El detalle de los gastos de personal se encuentra las planillas totales de la empresa la cual está constituida por cuatro personas, todas con sueldos mensuales acorde a su perfil y a los ofrecidos en el mercado. En la fila de sueldos mensuales se considera los catorce sueldos exigidos por ley.

Tabla 37

Presupuesto de Sueldos

Presupuesto de Sueldos

\begin{tabular}{|c|c|c|c|c|c|c|}
\hline Cargos & Mensual & Año 1 & Año 2 & Año 3 & Año 4 & Año 5 \\
\hline Gerente general & S/. 4,500 & S/. 63,000 & S/. 63,000 & S/. 63,000 & S/. 63,000 & S/. 63,000 \\
\hline $\begin{array}{l}\text { Analista de evaluación y desarrollo de } \\
\text { proyectos }\end{array}$ & $\mathrm{S} / .3,000$ & $\mathrm{~S} / .42,000$ & S/. 42,000 & S/. 42,000 & $\mathrm{~S} / .42,000$ & S/. 42,000 \\
\hline Analista de seguimiento y monitoreo & $\mathrm{S} / .2,500$ & S/. 35,000 & S/. 35,000 & $\mathrm{~S} / .35,000$ & S/. 35,000 & S/. 35,000 \\
\hline Analista comercial & $\mathrm{S} / .2,500$ & $\mathrm{~S} / .35,000$ & $\mathrm{~S} / .35,000$ & $\mathrm{~S} / .35,000$ & $\mathrm{~S} / .35,000$ & S/. 35,000 \\
\hline Total & S/. 12,500 & S/. 175,000 & S/. 175,000 & S/. 175,000 & S/. 175,000 & S/. 175,000 \\
\hline
\end{tabular}

Nota. Elaboración propia 


\subsubsection{Presupuesto de Depreciación}

En la siguiente tabla se detalla la depreciación de los activos de la empresa

Tabla 38

Depreciación

\begin{tabular}{|c|c|c|c|c|c|c|c|}
\hline \multicolumn{8}{|c|}{ Depreciación } \\
\hline & $\begin{array}{c}\text { Porcentaje } \\
\text { de } \\
\text { Depreciación }\end{array}$ & V. Total & Año1 & Año2 & Año3 & Año4 & Año5 \\
\hline \multicolumn{8}{|l|}{ Equipos } \\
\hline Computadoras & $10.00 \%$ & S/. 7,996.00 & S/. 799.60 & S/. 799.60 & S/. 799.60 & S/. 799.60 & S/.799.60 \\
\hline Teléfono & $10.00 \%$ & S/. 996.00 & S/. 99.60 & S/. 99.60 & S/. 99.60 & S/. 99.60 & S/. 99.60 \\
\hline Total Equipos & & & S/. 899.20 & S/. 899.20 & S/. 899.20 & S/. 899.20 & S/. 899.20 \\
\hline \multicolumn{8}{|l|}{ Muebles } \\
\hline Escritorios & $25.00 \%$ & S/. 1,999.60 & S/. 499.90 & S/. 499.90 & S/. 499.90 & S/. 499.90 & S/. 499.90 \\
\hline Sillas para escritorio & $25.00 \%$ & S/. 359.60 & S/. 89.90 & S/. 89.90 & S/. 89.90 & S/. 89.90 & S/. 89.90 \\
\hline Sillas fijas & $25.00 \%$ & S/. 479.20 & S/. 119.80 & S/. 119.80 & S/. 119.80 & S/. 119.80 & S/. 119.80 \\
\hline Archivador & $25.00 \%$ & S/. 159.90 & S/. 39.98 & S/. 39.98 & S/. 39.98 & S/. 39.98 & S/. 39.98 \\
\hline Juego de Muebles & $25.00 \%$ & S/. 999.00 & S/. 249.75 & S/. 249.75 & S/. 249.75 & S/. 249.75 & S/. 249.75 \\
\hline Extintor & $25.00 \%$ & S/. 69.90 & S/. 17.48 & S/. 17.48 & S/. 17.48 & S/. 17.48 & S/. 17.48 \\
\hline Total Muebles & & & S/. 1,016.80 & S/. $1,016.80$ & S/. $1,016.80$ & $\mathrm{~S} / .1,016.80$ & S/. $1,016.80$ \\
\hline Total de Activos Tangibles & & & S/. 1,916.00 & $\mathrm{S} / . \quad 1,916.00$ & S/. 1,916.00 & S/. $1,916.00$ & S/. $1,916.00$ \\
\hline
\end{tabular}

Nota: Elaboración propia. 


\subsubsection{Balance General}

Al inicio de las operaciones Año 0 todavía no registran obligaciones y al ser

financiamiento propio no cuenta con obligaciones financieras.

Tabla 39

Balance General (Inicio de Operaciones)

\begin{tabular}{|l|l|}
\hline ACTIVO & \\
\hline ACTIVO CORRIENTE & \\
\hline Caja y Bancos & 72650.80 \\
\hline Cuentas por Cobrar Comerciales & \\
\hline Cuentas por Cobrar a Vinculadas & \\
\hline Otras Cuentas por Cobrar & \\
\hline Existencias & \\
\hline Gastos Pagados por Anticipado & 72650.80 \\
\hline \multicolumn{1}{|c|}{ TOTAL ACTIVO CORRIENTE } & \\
\hline ACTIVO NO CORRIENTE & \\
\hline Cuentas por Cobrar a Largo Plazo & 290.00 \\
\hline Intangible ACTIVO NO CORRIENTE & 13349.20 \\
\hline Mueble & 4067.20 \\
\hline Inmuebles, Maquinaria y Equipo & \\
\hline & \\
\hline & \\
\hline & \\
\hline & \\
\hline & \\
\hline & \\
\hline & \\
\hline & \\
\hline
\end{tabular}

\begin{tabular}{|c|c|}
\hline PASIVO Y PATRIMONIO & \\
\hline PASIVO CORRIENTE & \\
\hline Sobregiros y Pagarés Bancarios & \\
\hline Cuentas por Pagar a Vinculadas & \\
\hline Otras Cuentas por Pagar & \\
\hline Parte Corriente de las Deudas a Largo Plazo & \\
\hline TOTAL PASIVO CORRIENTE & \\
\hline PASIVO NO CORRIENTE & \\
\hline Deudas a Largo Plazo & \\
\hline Cuentas por Pagar a Vinculadas & \\
\hline Ingresos Diferidos & \\
\hline TOTAL PASIVO NO CORRIENTE & \\
\hline TOTAL PASIVO & \\
\hline PATRIMONIO NETO & \\
\hline Capital & 86000.00 \\
\hline Capital Adicional & \\
\hline Reservas Legales & \\
\hline Otras Reservas & \\
\hline Resultados Acumulados & \\
\hline TOTAL PATRIMONIO NETO & 86000.00 \\
\hline TC & 86000.00 \\
\hline
\end{tabular}

Nota. Elaboración propia 


\subsubsection{Estado de Ganancias y Pérdidas}

El estado de Ganancias y Pérdidas se encuentra proyectado de operaciones tomando en cuenta que estamos colocando el servicio al $100 \%$ del mercado objetivo y con un crecimiento del $3 \%$ constante.

Tabla 40

Estado de Ganancias y Pérdidas

2017

2018

2019

Ventas Netas (ingresos operacionales)

Costo de ventas

Bruta

\section{Gastos Operacionales}

Gastos de Administración

Gastos de Venta

Depreciacion

Utilidad Operativa

Resultados antes de Participaciones,

Impuesto a la Renta y Partidas

Extraordinarias

Impuesto a la Renta

Utilidad (Pérdida) Neta del Ejercicio

Utilidad

$\begin{array}{ccccc}\text { S/. 798,770 } & \text { S/. 822,733 } & \text { S/. 847,415 } & \text { S/. 872,838 } & \text { S/. 899,023 } \\ \text { S/. 474,524.13 } & \text { S/. 488,759.85 } & \text { S/. 503,422.65 } & \text { S/. 518,525.33 } & \text { S/. 534,081.09 } \\ \text { S/. 324,246.25 } & \text { S/. 333,973.63 } & \text { S/. 343,992.84 } & \text { S/. 354,312.63 } & \text { S/. 364,942.01 }\end{array}$

S/. $175,000.00$

S/. $64,152.00$

S/. $1,916.00$

S/. 83, 178.25

S/. 175,000.00

S/. 64, 152.00

S/. $1,916.00$

S/. 92,905.63

S/. $175,000.00$

S/. $64,152.00$

S/. $1,916.00$

S/. $102,924.84$

S/. 24,953.47

S/. 58, 224.77
S/. $27,871.69$
S/. $65,033.94$

S/. $30,877.45$

S/. 37, 162.20 S/. $72,047.39$
S/. 33,973.39

S/. 175,000.00

S/. 64,152.00

S/. $1,916.00$

S/. 113,244.63

S/. 79,271.24
S/. $175,000.00$

S/. 64, 152.00

S/. $1,916.00$

S/. 123,874.01

Nota. Elaboración propia 


\section{Capítulo IX. Evaluación Económica Financiera}

\subsection{Evaluación Financiera}

\subsubsection{Desarrollo de Escenarios.}

Se consideró como factor de crecimiento al PBI para el análisis de los escenarios.

\subsubsection{Escenario optimista.}

En este escenario se tomó el PBI al 6.3\% uno de los más altas de los últimos siete años.

El crecimiento en el índice de ventas es significativo en ambos perfiles de cliente.

Ventas proyectadas en un crecimiento permanente de cinco años.

Tabla 41

Escenario Optimista

Ingresos

2017

2018

2019

2020

2021

$\begin{array}{llllll}\text { Estudiantes } & \text { S/. 755,088 } & \text { S/. 802,659 } & \text { S/. 853,227 } & \text { S/. 906,980 } & \text { S/. 964,120 }\end{array}$

$\begin{array}{llllll}\text { Empresas } & \text { S/. 69,274 } & \text { S/. 73,638 } & \text { S/. 78,277 } & \text { S/. 83,208 } & \text { S/. 85,705 }\end{array}$

TOTAL VENTAS

S/. 824,362

S/. 876,297

S/. 931,504

S/. 990,188

S/. 1,049,824

Nota: Elaboración propia. 


\subsubsection{Escenario normal}

En los últimos años se mostró al cierre de los últimos años un crecimiento no menor al 3\% por ello se toma para el análisis del escenario normal este porcentaje.

Tabla 42

Escenario Normal

\begin{tabular}{cccccc} 
Ingresos & 2017 & 2018 & 2019 & 2020 & 2021 \\
\hline Estudiantes & S/. 731,647 & S/. 753,597 & S/. 776,205 & S/. 799,491 & S/. 823,476 \\
Empresas & S/. $67,123.03$ & S/. 69,136.72 & S/. 71,210.83 & S/. 73,347.15 & S/. 75,547.57 \\
TOTAL & S/. 798,770 & S/. 822,733 & S/. 847,415 & S/. 872,838 & S/. 899,023 \\
VENTAS & & & & & \\
\hline
\end{tabular}

Nota. Elaboración propia

\subsubsection{Escenario Pesimista}

Debido a los acontecimientos recientes ocasionados por el Niño Costero se ha proyectado el menor crecimiento del país al 2.4\% según Maximize.

Tabla 43

Escenario Pesimista

\begin{tabular}{lccccc}
\multicolumn{1}{c}{ Ingresos } & 2017 & 2018 & 2019 & 2020 & 2021 \\
\hline Estudiantes & S/. 727,385 & S/. 744,843 & S/. 762,719 & S/. 781,024 & S/. 799,769 \\
Empresas & S/. 66,732 & S/. 68,334 & S/. 69,974 & S/. 71,653 & S/. 73,373 \\
TOTAL VENTAS & S/.794,117 & S/.813,176 & S/. 832,692 & S/. 852,677 & S/. 873,141 \\
\hline
\end{tabular}

Nota: Elaboración propia. 


\subsubsection{Flujo de Caja Económico}

El flujo de económico presentado corresponde al siguiente cuadro, tener en consideración que no tenemos financiamiento externo.

Tabla 44

Flujo de caja económico en soles acumulado

\begin{tabular}{|c|c|c|c|c|c|c|c|c|c|}
\hline \multicolumn{10}{|c|}{ Flujo de Caja } \\
\hline Items & Año 0 & \multirow{2}{*}{\multicolumn{2}{|c|}{$\begin{array}{c}\text { Año } 1 \\
-72650.80\end{array}$}} & & Año 2 & \multirow{2}{*}{\multicolumn{2}{|c|}{$\frac{\text { Año } 3}{55732}$}} & Año 4 & \multirow{2}{*}{$\frac{\text { Año } 5}{212254}$} \\
\hline Caja Inicial & -72650.80 & & & $\mathrm{~S} /$. & $-11,873$ & & & 130371 & \\
\hline Ingresos & & $\mathrm{S} /$. & 798,770 & $\mathrm{~S} /$. & 822,733 & $\mathrm{~S} /$. & 847,415 & 872,838 & 899,023 \\
\hline $\begin{array}{l}\text { Total de } \\
\text { Ingresos }\end{array}$ & & S/. & $726,119.58$ & $\mathrm{~S} /$. & $810,860.19$ & $\mathrm{~S} /$. & $903,147.96$ & S/. 1,003,209.32 & S/. 1,111,277.47 \\
\hline EGRESOS & & & & & & & & & \\
\hline $\begin{array}{l}\text { Gastos de } \\
\text { Ventas }\end{array}$ & & $\mathrm{S} /$. & $474,524.13$ & $\mathrm{~S} /$. & $488,759.85$ & $\mathrm{~S} /$. & $503,422.65$ & S/. $\quad 518,525.33$ & S/. $\quad 534,081.09$ \\
\hline $\begin{array}{l}\text { Gastos } \\
\text { Administrat } \\
\text { vos }\end{array}$ & & & $64,152.00$ & S/. & $64,152.00$ & S/. & $64,152.00$ & $64,152.00$ & $64,152.00$ \\
\hline $\begin{array}{l}\text { Gastos de } \\
\text { Personal }\end{array}$ & & S/. & $175,000.00$ & $\mathrm{~S} /$. & $175,000.00$ & $\mathrm{~S} /$. & $175,000.00$ & S/. $\quad 175,000.00$ & S/. $\quad 175,000.00$ \\
\hline $\begin{array}{l}\text { Total } \\
\text { Egresos }\end{array}$ & & $\mathrm{S} /$. & 713,676 & $\mathrm{~S} /$. & 727,912 & $\mathrm{~S} /$. & 742,575 & 757,677 & 773,233 \\
\hline Impuesto & & S/. & $24,953.47$ & $\mathrm{~S} /$. & $27,871.69$ & S/. & $30,877.45$ & S/. $\quad 33,973.39$ & S/. $\quad 37,162.20$ \\
\hline $\begin{array}{l}\text { Flujo de } \\
\text { Caja } \\
\text { Operativo }\end{array}$ & -72650.80 & $\mathrm{~S} / \mathrm{.}$ & 60,141 & $\mathrm{~S} / \mathrm{s}$ & 66,950 & $\mathrm{~S} /$. & 73,963 & 81,187 & 88,628 \\
\hline $\begin{array}{l}\text { Flujo de } \\
\text { Caja } \\
\text { Economico } \\
\text { Acumulado }\end{array}$ & S/. $-72,650.80$ & $\mathrm{~S} /$. & $-12,510.03$ & $\mathrm{~S} /$. & $55,076.64$ & $\mathrm{~S} /$. & $129,695.86$ & S/. $\quad 211,558.60$ & S/. $\quad 300,882.18$ \\
\hline
\end{tabular}

Nota: Elaboración propia.

Tenemos una inversión de S/ 86000.00 el cual será recuperado 2 años y tres meses. 


\subsubsection{Análisis de Sensibilidad}

Según los indicadores financieros se puede observar que el VAN se encuentra por encima de la inversión inicial, por lo tanto, se puede decir que existe viabilidad para el plan de negocios. La tasa de descuento han sido tomadas como referencia de trabajos de investigación similares al nuestro, de manera adicional en la entrevista a profundidad se solicitó dicha información.

La información disponible en el mercado de consultoras no precisa una tasa de descuento. La tasa interna de retorno (TIR) nos revalida la rentabilidad de la inversión.

Tabla 45

Indicadores financieros

\begin{tabular}{|c|c|c|c|}
\hline \multirow{2}{*}{$\begin{array}{l}\text { TASA DE } \\
\text { DSCTO } \\
25 \%\end{array}$} & \multicolumn{2}{|c|}{$\boldsymbol{V A N}$} & $T I R$ \\
\hline & S/. & $172,080.72$ & \\
\hline $30 \%$ & S/. & $156,787.55$ & $88 \%$ \\
\hline $35 \%$ & S/. & $143,552.31$ & \\
\hline $40 \%$ & S/. & $132,034.31$ & \\
\hline
\end{tabular}

Nota: Elaboración propia.

Tabla 46

Análisis de Costo de Oportunidad (COK)

$$
\mathrm{CAPM}=\mathrm{Rf}+\text { Beta } *(\text { Prima de Riesgo })+\text { Riesgo País }
$$

\section{Rf (Rendimiento de Bono Peruano 30 Años) $\quad 6.415 \%$}


$\begin{array}{ll}\text { Riesgo País } & 1.39 \%\end{array}$

Beta $1.19 \%$

$\begin{array}{ll}\text { Prima de Riesgo } & 7.795 \%\end{array}$

Nota: Elaboración propia.

El resultado del desarrollo del ejercicio de costo de oportunidad nos indica que como mínimo el proyecto debe rendir $15.86 \%$

\subsection{Análisis de Riesgo}

Los cambios o la posible inestabilidad en la economía peruana, hace que muchos inversionistas tanto nacionales como internacionales cancelen o retrasen las proyecciones ante eventuales cambios no planificados, por ello es importante analizar posibles riesgos y desarrollar planes de contingencia, que permitan trabajar de manera inmediata sobre sus causas, con el fin de evitar riesgos y pérdidas económicas.

\section{Riesgos en Ventas / Colocaciones:}

El diseño de negocio define en:

- Servicio no atractivo: baja cantidad de clientes potenciales.

- Estrategia de marketing y venta no efectiva

- Estrategia de precio (estrategia descremada) por encima del promedio.

\section{Riesgo en la Calidad del Servicio:}

El diseño de negocio define en: 
- Falta de valor agregado en el sistema de reclutamiento de talento humano.

- Fallas en la plataforma informática. 


\section{Capítulo X. Conclusiones y Recomendaciones}

\section{Conclusiones}

La implementación de una consultora en el rubro de Recursos Humanos se considera altamente rentable, mediante el desarrollo del presente plan de negocios definimos como principal cliente a las empresas debido a la rentabilidad que la colocación del servicio representa y como cliente secundario a los estudiantes interesados en el desarrollo de habilidades personales.

A corto plazo no podemos aspirar a ser líderes del mercado de consultoría de recursos humanos, debido a que tenemos dos competidores (Manpower y Adecco) muy bien posicionados, con una larga experiencia en el sector, pero si dentro de nuestros objetivos se encuentra ser reconocidos como parte del rubro por nuestro trabajo, compromiso y calidad en el servicio.

El modelo de negocio desarrollado es fuerte potencial en el futuro de ofrecer otras líneas de servicios condicionados al crecimiento de la cartera de cliente que mantengamos vigente.

Finalmente, la parte económica desarrolla el sustento de rentabilidad que nos brinda poner en práctica nuestro plan de negocios. 


\section{Recomendaciones}

Como emprendedoras que nos consideramos, la consultora una vez implementada y posicionada dentro del mercado se encuentra la posibilidad de crecer ofreciendo otros servicios como colocación de trabajadores de mandos bajos y medios.

Se recomienda utilizar a las universidades como socios estratégicos debido al acceso a los estudiantes que estas representan.

Dentro de nuestras metas a largo plazo se encuentra la compra de un software que pueda administrar la base de datos de nuestros clientes con herramientas de seguridad que pueda mantener a salvo esta información valiosa.

En un futuro se recomienda implementar un sistema de bonos para nuestros trabajadores que cierren contratos con nuevos clientes y así superar nuestra meta de colocación anual. 


\section{Bibliografía}

Alles, M. A. (2015). Dirección estratégica de Recursos Humanos: gestión por competencias. Buenos Aires, República de Argentina: Ediciones Granica S.A.

Apolinar E. García. (2013). Estrategias Empresariales. Una visión holística. Bogotá, Colombia: Bilineata Publishing.

Baanante, M. J., \& Alcázar, B. S. (2014). Crecimiento y segmentación del empleo en el Perú, 2001 -2011. Lima: GRADE.

Banco Mundial (2006) Informe sobre el desarrollo mundial, 2007 El desarrollo y la próxima generación: Panorama general. Washington

David, F. R. (2003). Conceptos de administración estratégica. México: Pearson Educación.

Diagnóstico de la formación profesional en el Perú: aprobado por el Consejo Nacional de Trabajo y Promoción Social. (2001). Lima: Consejo Nacional del Trabajo y Promoción Social, Comisión de Formación Profesional y Capacitación para el Trabajo.

Diestra M.M.A, Espinoza, D.L (2012) Talent Development Consulting Consultora de Recursos Humanos. Tesis PUCP

Gonzales S, D.M (2007). Plan de negocios para emprendedores al éxito: metodología para el desarrollo de nuevos negocios. México: McGraw-Hill Interamericana.

INEI. (2015). Características Económicas y Financieras de las Empresas Comerciales en el Perú. Lima, Perú: INEI. 
Llarull, Graciela, Rovira, Silvia, Gómez, Florencia, Berger, Valeria (2015). Aporte de las Prácticas Pre-Profesionales a la Formación de Alumnos Universitarios en Prácticas Extensionistas- /Grupo De Extensión G.I.E.S Facultad De Psicología De La Universidad Nacional De Mar Del Plata Argentina

Manpower (2015). Estudio Manpower Group sobre escasez de talento $201510^{\circ}$ edición

Planas-Coll, J., \& Enciso-Ávila, I. (2014). Los estudiantes que trabajan: ¿tiene valor profesional el trabajo durante los estudios? del "Plan Nacional de investigación científica, desarrollo e innovación tecnológica” (cso2010-19271) financiado por el Ministerio de Ciencia e Innovación español. Revista Iberoamericana de Educación Superior, 5(12), 2345. doi:10.1016/s2007-2872(14)71941-9

Rodríguez, A. E. (2014). Las prácticas profesionales y las pasantías desde la legislación comparada*. Revista Latinoamericana de Derecho Social, 19, 111-132. doi:10.1016/s1870-4670(14)70666-9

Seminario, B., Sanborn, C., \& Alva, N. (2013). Cuando despertemos en el 2062: visiones del Perú en 50 años. Lima, Perú: Universidad del Pacifico. 


\title{
Anexos
}

\section{ANEXO 1: Ficha de Focus Group}

\author{
Introducción:
}

Buenos días /tardes, mi nombre es y en esta oportunidad estamos acá para conversar un poco sobre las prácticas pre profesionales. Esta es una conversación relajada y casual, así que les pido que sean honestos y digan la verdad, recuerden que no existen preguntas correctas ni incorrectas.

1. Prácticas pre profesionales

- Importancia

- Planificación de búsqueda en los próximos meses

- $\quad$ Práctica pre profesional ideal

- Porqué realizó prácticas pre profesionales.

2. Hábitos y necesidad de los alumnos en la búsqueda de prácticas

- Frecuencia de búsqueda

- A partir de qué ciclo inician la búsqueda

- Formas de búsqueda, medios consultados

- Condiciones de búsqueda 
- Razones de búsqueda

- Ventajas y desventajas de cada medio de búsqueda

- Roles: Búsqueda, influencia, decisión

- $\quad$ Tiempo de búsqueda

3. Prácticas y consultoras

- Uso de consultoras

- Nivel de conocimiento sobre consultoras de colocación de trabajo

- Consultora considerada la mejor. Razones

- Consultora rechazada. Razones

- Medios de información por lo que se informan de las consultoras

- Beneficios de ofrecen las consultoras a las empresas

4. Prueba de concepto

A continuación, les voy a leer una serie de atributos que se encuentran alineados a una consultora de recursos humanos, me gustaría saber su apreciación acerca de estas:

“El servicio propuesto es una consultora para que los alumnos universitarios de últimos ciclos accedan a prácticas pre profesionales. La consultora evalúa la orientación vocacional, habilidades internas- externas y monitorea la colocación de los alumnos, además ofrece a los universitarios talleres como liderazgo, motivación, plan de vida así 
capacita en la correcta presentación del currículo vitae y la entrevista personal-

comunicación con jefes".

- Nivel de necesidad

- Experiencia previa en servicios de implacement

- Conocimiento del servicio de implacement

5. Consultora ideal

- Beneficios esperados del servicio

- Monto a pagar por el servicio

- Lugar ideal

- Medio real vs. ideal

- Tono de mensaje

- Promociones esperadas

6. Intención

- De recomendación

- De inscripción 


\section{ANEXO 2: Encuesta para alumnos}

Información general:

Entrevistado (a):

Edad:

Sexo: Femenino ::: Masculino 2 :::

1. Universidad de procedencia

2. Ciclo que está cursando actualmente

3. ¿Qué tan importante considera realizar prácticas pre-profesionales?
a. No es importante
b. Poco importante
c. Medianamente importante
d. Importante
e. Muy importante

4. ¿Ha realizado o se encuentra realizando prácticas pre- profesionales?
a. $\quad \mathrm{Si}$
b. No (Pasar a la pregunta 6)

5. ¿Por qué realizó prácticas pre - profesionales?
a. Ingresos económicos.
b. Experiencia
c. Exigencia de malla curricular.
d. Otros 
6. ¿Por cuál medio realiza la búsqueda de prácticas pre- profesionales?
a. Página web de la universidad
b. Página web de empresas
c. Periódico
d. Otros

7. ¿Con qué frecuencia busca las practicas pre - profesionales?
a. Cada mes
b. Cada ciclo
c. Cada semana
d. Otro

8. ¿Alguna vez ha utilizado una consultora para acceder a un proceso de selección?
a. $\quad \mathrm{Si}$
b. No (Pasar a la pregunta 10)

9. Si ha utilizado los servicios de una consultora ¿Cómo califica su experiencia?
a. Mala
b. Regular
c. Buena
d. Muy buena
e. Excelente 
10 Prueba de concepto. A continuación, le voy a leer una serie de atributos que se encuentran alineadas a una consultora de recursos humanos, me gustaría saber su apreciación acerca de estas:

“El servicio propuesto es una consultora para que los alumnos universitarios de últimos ciclos accedan a prácticas pre profesionales. La consultora evalúa la orientación vocacional, habilidades internas- externas y monitorea la colocación de los alumnos, además ofrece a los universitarios talleres como liderazgo, motivación, plan de vida así capacita en la correcta presentación del currículo vitae y la entrevista personalcomunicación con jefes”.

11 Usando los atributos. ¿Cuál sería el nivel de probabilidad de adquirir los servicios de la consultora en recursos humanos?
a. Nada probable
b. Poco probable
c. Ni nada ni mucho probable
d. Probable
e. Muy probable

12 ¿Cuál es el precio que estaría dispuesto a pagar por la asesoría y los talleres ofrecidos por la consultora?
a. Menos de 50 nuevos soles.
b. Entre 50 a 100 nuevos soles.
c. Entre 101 a 200 nuevos.
d. Entre 201 a 300 nuevos soles 
e. Entre 201 a 300 nuevos soles

13 ¿En qué distrito le gustaría que este ubicado las oficinas de la consultora?
a. San Isidro
b. Miraflores
c. Surco
d. San Borja
e. Centro de Lima

14 ¿Por qué medio le gustaría tener información de la consultora?
a. Tv (Señal abierta y cerrada)
b. Radio
c. Facebook - LinkedIn/ Redes sociales
d. Correo electrónico
e. Revistas sociales - especializadas

15 ¿Qué tipo de presentación le gustaría tener de la empresa consultora?
a. Oficinas físicas
b. Oficinas virtuales (plataformas virtuales).
c. Oficinas a través de central de llamadas.
d. Oficinas descentralizadas (acudir al centro laboral para atender su requerimiento).

16 ¿Qué tipo de servicio estaría dispuesto a comprar?
a. Talleres de desarrollo de habilidades gerenciales.
b. Asesoría en orientación vocacional.
c. Otros. 


\section{ANEXO 3: Encuesta para empresas}

Información general:

Entrevistado (a):

Edad: años

Sexo: Femenino ::: Masculino 2 :::

1. Empresa de procedencia

2. Área en que labora

3. Cargo

4. ¿En su empresa se contratan practicantes pre - profesionales?
a. $\quad \mathrm{Si}$
b. No (Fin de la encuesta)

5. ¿Cuántos practicantes contratan al año en su empresa?
a. Entre 1 a 10
b. Entre 11 a 30
c. Entre 31 a 50
d. Más de 51

6. ¿Con qué frecuencia al año contratan practicantes?
a. Bimestral
b. Trimestral
c. Semestral
d. Anual 
7. ¿Por cuál medio realiza la búsqueda de practicantes pre- profesionales?
a. Contacto con universidad
b. Consultoras
c. Páginas web
d. Anuncios en el periódico
e. Otros

8. ¿Alguna vez ha utilizado una consultora para acceder a un proceso de selección?
a. $\quad \mathrm{Si}$
b. No (Pasar a la pregunta 10)

9. Si ha utilizado los servicios de una consultora ¿Cómo califica su experiencia?
a. Mala
b. Regular
c. Buena
d. Muy buena
e. Excelente

10. Prueba de concepto. A continuación, le voy a leer una serie de atributos que se encuentran alineadas a una consultora de recursos humanos, me gustaría saber su apreciación acerca de estas:

“El servicio propuesto es una consultora para que los alumnos universitarios de últimos ciclos accedan a prácticas pre profesionales. La consultora evalúa la orientación 
vocacional, habilidades internas- externas y monitorea la colocación de los alumnos, además ofrece a los universitarios talleres como liderazgo, motivación, plan de vida así capacita en la correcta presentación del currículo vitae y la entrevista personalcomunicación con jefes".

Usando los atributos. ¿Cuál sería el nivel de probabilidad de adquirir los servicios de la consultora en recursos humanos?
f. Nada probable
g. Poco probable
h. Ni nada ni mucho probable
i. Probable
j. Muy probable

11. ¿Cuál es el precio que estaría dispuesto a pagar por los servicios ofrecidos por la consultora?
a. Menos de 50 nuevos soles.
b. Entre 50 a 100 nuevos soles.
c. Entre 101 a 200 nuevos.
d. Entre 201 a 300 nuevos soles
e. $\quad$ Entre 201 a 300 nuevos soles

12. ¿En qué distrito le gustaría que este ubicado las oficinas de la consultora?
a. San Isidro
b. Miraflores
c. Surco
d. San Borja 
e. Centro de Lima

13. ¿Por qué medio le gustaría tener información de la consultora?
a. $\quad \operatorname{Tv}($ Señal abierta y cerrada)
b. Radio
c. Facebook - LinkedIn/ Redes sociales
d. Correo electrónico
e. Revistas sociales - especializadas

14. ¿Qué tipo de presentación le gustaría tener de la empresa consultora?
a. Oficinas físicas
b. Oficinas virtuales (plataformas virtuales).
c. Oficinas a través de central de llamadas.
d. Oficinas descentralizadas (acudir al centro laboral para atender su requerimiento).

15. ¿Qué tipo de servicio estaría dispuesto a comprar?
a. Talleres de desarrollo de habilidades gerenciales.
b. Asesoría en orientación vocacional.
c. Base de datos de postulantes
d. Otros. 


\section{ANEXO 4: Entrevista}

1. ¿En su empresa se contratan practicantes pre - profesionales?

2. ¿En su empresa existe un equipo encargado de la contratación de practicantes?

3. ¿Un promedio de cuantos practicantes contratan al año en su empresa?

4. Si ha contratado un servicio de una consultora antes, ¿Cómo calificaría su experiencia?

5. ¿Cuáles consideraría usted son las ventajas y desventajas de contratar a una consultora?

6. ¿Qué tipo de servicio estaría dispuesto a comprar de una consultora?

7. ¿Cuál es el precio que estaría dispuesto a pagar por el servicio contratado?

8. ¿Qué distrito consideraría usted que es apropiado para tener reuniones de avance del servicio contratado por la consultora? 


\section{ANEXO 5: Tablas de formación para la matriz Peyea}

Tabla 47

Fuerza financiera y capacidades de Base (FF)

Fuerza Financiera y Capacidades de Base (FF) Valor (+)

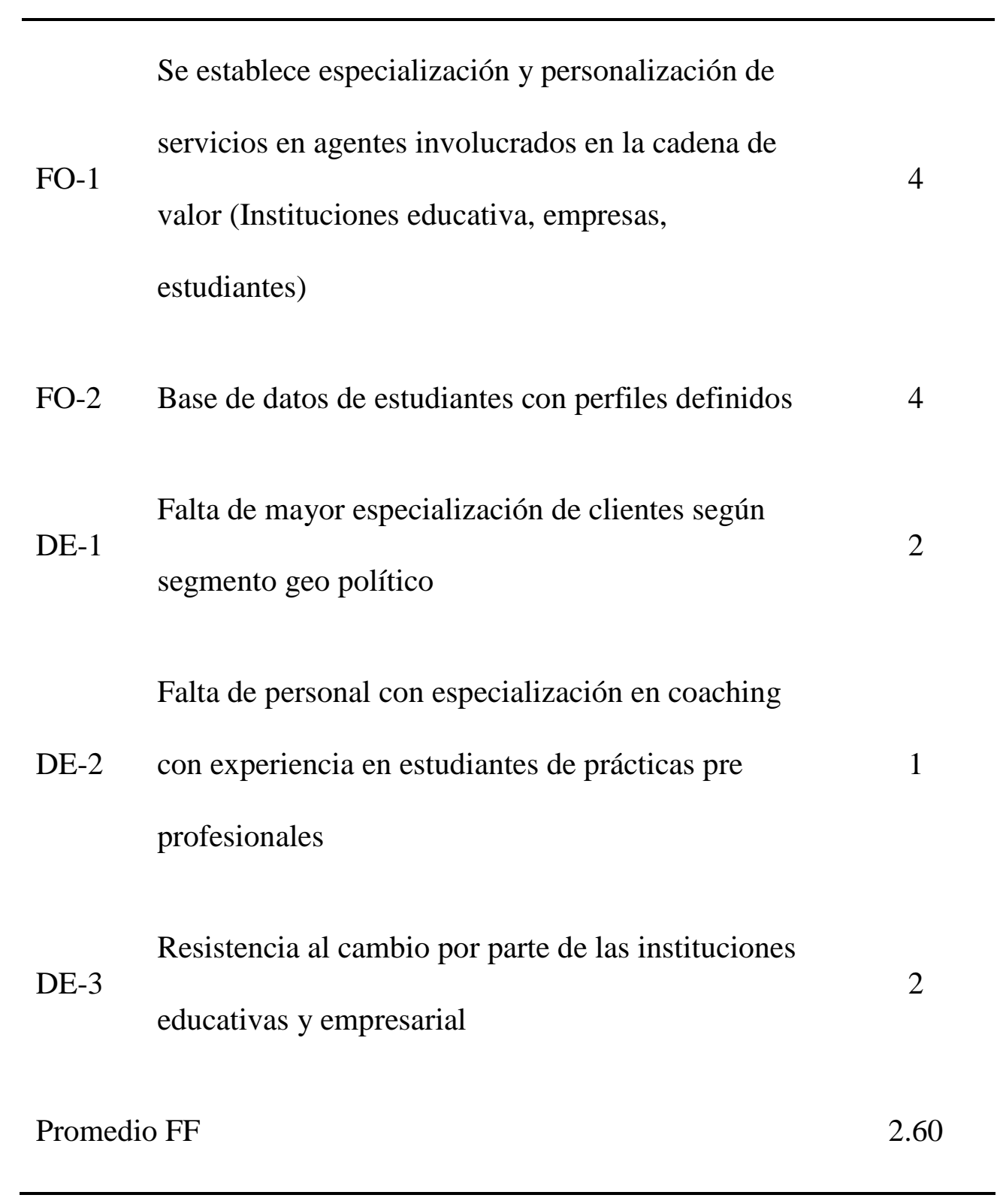

Nota.: Elaboración propia. Validada por experto. 
Tabla 48

Estabilidad del ambiente

$\begin{array}{ll}\text { Estabilidad del Ambiente (EA) } & \text { Valor (-) }\end{array}$

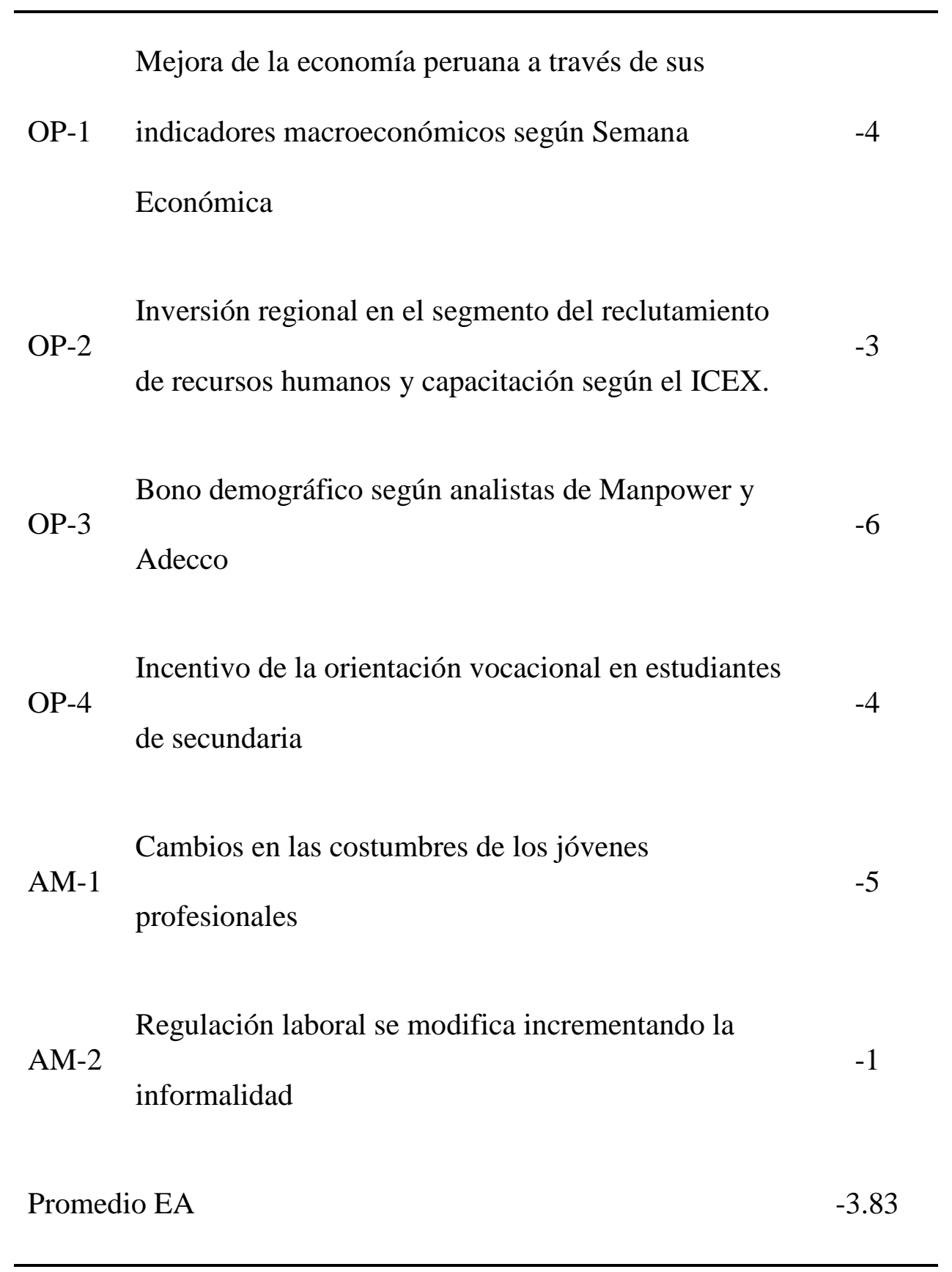

Nota: Elaboración propia. Validada por Experto. 
Tabla 49

Fuerza de la Industria (FI)

Fuerza de la Industria (FI)

Valor

(+)

\begin{tabular}{lll}
\hline OP-5 & Expansión de universidades duplicando la & 4 \\
& capacidad instalada desde hace 13 años. & \\
AM-3 & Informalidad en el reclutamiento de recursos & 1 \\
& humanos & 4 \\
AM-4 & Reclutamiento de recursos humanos a nivel \\
& internacional & 3 \\
AM-5 & Alianzas estratégicas entre la competencia & \\
& & \\
& (Manpower y Adecco) & 3.00 \\
\hline
\end{tabular}

Nota. Elaboración propia. Validada por Experto. 
Tabla 50

Ventaja Competitiva

Ventaja Competitiva (VC) Valor

$(-)$

FO-3 Diseño de negocio con valor agregado debido que

se puede extrapolar a las instituciones educativas

FO-4 Nicho de mercado para segmento de estudiantes

con necesidad de inserción laboral

FO-5 Nicho de mercado para segmento de empresas con $\quad-1$

necesidad de talento humano monitoreado

DE-4 Contracción de la economía, por ello no invierten -4

en nuevos servicios

DE-5 Falta de mayor especialización de clientes según segmento geo político

Promedio VC

Nota. Elaboración propia. Validada por Experto. 
ANEXO 6: Validación de experto para el área de localización

\begin{tabular}{|l|l|}
\hline Empresa & Banco de Crédito \\
\hline Función & Asesora de Financiamiento \\
\hline Experiencia & Once años de experiencia en asesoría a clientes. \\
\hline
\end{tabular}

Estimada ,

Somos estudiantes de la Maestría de Ciencias Empresariales de la Universidad San Ignacio de Loyola, nos encontramos en la elaboración de nuestro plan de Negocios y acudimos en tu ayuda debido a la amplia experiencia que tienes en el rubro de la asesoría de los clientes (especialmente en el financiamiento de pequeños empresarios).

De acuerdo con lo que nos comentas en tus años de asesora uno de los principales de financiamiento que te han solicitado es para compra/alquiler de oficinas.

¿Qué factores considerarías que son los más importantes para escoger la ubicación de una oficina y que pesos le asignaría a cada uno?

En primer lugar, no recomendaría que incurran en el endeudamiento para alquilar una oficina, si están en condiciones económicas de alquilar esta ubicación variara de acuerdo con el core del negocio. Según me comentan ustedes necesitan estar en una zona cerca a empresas y universidades.

Cercanía a fuentes de abastecimientos $14.3 \%$

Disponibilidad de ubicación $28.6 \%$ 
Accesibilidad de servicios $14.3 \%$

Costo de la ubicación $42.9 \%$

En su caso por ser servicio consideren Cercanía a fuentes de abastecimiento a los clientes, para empresarios en su inicio lo más importante es el costo de la ubicación. 


\section{ANEXO 7: Validación de costo de oficina}

http://www.adondevivir.com/propiedades/alquilo-departamento-en-condominioexcelente-ubicacion-52984276.html



Al contactar al anunciante se indicó que el precio final sería US\$ 620.00 


\section{Referencias Electrónicas}

Alcántara, Carlos. (2016). Ranking Universidades Perú 2016. 27 de agosto 2017, de América Economía Sitio web: https://rankings.americaeconomia.com/2016/universidades-peru/

Cuadra, M. J. (2 de diciembre 2013). Las consultoras en recursos humanos que aún no hacen clic. Revisado el 17 de junio, 2017, recolectado desde http://semanaeconomica.com/article/servicios/servicios-profesionales/129130-lasconsultoras-en-recursos-humanos-que-aun-no-hacen-click/

De, S. N., Falconi, F. M., \& Rojas, E. P. (2009, agosto 01). Plan de negocios para producir y comercializar productos vegetales orgánicos en Lima. Buscado 17 de junio 2017, de http://tesis.pucp.edu.pe/repositorio/handle/123456789/1674

Diario Gestión. (10 de julio 2015). El 72\% de ejecutivos de RR.HH. contrató personal que contactó por redes sociales. Revisado el 17 de junio, 2017, recolectado desde http://gestion.pe/empleo-management/72-ejecutivos-recursos-humanos-afirmacontratado-personal-que-contacto-traves-red-social-2136691

Diario Gestión. (17 de mayo de 2014). Manpower y Adecco se pronuncian: La oportunidad del bono demográfico. Revisado el 17 de junio, 2017, recolectado desde http://gestion.pe/empleo-management/manpower-y-adeccose-pronuncian-oportunidadbono-demografico-2097524

Diario Gestión. (14 de enero de 2015). ¿Qué busca el mercado laboral en los trabajadores de hoy? Revisado el 17 de junio, 2017, recolectado desde http://gestion.pe/empleomanagement/que-busca-mercado-laboral-trabajadores-hoy-2120404 
Diario Gestión. (08 de mayo de 2015). Universitarios deben comenzar prácticas pre profesionales desde quinto ciclo de sus carreras. Revisado el: 17 de junio, 2017, recolectado desde: http://gestion.pe/empleo-management/universitarios-deben-comenzarpracticas-pre-profesionales-desde-quinto-ciclo-sus-carreras-2131317

Diario Gestión. (23 enero 2017). FMI elevó proyección de crecimiento de economía peruana de 4.1\% a 4.3\% el 2017. Revisado el 17 de junio, 2017, recolectado desde http://gestion.pe/economia/fmi-elevo-proyeccion-crecimiento-economia-peruana-41-432017-2180315

Gestión (2015). Ejecutivos de recursos humanos afirma contratado de personal a través de las redes sociales. Recolectado por la página web: http://goo.gl/zXz5Nm

ICEX (2011). Perú: The Top 10.000 compañías. Recolectado de la página web: http://goo.gl/1dc8fA

INEI “Perú: Perfil de pobreza por departamentos 2001-2010”, por el Instituto Nacional de Estadística e Informática (INEI) 2011.Recuperado de https://www.inei.gob.pe/media/MenuRecursivo/publicaciones_digitales/Est/Lib0981/Libr o.pdf

INEI, Directorio central de empresas y establecimientos. (2015, Setiembre). Revisado el: 17 de junio, 2017, recolectado desde http://www.bing.com/cr?IG=452E87D830D5481BB7F404CDE46C8550\&CID=3FC59F EDAB3860353D419548AA3E6170\&rd=1\&h=Prfg1KrDn5q5pmRgnTYoEtTa8uRk9MB 2UfjCpt6WeR0\&v=1\&r=http\%3a\%2f\%2funstats.un.org\%2funsd\%2ftrade\%2fevents\%2f 
2015\%2faguascalientes\%2f9.-Panel\%2520III\%2520-\%2520Presentation\%25201\%2520\%2520INEI\%2520Peru.pdf\&p=DevEx,5060.1

Ministerio de Economía y Finanzas (2015). Proyectos de inversión pública para poblaciones vulnerables. Recolectado de la página web: https://goo.gl/qAKDwF

Ministerio de Trabajo (2014) Informe Anual de Empleo del Ministerio de Trabajo. Revisado el 15 de enero, 2017 Recolectado de: http://www.mintra.gob.pe/archivos/file/estadisticas/peel/enaho/INFORME_ANUAL_EM PLEO_ENAHO_2014.pdf

Ministerio de Trabajo "Demanda de Ocupaciones al 2016 - Encuesta de Demanda Ocupacional 2016" por la Dirección General de Promoción del Empleo (DGPE), 2016. Recuperado de: http://www.mintra.gob.pe/archivos/file/estadisticas/peel/publicacion/2016/edoDO_2016. pdf

MINTRA (2014). Ley sobre modalidades formativas laborales Ministerio de trabajo. Recolectado de la página web: http://goo.gl/Z3Gqcr

Organización Internacional del Trabajo. (2015, April 22). 27 millones de jóvenes en la informalidad en América Latina y el Caribe. Revisado el 17 de junio, 2017, recolectado desde http://www.ilo.org/americas/sala-de-prensa/WCMS_362579/lang--es/index.htm

Pymex. (2016). ¿Cuánto es el sueldo de un practicante en el Perú? Revisado el 17 de junio, 2017, recolectado desde: https://pymex.pe/liderazgo/cuanto-es-el-sueldo-de-unpracticante-en-el-peru 
RPP (2013). Jóvenes prefieren trabajar en casa y alejarse de la oficina. Recolectado de la página web: http://goo.gl/RbqYHf

RPP (2015). FMI Perú liderará crecimiento económico en América Latina. Recuperado en la página web: http://goo.gl/0GpMGD

Semana económica (2013), Las consultoras en recursos humanos que aún no hacen clic. Revisado el 17 de junio, 2017, recolectado desde: http://goo.gl/kd8Qob

SUNEDU (2015), Ley Universitaria. Recolectado de la página web: http://goo.gl/6NdpJi

Universia España. (2014). Prácticas profesionales online: la nueva tendencia laboral. Revisado el 17 de junio, 2017, recolectado desde: http://noticias.universia.es/enportada/noticia/2014/07/30/1108783/practicas-profesionales-online-nueva-tendencialaboral.html

Universia. (2 de octubre 2015). El mercado laboral hoy y las tendencias a futuro. Revisado el 17 de junio, 2017, recolectado desde http://noticias.universia.es/portada/noticia/2015/10/02/1131866/mercado-laboral-hoytendencias-futuro.html

Universia. (30 de julio 2014). Prácticas profesionales online: la nueva tendencia laboral. Revisado el 17 de junio, 2017, recolectado desde http://noticias.universia.es/enportada/noticia/2014/07/30/1108783/practicas-profesionales-online-nueva-tendencialaboral.html 
Workforce Institute en Kronos Incorporated y Dan Schawbel. (2016). 10 tendencias de capital humano en 2016. Revisado el 17 de junio, 2017, recolectado desde: Forbes Sitio web: https://www.forbes.com.mx/10-tendencias-de-capital-humano-en-2016/ 